\title{
Artificial host molecules to covalently capture 8-nitro-cGMP in neutral aqueous solutions and in cells
}

\author{
Yasufumi Fuchi $^{\dagger \uparrow}$, Hirotaka Murase ${ }^{\S}$, Ryosuke Kai ${ }^{\dagger}$, Kakeru Kurata $^{\ddagger}$, Satoru Karasawa ${ }^{\ddagger}$ \\ and Shigeki Sasaki ${ }^{\dagger} *$ \\ ${ }^{\dagger}$ Graduate School of Pharmaceutical Sciences, Kyushu University, 3-1-1 Maidashi, Higashi-Ku, Fukuoka \\ 812-8582, Japan, ${ }^{+}$Faculty of Pharmaceutical Sciences, Showa Pharmaceutical University, 3-3165 \\ Higashi-tamagawagakuen, Machida 194-8543, Japan, "I Graduate School of Pharmaceutical Sciences, \\ Tokushima Bunri University, 180 Yamashiro-cho Tokushima 770-8514, Japan, ${ }^{\S}$ Graduate School of
}

Pharmaceutical Sciences, Nagasaki International University, 2825-7 Huis Ten Bosch Machi, Sasebo 8593298, Japan.

\section{List of contents}

Synthesis of benzylthiol units

p. $2-4$

Synthesis of NG-cG

p. 5

Synthesis of NGG-H-cGMP adduct

p. 6

Table S1. Crystallographic and Refinement Parameters of compound 7

p. 7

Figure S1. ORTEP drawing and hydrogen-bond interactions of compound 7

p. 8

Figure S2. ROESY spectrrum of NGG-H-cGMP adduct

p. 9

Figure S3. Reaction analysis of nitroG-Grasp 2

p. 10

Figure S4. Reaction analysis of NGG-H for 8-nitroguanosine

p. 11

Figure S5. Reaction analysis of NG-cG for 8-nitro-cGMP

p. 12

Figure S6. Comparison of the reactivity of NGG-H in the presence of cGMP or dGTP

p. 13

Figure S7. Kinetic constant plot and Arrehnius plot

p. 14

Figure S8. Fluorescence images of HEK293 cells

p. 15

Figure S9. Fluorescence images of RAW 264.7 cells

p. 16

${ }^{1} \mathrm{H},{ }^{13} \mathrm{C}-\mathrm{NMR}$ spectra of compounds

p. $17-37$ 


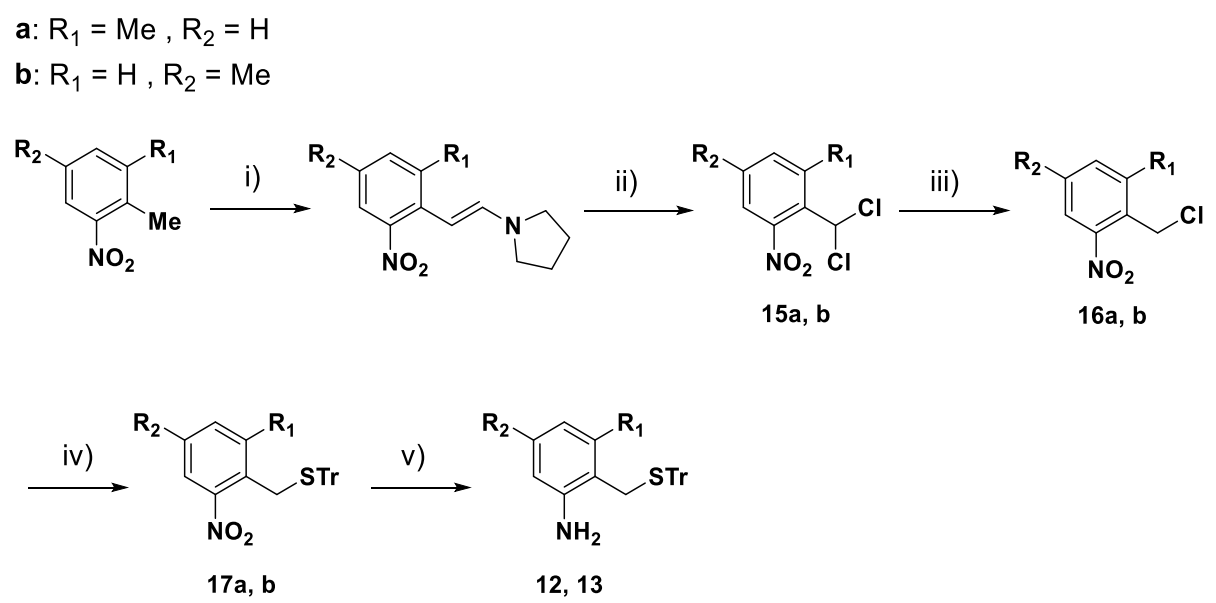

Scheme S1. Synthesis scheme of BnSH unit 12 and 13.

Reagents and conditions; i) DMF-DMA, CuI, pyrolidine, $100{ }^{\circ} \mathrm{C}$, ii) $\mathrm{NaOCl}$ aq., $\mathrm{CH}_{3} \mathrm{CN}$, rt, $63 \%$ (15a) and $51 \%$ (15b) in 2 steps. iii) $\mathrm{Pd} / \mathrm{C}, \mathrm{HCOONH}_{4}, 1,2$-Dimethoxyethane, $\mathrm{H}_{2} \mathrm{O}, \mathrm{rt}, 50 \%$ (16a) and $49 \%$ (16b). iv) Tr-SH, DIPEA, $\mathrm{CH}_{3} \mathrm{CN}, \mathrm{rt}, 80 \%$ (17a) and $58 \%$ (17b). v) $\mathrm{Na}_{2} \mathrm{~S}_{2} \mathrm{O}_{4}, \mathrm{Na}_{2} \mathrm{CO}_{3}, \mathrm{TBAH}$, $\mathrm{THF} / \mathrm{H}_{2} \mathrm{O}, \mathrm{rt}, 80 \%(\mathbf{1 2})$ and $45 \%(\mathbf{1 3})$.

2-(dichloromethyl)-1-methyl-3-nitrobenzene (15a) Dimethylformamide-dimethylacetal (100 mg, $0.66 \mathrm{mmol})$ and copper iodide (I) $(13 \mathrm{mg}$ ) were added to a solution of 2,3-dimethyl-nitrobenzene (158 $\mathrm{mg}, 1.33 \mathrm{mmol})$ in pyrrolidine $(0.27 \mathrm{~mL})$ under an argon atmosphere. The reaction mixture was stirred at room temperature for at $100{ }^{\circ} \mathrm{C}$ for $5 \mathrm{~h}$ before quenching with satd $\mathrm{Na}_{2} \mathrm{~S}_{2} \mathrm{O}_{3}$ aq. The resulting mixture was extracted with AcOEt. The organic layer was washed with brine, dried over $\mathrm{Na}_{2} \mathrm{SO}_{4}$ and evaporated in vacuo. The resulting residue $(151 \mathrm{mg})$ was used for next reaction step without further purification. The imine compound was dissolved in $\mathrm{CH}_{3} \mathrm{CN}(1.3 \mathrm{~mL})$ and stirred with $5 \% \mathrm{NaClO}(3.3$ $\mathrm{mL}$ ) at $0{ }^{\circ} \mathrm{C}$ for $2 \mathrm{~h}$. The reaction mixture was diluted with brine, and extracted with AcOEt. The organic layer was washed with brine, dried over $\mathrm{Na}_{2} \mathrm{SO}_{4}$ and evaporated in vacuo. The resulting residue was purified by flash column chromatography (Hexane/AcOEt $=50 / 1$ ) to afford compound 15a (91 mg, $63 \%$ in 2 steps) as a pale red oil. ${ }^{1} \mathrm{H}-\mathrm{NMR}\left(500 \mathrm{MHz}, \mathrm{DMSO}-\mathrm{d}_{6}\right) \delta$ (ppm): $7.73(1 \mathrm{H}, \mathrm{d}$, $J=8.0), 7.65(1 \mathrm{H}, \mathrm{d}, J=7.4), 7.59(1 \mathrm{H}, \mathrm{s}), 7.58(1 \mathrm{H}, \mathrm{t}, J=7.8), 2.69(3 \mathrm{H}, \mathrm{s}) .{ }^{13} \mathrm{C}-\mathrm{NMR}(125 \mathrm{MHz}$, DMSO-d $\left.{ }_{6}\right) \delta(\mathrm{ppm}): 148.8,139.7,136.3,128.9,122.3,65.6,19.7$. HR-ESI-MS (m/z): $\left[\mathrm{C}_{8} \mathrm{H}_{7} \mathrm{NO}_{2} \mathrm{Cl}_{2}\right]$ calcd $241.9746[\mathrm{M}+\mathrm{Na}]^{+}$, found 241.9854 .

1-(dichloromethyl)-4-methyl-2-nitrobenzene (15b) Same procedure as compound 15a to afford compound $11 \mathbf{b}$ (51\% in 2 steps) as a pale red amorphous. ${ }^{1} \mathrm{H}-\mathrm{NMR}\left(500 \mathrm{MHz}, \mathrm{DMSO}-\mathrm{d}_{6}\right) \delta(\mathrm{ppm})$ : $8.02(1 \mathrm{H}, \mathrm{d}, J=8.1), 7.87(1 \mathrm{H}, \mathrm{s}), 7.72(1 \mathrm{H}, \mathrm{d}, J=8.1), 7.64(1 \mathrm{H}, \mathrm{s}), 2.43(3 \mathrm{H}, \mathrm{s}) .{ }^{13} \mathrm{C}-\mathrm{NMR}(125 \mathrm{MHz}$, DMSO-d $\left._{6}\right) \delta(\mathrm{ppm}): 145.5,142.2,135.0,130.8,129.3,124.5,67.3,20.3$. HR-ESI-MS (m/z): $\left[\mathrm{C}_{8} \mathrm{H}_{7} \mathrm{NO}_{2} \mathrm{Cl}_{2}\right]$ calcd. $241.9746[\mathrm{M}+\mathrm{Na}]^{+}$, found 241.9747. 
1-(chloromethyl)-1-methyl-2-nitrobenzene (16a) Compound 15a (52 mg, $0.24 \mathrm{mmol}$ ) was dissolved in 1,2-dimethoxyethane $/ \mathrm{H}_{2} \mathrm{O}=1: 1(0.4 \mathrm{~mL})$ solution. $10 \% \mathrm{Pd} / \mathrm{C}(17 \mathrm{mg})$ and ammonium formate $(225$ $\mathrm{mg}, 3.6 \mathrm{mmol}$ ) were added to this solution under argon atmosphere. The reaction mixture was stirred at r.t. for $5 \mathrm{~h}$. The reaction mixture was filtered through celite, and resulting filtrate was extracted with AcOEt. The organic layer was washed with brine, dried over $\mathrm{Na}_{2} \mathrm{SO}_{4}$ and evaporated in vacuo. The resulting residue was purified by flash column chromatography (Hexane/AcOEt $=50 / 1)$ to afford compound 16a (23 mg, $50 \%$ ) as a pale orange solid. ${ }^{1} \mathrm{H}-\mathrm{NMR}\left(500 \mathrm{MHz}, \mathrm{CDCl}_{3}\right) \delta(\mathrm{ppm}): 7.73(1 \mathrm{H}$, $\mathrm{d}, J=8.0), 7.47(1 \mathrm{H}, \mathrm{d}, J=7.5), 7.38(1 \mathrm{H}, \mathrm{t}, J=7.9), 4.82(2 \mathrm{H}, \mathrm{s}), 2.56(3 \mathrm{H}, \mathrm{s}) .{ }^{13} \mathrm{C}-\mathrm{NMR}(125 \mathrm{MHz}$, $\left.\mathrm{CDCl}_{3}\right) \delta(\mathrm{ppm}): 150.1,140.5,135.3,129.7,129.3,122.8,38.1,19.5$. HR-ESI-MS (m/z): $\left[\mathrm{C}_{8} \mathrm{H}_{8} \mathrm{NO}_{2} \mathrm{Cl}\right]$ calcd $208.0136[\mathrm{M}+\mathrm{H}]^{+}$, found 208.0151 .

1-(chloromethyl)-4-methyl-2-nitrobenzene (16b) Same procedure as compound 16a to afford compound 16b $(49 \%)$ as a pale orange solid. ${ }^{1} \mathrm{H}-\mathrm{NMR}\left(500 \mathrm{MHz}, \mathrm{CDCl}_{3}\right) \delta(\mathrm{ppm})$ : 7.87(1H, s), $7.54(1 \mathrm{H}, \mathrm{d}, J=7.9), 7.44(1 \mathrm{H}, \mathrm{d}, J=7.9), 4.93(2 \mathrm{H}, \mathrm{s}), 2.45(3 \mathrm{H}, \mathrm{s}) \cdot{ }^{13} \mathrm{C}-\mathrm{NMR}\left(125 \mathrm{MHz}, \mathrm{CDCl}_{3}\right) \delta$ (ppm): 148.0, 140.3, 134.5, 131.7, 129.7, 125.7, 42.9, 21.0. HR-ESI-MS (m/z): $\left[\mathrm{C}_{8} \mathrm{H}_{8} \mathrm{NO}_{2} \mathrm{Cl}\right]$ calcd. $241.9746[\mathrm{M}+\mathrm{Na}]^{+}$, found 241.9747 .

(2-methyl-6-nitrobenzyl)(trityl)sulfane (17a) Triphenylmethanethiol (385 mg, $1.39 \mathrm{mmol}$ ) and DIPEA $(0.46 \mathrm{~mL}, 2.79 \mathrm{mmol})$ were added to a solution of compound $\mathbf{1 6 a}$ in $\mathrm{CH}_{3} \mathrm{CN}(2.8 \mathrm{~mL})$ under argon atmosphere. The reaction mixture was stirred at r.t. for $24 \mathrm{~h}$ before extracting with AcOEt and satd. $\mathrm{NaHCO}_{3}$ aq. The organic layer was washed with brine, dried over $\mathrm{Na}_{2} \mathrm{SO}_{4}$ and evaporated in vacuo. The resulting residue was purified by flash column chromatography (Hexane/AcOEt=20/1) to afford compound $17 \mathbf{a}\left(509 \mathrm{mg}, 86 \%\right.$ ) as a white solid. ${ }^{1} \mathrm{H}-\mathrm{NMR}\left(500 \mathrm{MHz}, \mathrm{CDCl}_{3}\right) \delta$ (ppm): 7.62 $(1 \mathrm{H}, \mathrm{d}, J=8.0), 7.32-7.21(17 \mathrm{H}, \mathrm{m}), 3.46(2 \mathrm{H}, \mathrm{s}), 2.06(3 \mathrm{H}, \mathrm{s}) .{ }^{13} \mathrm{C}-\mathrm{NMR}\left(125 \mathrm{MHz}, \mathrm{CDCl}_{3}\right) \delta(\mathrm{ppm})$ : 151.2, 144.3, 140.7, 134.6, 129.6, 128.8, 128.2, 127.8, 126.9, 122.4, 67.6, 29.6, 19.3. HR-ESI-MS $(\mathrm{m} / \mathrm{z}):\left[\mathrm{C}_{27} \mathrm{H}_{23} \mathrm{NO}_{2} \mathrm{~S}\right]$ calcd. $448.1342[\mathrm{M}+\mathrm{Na}]^{+}$, found 448.1348.

(4-methyl-6-nitrobenzyl)(trityl)sulfane (17b) Same procedure as compound 17a to afford compound 17b $(58 \%)$ as a white solid. ${ }^{1} \mathrm{H}-\mathrm{NMR}\left(500 \mathrm{MHz}, \mathrm{CDCl}_{3}\right) \delta(\mathrm{ppm}): 7.74(1 \mathrm{H}, \mathrm{s}), 7.34-7.24(16 \mathrm{H}, \mathrm{m})$, $6.83(1 \mathrm{H}, \mathrm{d}, J=7.9), 3.57(2 \mathrm{H}, \mathrm{s}), 2.33(3 \mathrm{H}, \mathrm{s}) .{ }^{13} \mathrm{C}-\mathrm{NMR}\left(125 \mathrm{MHz}, \mathrm{CDCl}_{3}\right) \delta(\mathrm{ppm}): 148.3,143.9$, 138.7, 134.0, 132.0, 129.1，128.7，128.1，126.9，124.7，67.2，32.7, 20.1. HR-ESI-MS (m/z): $\left[\mathrm{C}_{27} \mathrm{H}_{23} \mathrm{NO}_{2} \mathrm{~S}\right]$ calcd. $448.1342[\mathrm{M}+\mathrm{Na}]^{+}$, found 448.1376 .

3-methyl-2-((tritylthio)methyl)aniline (12) Compound 17a $(50 \mathrm{mg}, 0.12 \mathrm{mmol})$ and $0.5 \mathrm{M}$ tetra- $n$ butylammonium hydroxide in $\mathrm{H}_{2} \mathrm{O}(47 \mu \mathrm{L}, 0.023 \mathrm{mmol})$ were dissolved in dry THF (1.4 mL) under argon atmosphere. $\mathrm{Na}_{2} \mathrm{~S}_{2} \mathrm{O}_{4}(123 \mathrm{mg}, 0.71 \mathrm{mmol})$ and $\mathrm{Na}_{2} \mathrm{CO}_{3}(125 \mathrm{mg}, 1.18 \mathrm{mmol})$ in $\mathrm{H}_{2} \mathrm{O}(1 \mathrm{~mL})$ was added dropwise to this mixture, and the reaction mixture was stirred at r.t. for $16 \mathrm{~h}$. The reaction was diluted with AcOEt and extracted with $\mathrm{H}_{2} \mathrm{O}$. The organic layer was washed with brine, dried over 
$\mathrm{Na}_{2} \mathrm{SO}_{4}$ and evaporated in vacuo. The resulting residue was purified by flash column chromatography (Hexane/AcOEt = 20/1) to afford compound $12(37 \mathrm{mg}, 80 \%)$ as a white amorphous. ${ }^{1} \mathrm{H}-\mathrm{NMR}(500$ $\left.\mathrm{MHz}, \mathrm{CDCl}_{3}\right) \delta(\mathrm{ppm}): 7.58-7.24(15 \mathrm{H}, \mathrm{m}), 6.92(1 \mathrm{H}, \mathrm{t}, J=7.6), 6.57(1 \mathrm{H}, \mathrm{d}, J=7.6), 6.44(1 \mathrm{H}, \mathrm{d}, J$ = 7.6), $3.47(2 \mathrm{H}, \mathrm{s}), 3.23(2 \mathrm{H}, \mathrm{s}), 2.31(3 \mathrm{H}, \mathrm{s}) .{ }^{13} \mathrm{C}-\mathrm{NMR}\left(125 \mathrm{MHz}, \mathrm{CDCl}_{3}\right) \delta(\mathrm{ppm}): 145.6,144.8$, 138.2, 129.5, 128.2, 126.9, 120.9, 119.1, 114.2, 66.9, 29.7, 19.8. HR-ESI-MS (m/z): [C $\left.\mathrm{C}_{27} \mathrm{H}_{25} \mathrm{NS}\right]$ calcd. $418.1600[\mathrm{M}+\mathrm{Na}]^{+}$. Found 418.1601 .

5-methyl-2-((tritylthio)methyl)aniline (13) Same procedure as compound 12 to afford compound 13 (45\%) as a white solid. ${ }^{1} \mathrm{H}-\mathrm{NMR}\left(500 \mathrm{MHz}, \mathrm{CDCl}_{3}\right) \delta(\mathrm{ppm})$ : $7.73(1 \mathrm{H}, \mathrm{s}), 7.35-7.24(16 \mathrm{H}, \mathrm{m}), 6.82$ $(1 \mathrm{H}, \mathrm{d}, J=7.9), 3.57(2 \mathrm{H}, \mathrm{s}), 3.23(2 \mathrm{H}, \mathrm{s}), 2.33(3 \mathrm{H}, \mathrm{s}) .{ }^{13} \mathrm{C}-\mathrm{NMR}\left(125 \mathrm{MHz}, \mathrm{CDCl}_{3}\right) \delta(\mathrm{ppm}): 145.0$, 144.8, 138.7, 130.9, 129.6, 128.2, 128.1, 126.9, 119.8, 117.7, 116.9, 67.1, 33.6, 21.3. HR-ESI-MS $(\mathrm{m} / \mathrm{z}):\left[\mathrm{C}_{27} \mathrm{H}_{25} \mathrm{NS}\right]$ calcd. $418.1600[\mathrm{M}+\mathrm{Na}]^{+}$, found 418.1602 . 
Synthesis of NG-cG(14)

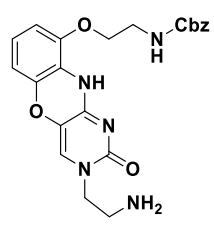

8

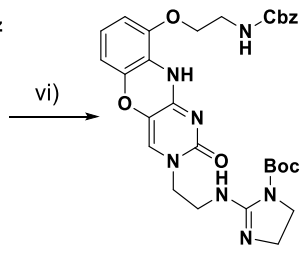

18

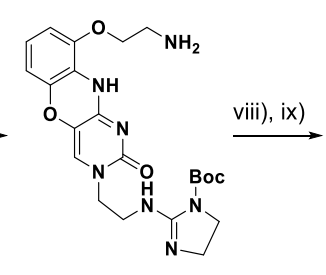

19

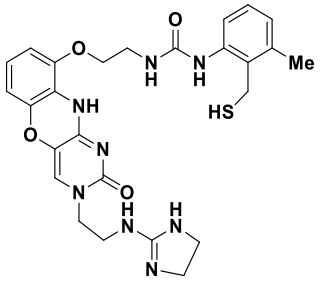

NG-CG (14)

Scheme S1. Synthesis scheme of NG-cG.

Reagents and conditions; vi) 1-Boc-2-methylthio-2-imidazoline, $\mathrm{EtOH} / \mathrm{AcOH}=9: 1,50{ }^{\circ} \mathrm{C}, 47 \%$. vii) $\mathrm{Pd}(\mathrm{OH})_{2} / \mathrm{C}, \mathrm{Et}_{3} \mathrm{SiH}, \mathrm{THF} / \mathrm{MeOH}, \mathrm{rt}, 74 \%$. viii) 12, triphosgen, $\mathrm{Et}_{3} \mathrm{~N}, \mathrm{CH}_{2} \mathrm{Cl}_{2}, 0{ }^{\circ} \mathrm{C}$ to rt, then $\mathbf{1 9}, \mathrm{rt}$, $61 \%$ in 2 steps. ix) TFA, $\operatorname{iPr}_{3} \mathrm{SiH}, 0^{\circ} \mathrm{C}$ to rt, $39 \%$.

Compound 18 1-Boc-2-methylthio-2-imidazoline (74 mg, $0.34 \mathrm{mmol}$ ) was added to a solution of compound 8 in $\mathrm{EtOH} / \mathrm{AcOH}=9: 1$ solution $(2.3 \mathrm{~mL})$ under argon atmosphere. The reaction mixture was heated at $50{ }^{\circ} \mathrm{C}$ for $21 \mathrm{~h}$. The reaction mixture was quenched with satd $\mathrm{NaHCO}_{3}$ aq. and extracted with $\mathrm{CH}_{2} \mathrm{Cl}_{2}$. The organic layer was washed with brine, dried over $\mathrm{Na}_{2} \mathrm{SO}_{4}$ and evaporated in vacuo. The resulting residue was purified by flash column chromatography (aminopropyl-modified silica gel, $\left.\mathrm{CH}_{2} \mathrm{Cl}_{2} / \mathrm{MeOH}=50: 1\right)$ to afford compound 15 (32 mg, 47\% as conversion yield) as a yellow solid. ${ }^{1} \mathrm{H}$ $\operatorname{NMR}\left(500 \mathrm{MHz}, \mathrm{CD}_{3} \mathrm{OD}\right) \delta(\mathrm{ppm}): 7.31-7.24(5 \mathrm{H}, \mathrm{m}), 7.19(1 \mathrm{H}, \mathrm{s}), 6.78(1 \mathrm{H}, \mathrm{t}, J=8.3 \mathrm{~Hz}), 6.55$ $(1 \mathrm{H}, \mathrm{d}, J=8.3), 6.35(1 \mathrm{H}, \mathrm{d}, J=8.3 \mathrm{~Hz}), 5.10(2 \mathrm{H}, \mathrm{s}), 4.03(2 \mathrm{H}, \mathrm{t}, J=5.6 \mathrm{~Hz}), 3.85(2 \mathrm{H}, \mathrm{t}, J=5.0$ $\mathrm{Hz}), 3.74$ (2H, m), 3.55-3.49 (4H, m), 1.47 (9H, s). ${ }^{13} \mathrm{C}-\mathrm{NMR}$ (125 MHz, CD $\left.3 \mathrm{OD}\right) \delta(\mathrm{ppm}): 159.1$, 157.6, 156.0, 155.8, 147.8, 144.2, 138.4, 129.4, 129.3, 129.1, 128.9, 128.7, 124.8, 117.1, 109.3, 108.3, 83.8, 69.6, 67.5, 41.9, 41.3, 30.7, 28.7, 28.4, 28.2. HR-ESI-MS (m/z): $\left[\mathrm{C}_{30} \mathrm{H}_{35} \mathrm{~N}_{7} \mathrm{O}_{7}\right]$ calcd 606.2671 $[\mathrm{M}+\mathrm{H}]^{+}$, found 606.2690 .

Compound 19 The synthesis of $\mathbf{1 9}$ was performed by the procedure of compound $\mathbf{1 0}$ described above to obtain the compound $19(74 \%)$ as a yellow solid. ${ }^{1} \mathrm{H}-\mathrm{NMR}\left(500 \mathrm{MHz}, \mathrm{CD}_{3} \mathrm{OD}\right) \delta(\mathrm{ppm}): 7.20(1 \mathrm{H}$, s), $6.81(1 \mathrm{H}, \mathrm{t}, J=8.1 \mathrm{~Hz}), 6.59(1 \mathrm{H}, \mathrm{d}, J=8.1 \mathrm{~Hz}), 6.39(1 \mathrm{H}, \mathrm{d}, J=8.1 \mathrm{~Hz}), 4.04(2 \mathrm{H}, \mathrm{t}, J=4.9 \mathrm{~Hz})$, $3.86(2 \mathrm{H}, \mathrm{t}, J=5.9 \mathrm{~Hz}), 3.76(2 \mathrm{H}, \mathrm{t}, J=8.4 \mathrm{~Hz}), 3.58(2 \mathrm{H}, \mathrm{t}, J=8.4 \mathrm{~Hz}), 3.51(2 \mathrm{H}, \mathrm{t}, J=5.9 \mathrm{~Hz}), 3.06$ $(2 \mathrm{H}, \mathrm{t}, J=4.9 \mathrm{~Hz}), 1.48(9 \mathrm{H}, \mathrm{s}) .{ }^{13} \mathrm{C}-\mathrm{NMR}\left(125 \mathrm{MHz}, \mathrm{CD}_{3} \mathrm{OD}\right) \delta(\mathrm{ppm}): 157.7,156.1,148.1,144.3$, 129.3, 129.0, 124.8, 117.2, 109.3, 108.3, 83.8, 79.5, 71.0, 41.9, 41.6, 28.4, 28.2. HR-ESI-MS (m/z): Calcd for $\mathrm{C}_{53} \mathrm{H}_{71} \mathrm{~N}_{11} \mathrm{O}_{11}(\mathrm{M}+\mathrm{Na})^{+}$1060.5227. Found 1060.5219.

NG-cG (14) After precursor synthesis using 12 to afford precursor (61\%) as a pale yellow solid, NGcG (14) was synthesized by deprotection reaction using TFA and $\mathrm{iPr}_{3} \mathrm{SiH} .{ }^{1} \mathrm{H}-\mathrm{NMR}(500 \mathrm{MHz}$, $\left.\mathrm{CD}_{3} \mathrm{OD}\right) \delta(\mathrm{ppm}): 7.28(1 \mathrm{H}, \mathrm{s}), 7.21(1 \mathrm{H}, \mathrm{d}, J=7.8 \mathrm{~Hz}), 7.11(1 \mathrm{H}, \mathrm{t}, J=7.8 \mathrm{~Hz}), 7.01(1 \mathrm{H}, \mathrm{d}, J=7.5 \mathrm{~Hz})$, $6.84(1 \mathrm{H}, \mathrm{t}, J=8.4 \mathrm{~Hz}), 6.64(1 \mathrm{H}, \mathrm{t}, J=8.4 \mathrm{~Hz}), 6.41(1 \mathrm{H}, \mathrm{d}, J=8.4 \mathrm{~Hz}), 4.11(2 \mathrm{H}, \mathrm{t}, J=5.2 \mathrm{~Hz}), 3.87$ $(2 \mathrm{H}, \mathrm{t}, J=6.0 \mathrm{~Hz}), 3.61(2 \mathrm{H}, \mathrm{t}, J=5.2 \mathrm{~Hz}), 3.51(2 \mathrm{H}, \mathrm{t}, J=6.0 \mathrm{~Hz}) .{ }^{13} \mathrm{C}-\mathrm{NMR}\left(125 \mathrm{MHz}, \mathrm{CD}_{3} \mathrm{OD}\right) \delta$ 
(ppm): 161.7, 159.7, 158.4, 156.0, 155.7, 149.6, 148.1, 144.2, 138.3, 136.9, 136.1, 132.3, 129.7, 129.1, 128.7, 128.4, 125.9, 125.2, 109.3, 108.8, 70.1, 44.2, 42.3, 40.5, 21.7, 19.6. HR-ESI-MS (m/z): $\left[\mathrm{C}_{59} \mathrm{H}_{73} \mathrm{~N}_{11} \mathrm{O}_{11}\right]$ calcd $551.2216[\mathrm{M}+\mathrm{H}]^{+}$, found 551.2183 .

Synthesis of NGG-H-cGMP adduct<smiles>NC(=[NH2+])NCCn1cc2c(nc1=O)Nc1c(OCCNC(=O)Nc3ccccc3CS)cccc1O2</smiles>

NGG-H

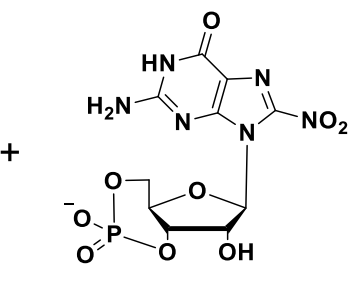

8-nitro-cGMP

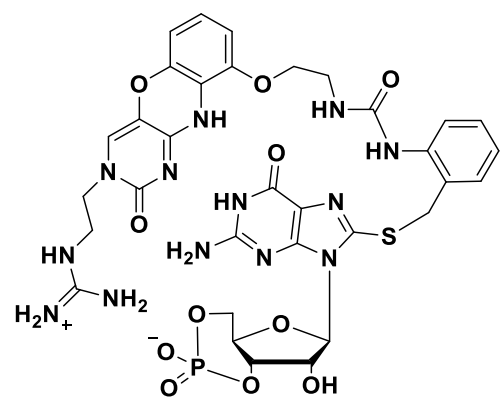

NGG-H-cGMP adduct

NGG-H-cGMP adduct $1 \mathrm{mM}$ solution of NGG-H $(5.3 \mathrm{~mL}, 5.3 \mu \mathrm{mol})$ in $\mathrm{MeOH}$ and $1 \mathrm{mM}$ solution of 8-nitro-cGMP (5.3 mL, $5.3 \mu \mathrm{mol})$ in $\mathrm{H}_{2} \mathrm{O}$ were added to a solution of $\mathrm{Et}_{3} \mathrm{~N}(11.4 \mu \mathrm{mol})$ in $\mathrm{MeOH}$ $(3.4 \mathrm{~mL})$ at r.t. The reaction mixture was stirred at r.t. for $12 \mathrm{~h}$ and analyzed by HPLC. A solution of $\mathrm{CH}_{3} \mathrm{CN} / \mathrm{H}_{2} \mathrm{O}=1: 1(2 \mathrm{~mL})$ was added to the mixture, and resulting suspension was centrifuged $(1,000$ $\mathrm{rpm}, 5 \mathrm{~min}$ ). The resulting supernatant was removed, and the precipitate was suspended again in $\mathrm{CH}_{3} \mathrm{CN} / \mathrm{H}_{2} \mathrm{O}=1: 1(2 \mathrm{~mL})$. After centrifugation and removal of supernatant, the precipitate was dried in vacuo. The resulting yellow solid (7 $\mathrm{mg}$, containing some water) was determined as a NGG-HcGMP adduct by HPLC analysis (peak at $19 \mathrm{~min}$ ). ${ }^{31} \mathrm{P}-\mathrm{NMR}$ (202 MHz, DMSO-d6) $\delta$ (ppm): -3.01. HR-ESI-MS (m/z): [ $\left.\mathrm{C}_{33} \mathrm{H}_{36} \mathrm{~N}_{13} \mathrm{O}_{11} \mathrm{PS}\right]$ calcd $876.2008[\mathrm{M}+\mathrm{Na}]^{+}$, found 876.1990 . 
Table S1 Crystallographic and Refinement Parameters of Single-Crystal Analyses of compound 7

\begin{tabular}{|c|c|}
\hline & Compound 7 \\
\hline Empirical Formula & $\mathrm{C}_{22} \mathrm{H}_{21} \mathrm{~N}_{7} \mathrm{O}_{5}$ \\
\hline Formula Weight & 463.45 \\
\hline Crystal Dimensions & $0.5 \times 0.3 \times 0.3 \mathrm{~mm}$ \\
\hline Crystal System & orthorhombic \\
\hline Space Group & Pna2 1 (\#33) \\
\hline \multicolumn{2}{|l|}{ Lattice Parameters } \\
\hline$a / \AA$ & $32.090(2)$ \\
\hline$b / \AA$ & $10.7804(3)$ \\
\hline$c / \AA$ & $6.0665(2)$ \\
\hline$\alpha / \operatorname{deg}$ & 90 \\
\hline$\beta / \operatorname{deg}$ & 90 \\
\hline$\gamma / \operatorname{deg}$ & 90 \\
\hline Volume / $\AA^{3}$ & $2098.7(2)$ \\
\hline$Z$ & 4 \\
\hline Density (calc.) / g/cm ${ }^{3}$ & 1.467 \\
\hline$F_{000}$ & 968.00 \\
\hline $2 \theta_{\max }$ cutoff / deg & 136.3 \\
\hline Reflections collected & 22457 \\
\hline Unique reflections & 3697 \\
\hline $\boldsymbol{R}_{\text {int }}$ & 0.0802 \\
\hline Absorption coefficient / $\mathbf{c m}^{-1}$ & 9.018 \\
\hline$R_{I}[\mathrm{I}>2.00 \sigma(\mathrm{I})]$ & 0.0345 \\
\hline$w R_{2}$ (All reflections) & 0.0952 \\
\hline Goodness-of-fit on $\mathbf{F}^{2}$ & 0.891 \\
\hline Largest diff. peak/hole / e $\AA^{-3}$ & $0.15 /-0.14$ \\
\hline CCDC No. & \\
\hline
\end{tabular}


A)
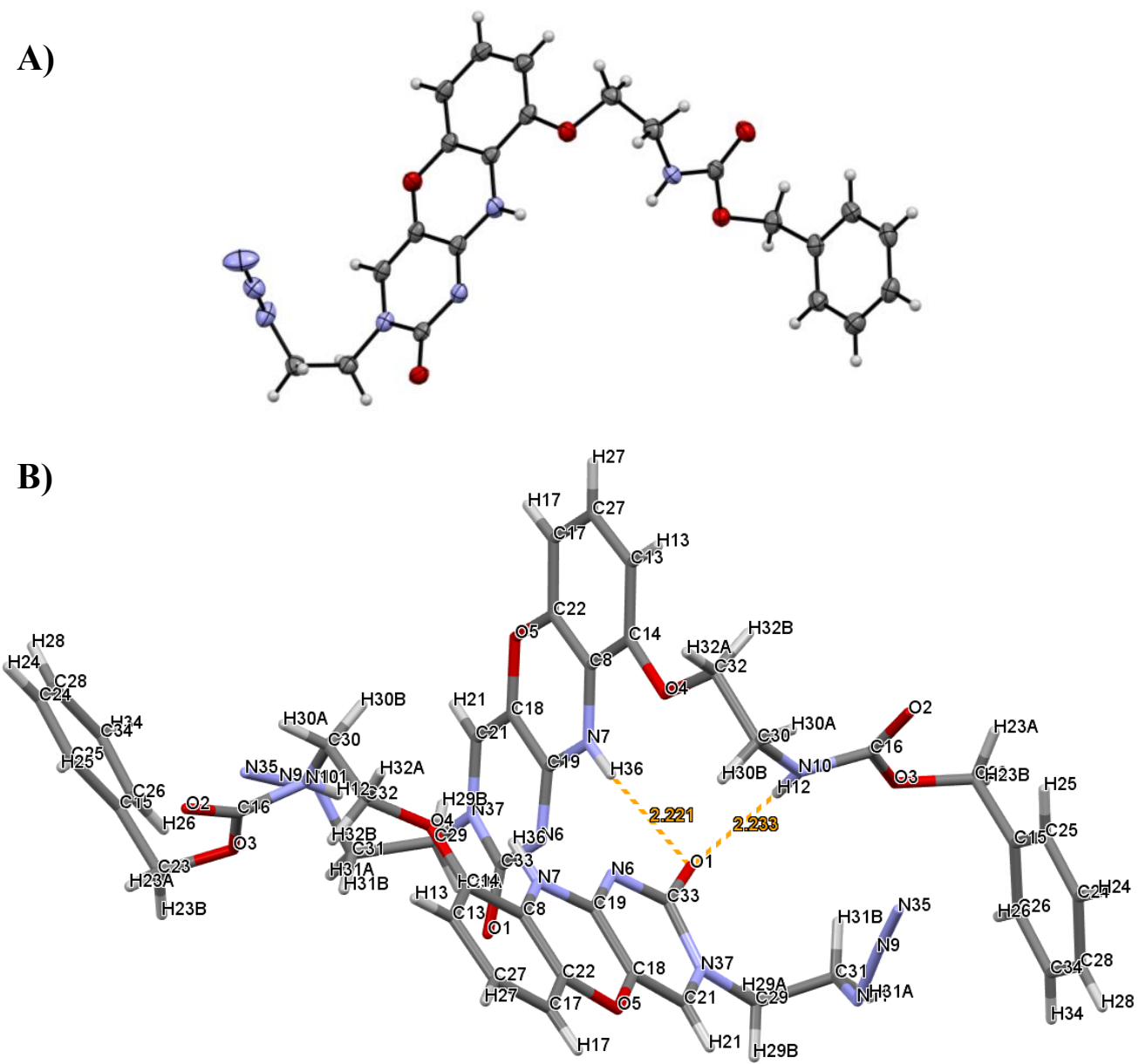

Figure S1. A) ORTEP drawing of azido compound 7. B) Hydrogen-bond interactions in the crystal packing of compound 7. Distances of H-bond interaction; O1-H36=2.221 $\mathrm{A}, \mathrm{O} 1-\mathrm{H} 12=2.233 \AA$. 


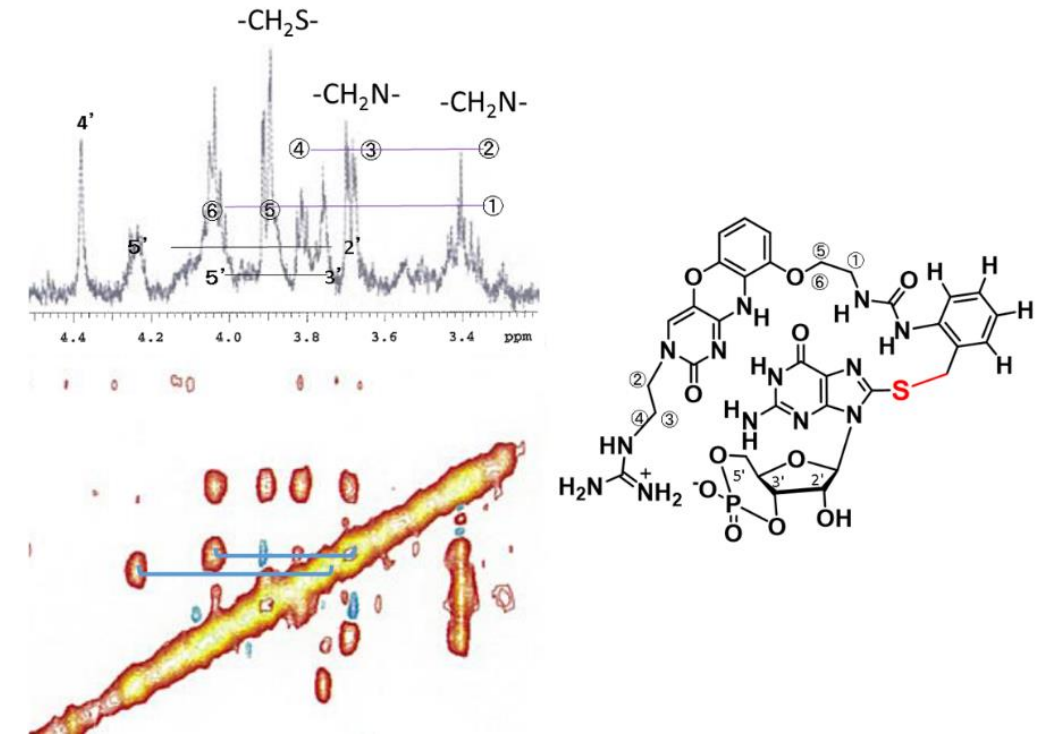

Figure S2 . Magnified ROESY spectrum between 3.2-4.4 ppm, and the structure assignment of NGGH (3)-cGMP adduct. Whole spectrum of ROESY and ${ }^{1} \mathrm{H}-\mathrm{NMR}$ spectrum were attached at later page (p. 36). 


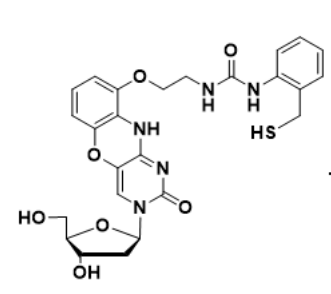

nitroG-Grasp 2

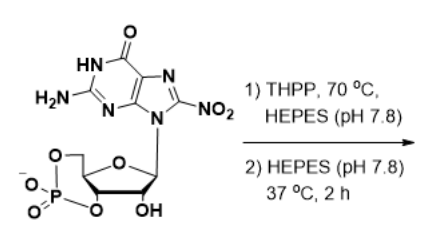

8-nitro-cGMP

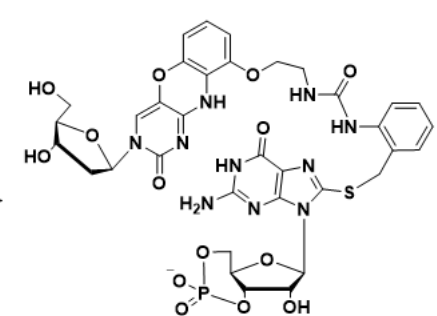

Product

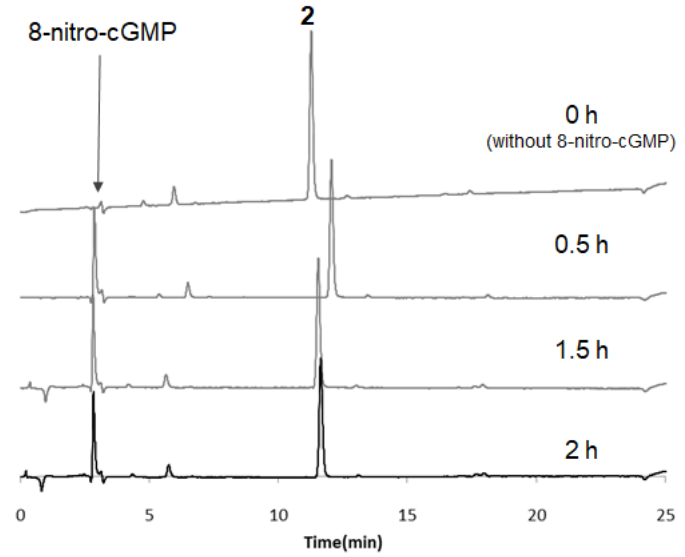

Figure S3. Reaction analysis of nitroG-Grasp 2 for 8-nitro-cGMP by HPLC. The reaction was performed using $25 \mu \mathrm{M}$ of nitroG-Grasp 2 and 8-nitro-cGMP. HPLC analytical conditions; column: cosmosil AR-II $4.6 \times 250 \mathrm{~mm}$, column temperature: $30^{\circ} \mathrm{C}$. flow rate: $1 \mathrm{~mL} / \mathrm{min}$, UV detection: $365 \mathrm{~nm}$, mobile phase: $0.05 \%$ TFA in $\mathrm{CH}_{3} \mathrm{CN} / 0.05 \%$ TFA in $\mathrm{H}_{2} \mathrm{O}=25 / 75$ to $45 / 55$ (linear gradient $0-20 \mathrm{~min}$ ), and $100 / 0$ after $20 \mathrm{~min}$. 


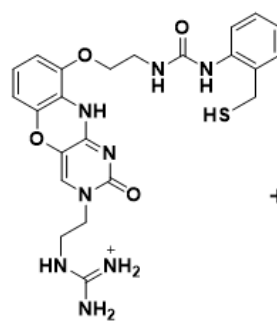

NGG-H

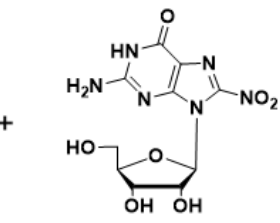

8-nitroguanosine

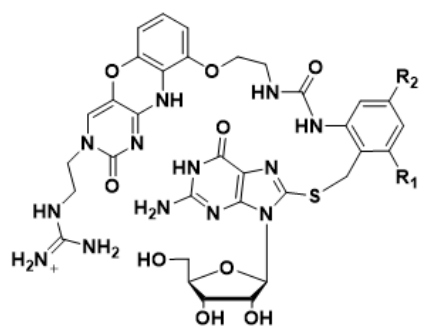

Product

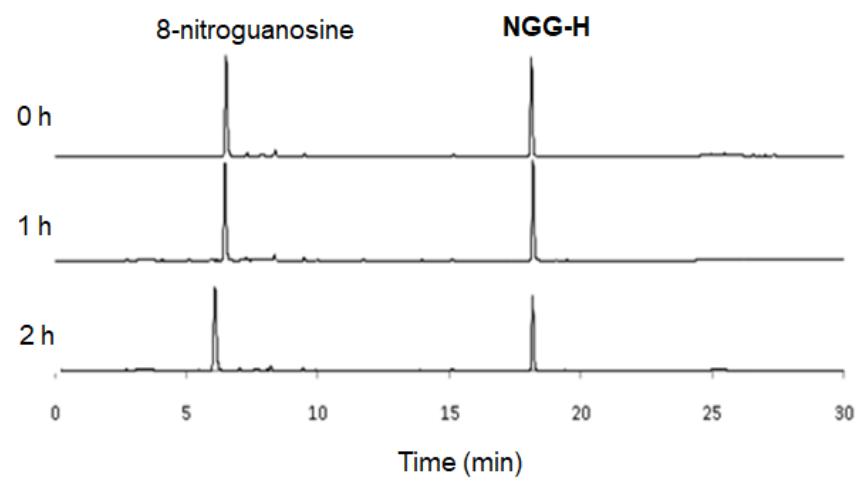

Figure S4. Reaction analysis of NGG-H for 8-nitroguanosine by HPLC. The reaction was performed using $25 \mu \mathrm{M}$ of NGG-H and 8-nitroguanosine. HPLC analytical conditions; column: cosmosil AR-II $4.6 \times 250 \mathrm{~mm}$, column temperature: $30^{\circ} \mathrm{C}$. flow rate: $1 \mathrm{~mL} / \mathrm{min}$, $U V$ detection: $365 \mathrm{~nm}$, mobile phase: $0.05 \%$ TFA in $\mathrm{CH}_{3} \mathrm{CN} / 0.05 \%$ TFA in $\mathrm{H}_{2} \mathrm{O}=20 / 80$ to $45 / 55$ (linear gradient 0-20 min), and 100/0 after $20 \mathrm{~min}$. 

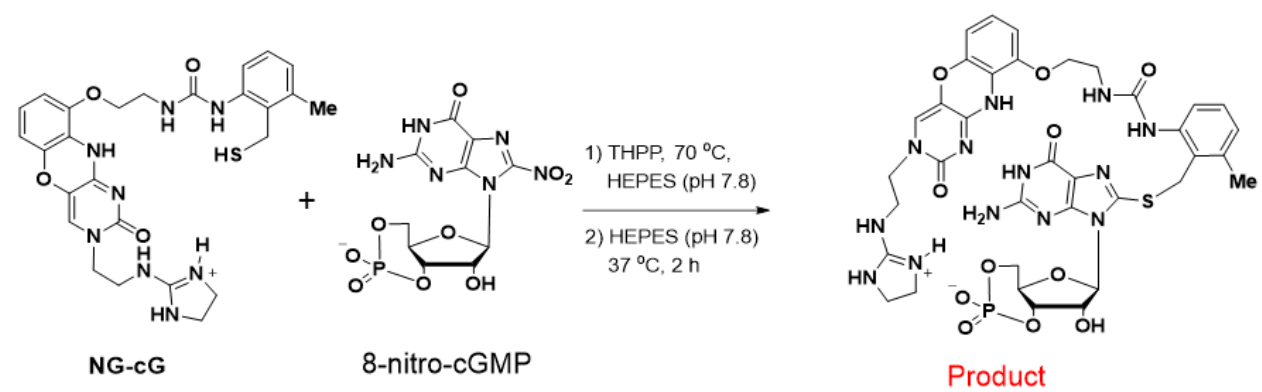

A)

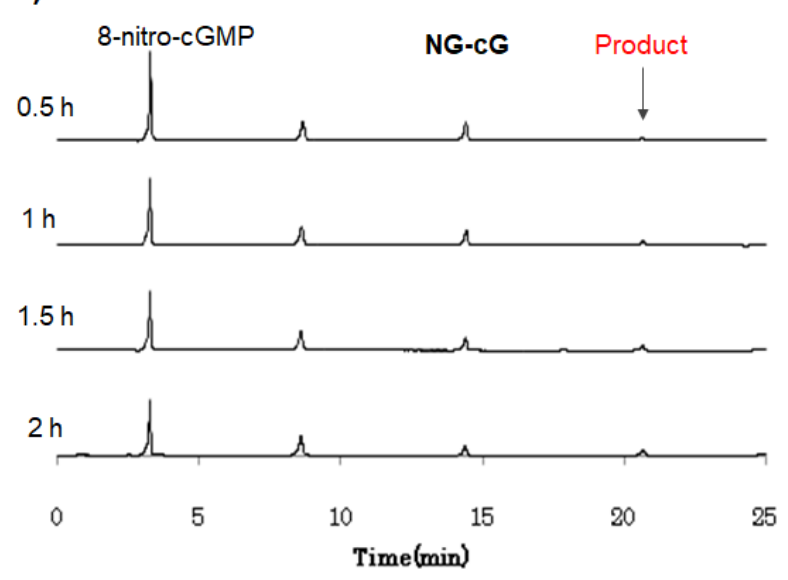

B)

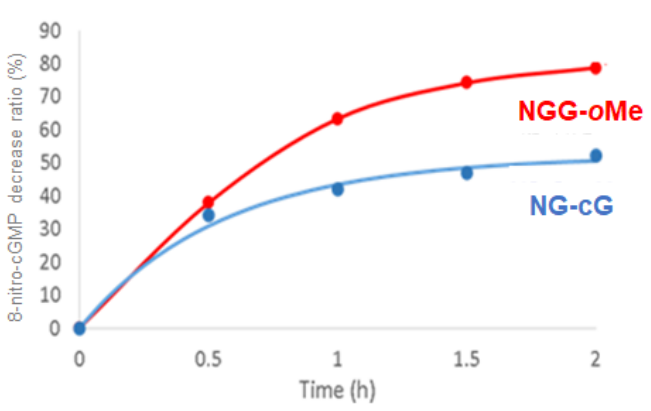

Figure S5 Reaction analysis of NG-cG for 8-nitro-cGMP by HPLC (A), and comparison of decrease ratio of 8-nitro-cGMP between NG-cG and NGG-oMe (B). HPLC analytical conditions; column: cosmosil AR-II $4.6 \times 250 \mathrm{~mm}$, column temperature: $30^{\circ} \mathrm{C}$. flow rate: $1 \mathrm{~mL} / \mathrm{min}$, UV detection: $365 \mathrm{~nm}$, mobile phase: $0.05 \%$ TFA in $\mathrm{CH}_{3} \mathrm{CN} / 0.05 \%$ TFA in $\mathrm{H}_{2} \mathrm{O}=20 / 80$ to $45 / 55$ (linear gradient $0-20$ min), and $100 / 0$ after $20 \mathrm{~min}$. 


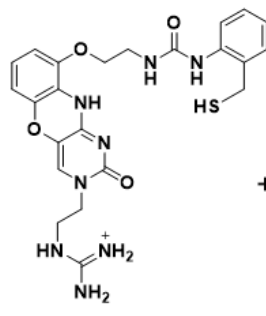

NGG-H

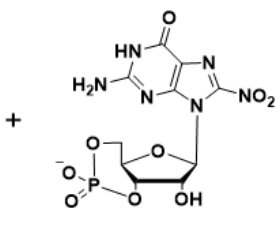

8-nitro-cGMP
1) THPP, $70^{\circ} \mathrm{C}$

HEPES ( $\mathrm{pH} 7.8)$

2) HEPES (pH 7.8)

+ CGMP

or

+ dGTP

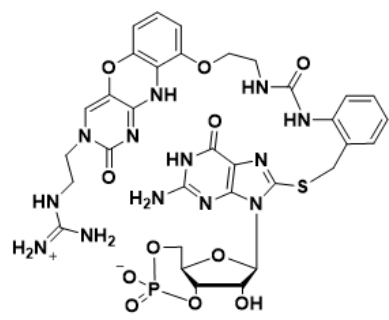

Product

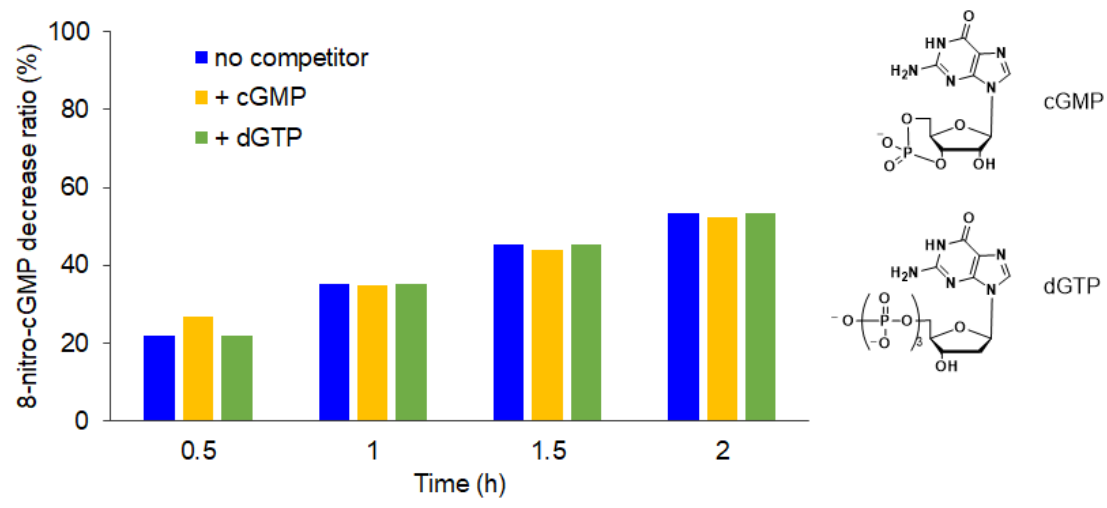

Figure S6. Comparison of the reactivity of NGG-H in the presence of cGMP or dGTP $(25 \mu \mathrm{M})$. The reaction was performed using $25 \mu \mathrm{M}$ of NGG-H and 8-nitro-cGMP. 
A)

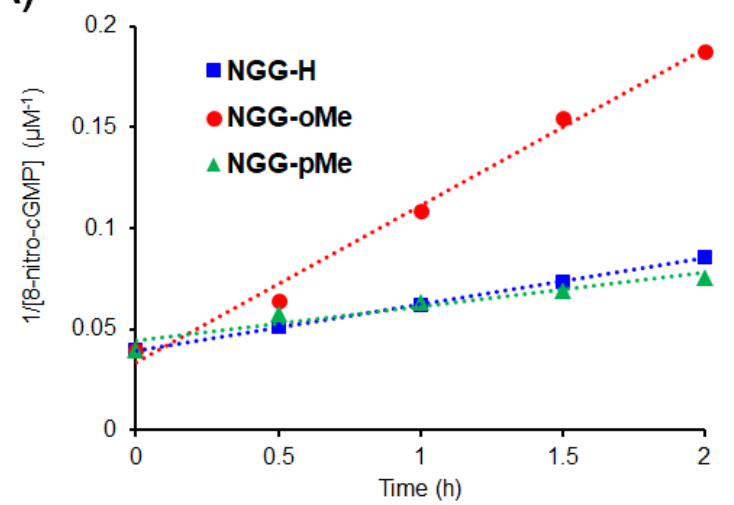

B)

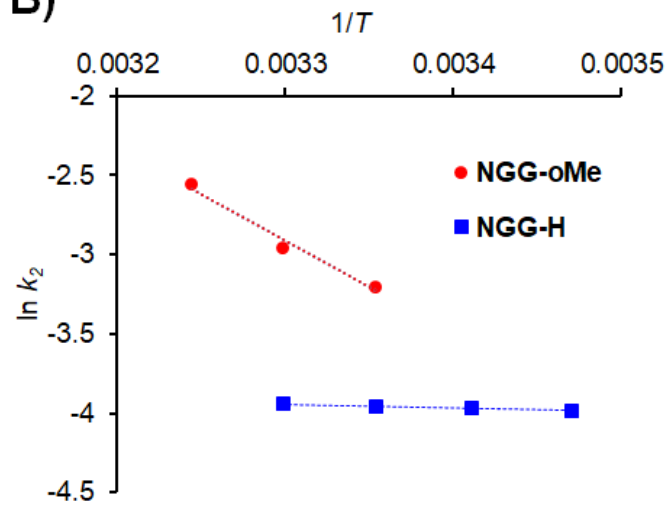

Figure S7 (A) Plot of 1/[8-nitro-cGMP] $\left(\mu \mathrm{M}^{-1}\right)$ versus time (h) for respective NGG derivatives according to HPLC analyses. The reactions were performed at $37{ }^{\circ} \mathrm{C}$ in HEPES buffer ( $\mathrm{pH}$ 7.8). (B) Arrhenius plot of NGG-H and NGG-oMe. The reactions of NGG-H were performed at 15, 20, 25 and $30^{\circ} \mathrm{C}$. The reactions of NGG-oMe were performed at 25,30 and $37^{\circ} \mathrm{C}$. 


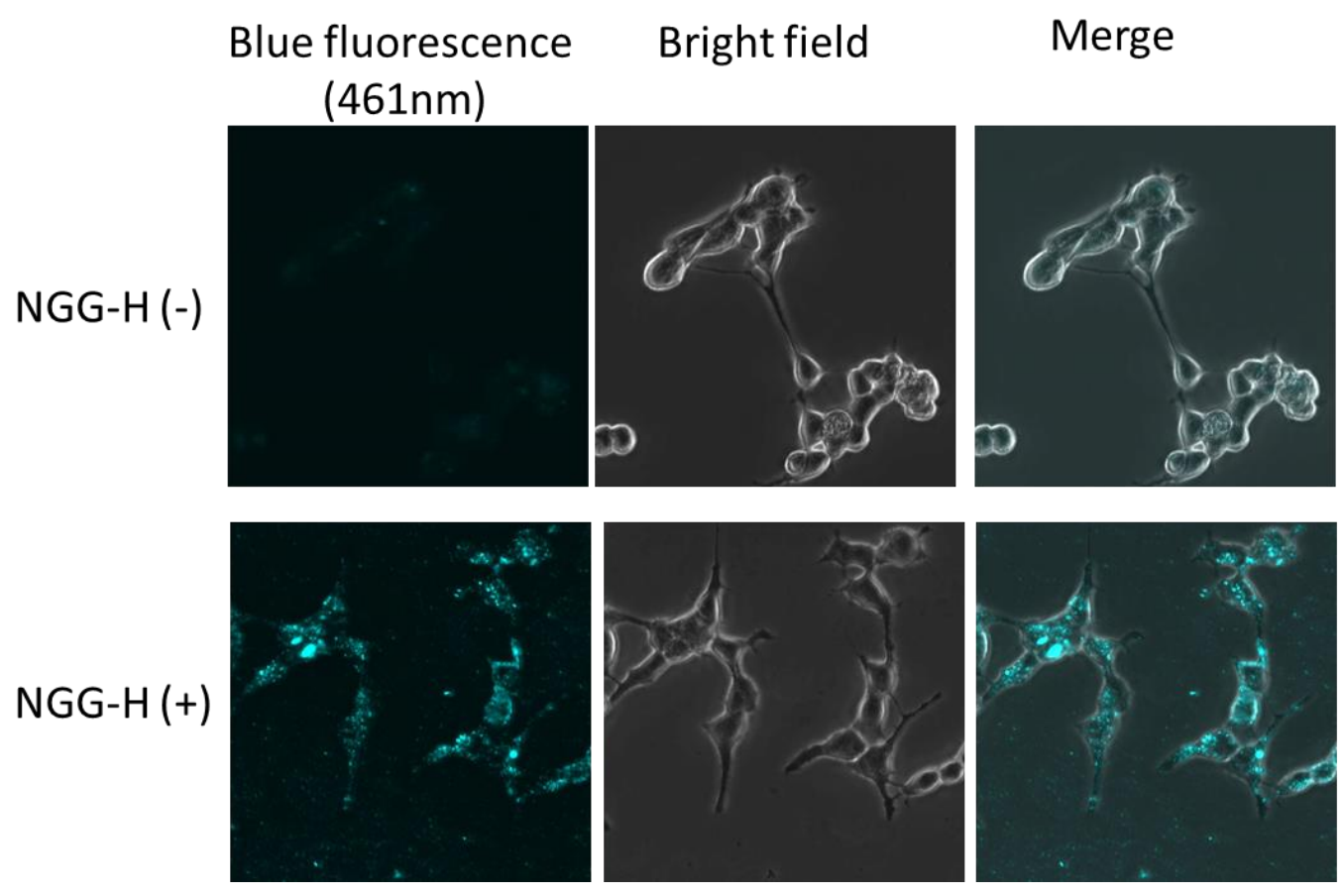

Figure S8. Fluorescence images of HEK293 cells. Upper panels for background fluorescence of HEK293. Lower panels for the cells incubated with NGG-H (3) $(25 \mu \mathrm{M})$ for $1 \mathrm{~h}$. The fluorescence signals were captured by confocal laser microscopy. Excitation laser wavelength: $359 \mathrm{~nm}$, Emission filter: $461 \mathrm{~nm}$. 


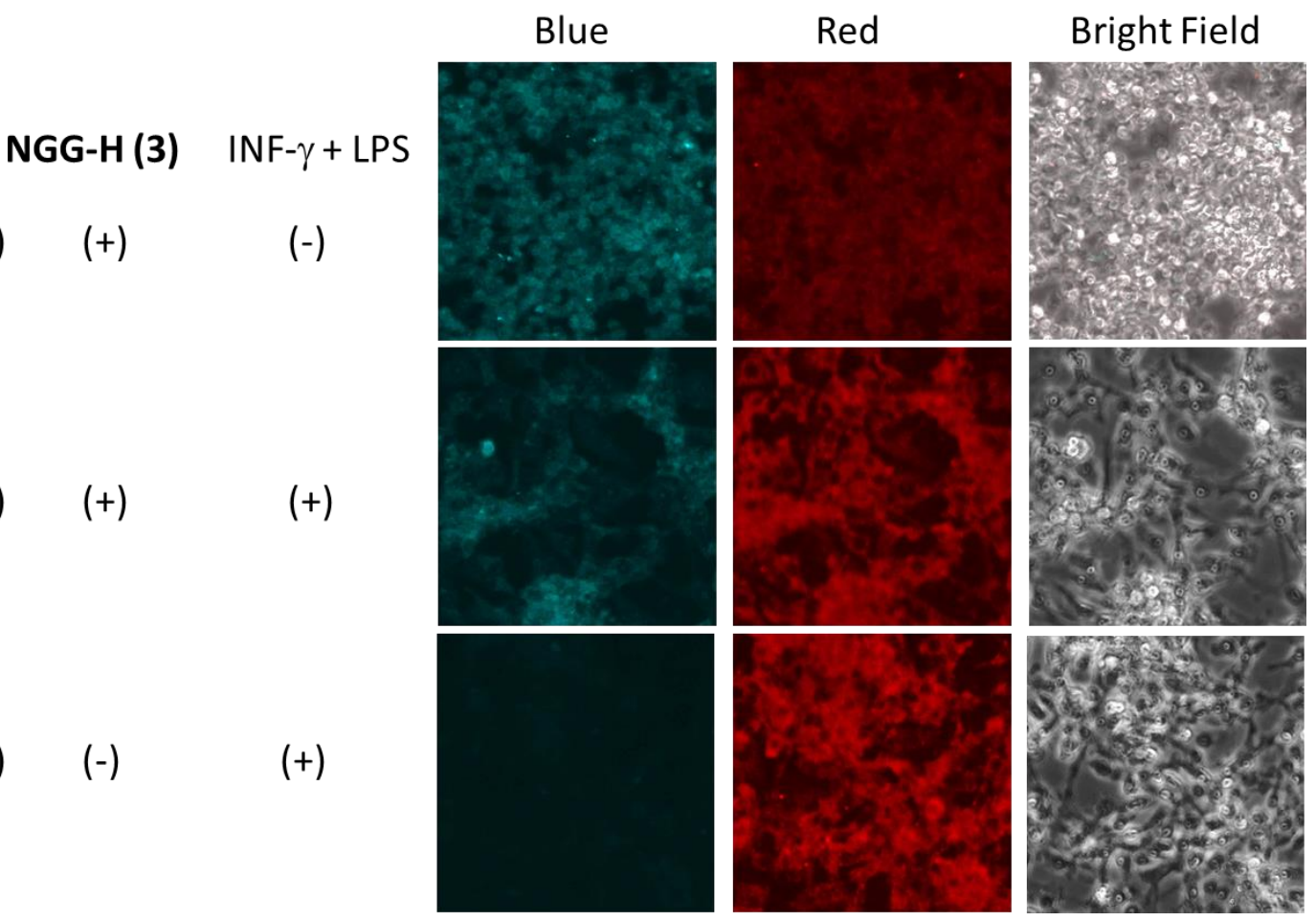

Figure S9. Fluorescence images of RAW 264.7 cells. The blue and red fluorescence images were observed with $\lambda_{\mathrm{ex}}=359 \mathrm{~nm}, \lambda_{\mathrm{em}}=461 \mathrm{~nm}$ and $\lambda_{\mathrm{ex}}=557 \mathrm{~nm}, \lambda_{\mathrm{em}}=572 \mathrm{~nm}$, respectively. 
${ }^{1} \mathrm{H}-\mathrm{NMR}$ spectrum of $\mathbf{8} \quad\left(500 \mathrm{MHz}, \mathrm{CD}_{3} \mathrm{OD}\right)$

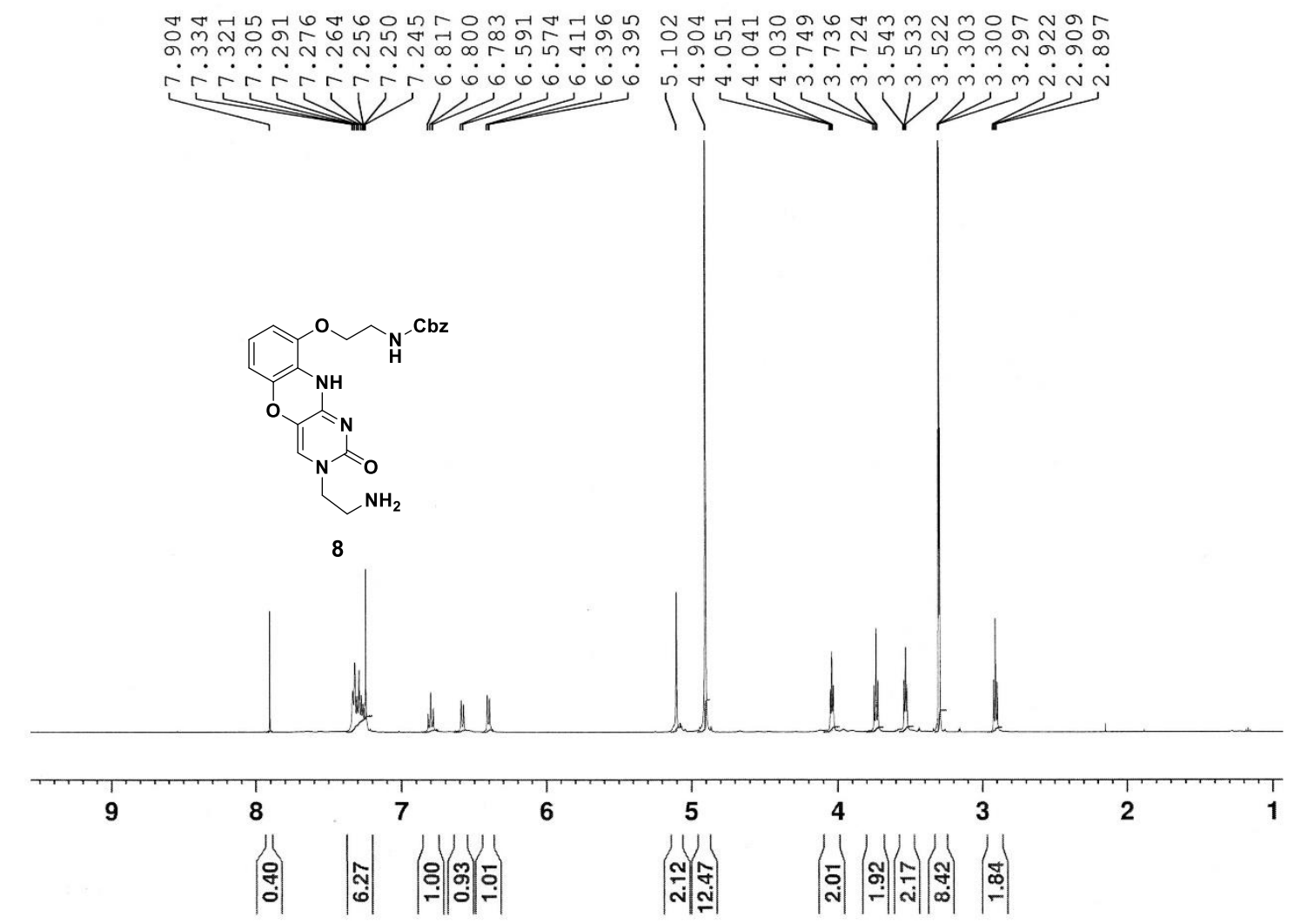

${ }^{13} \mathrm{C}-\mathrm{NMR}$ spectrum of 8 (125 MHz, $\left.\mathrm{CD}_{3} \mathrm{OD}\right)$

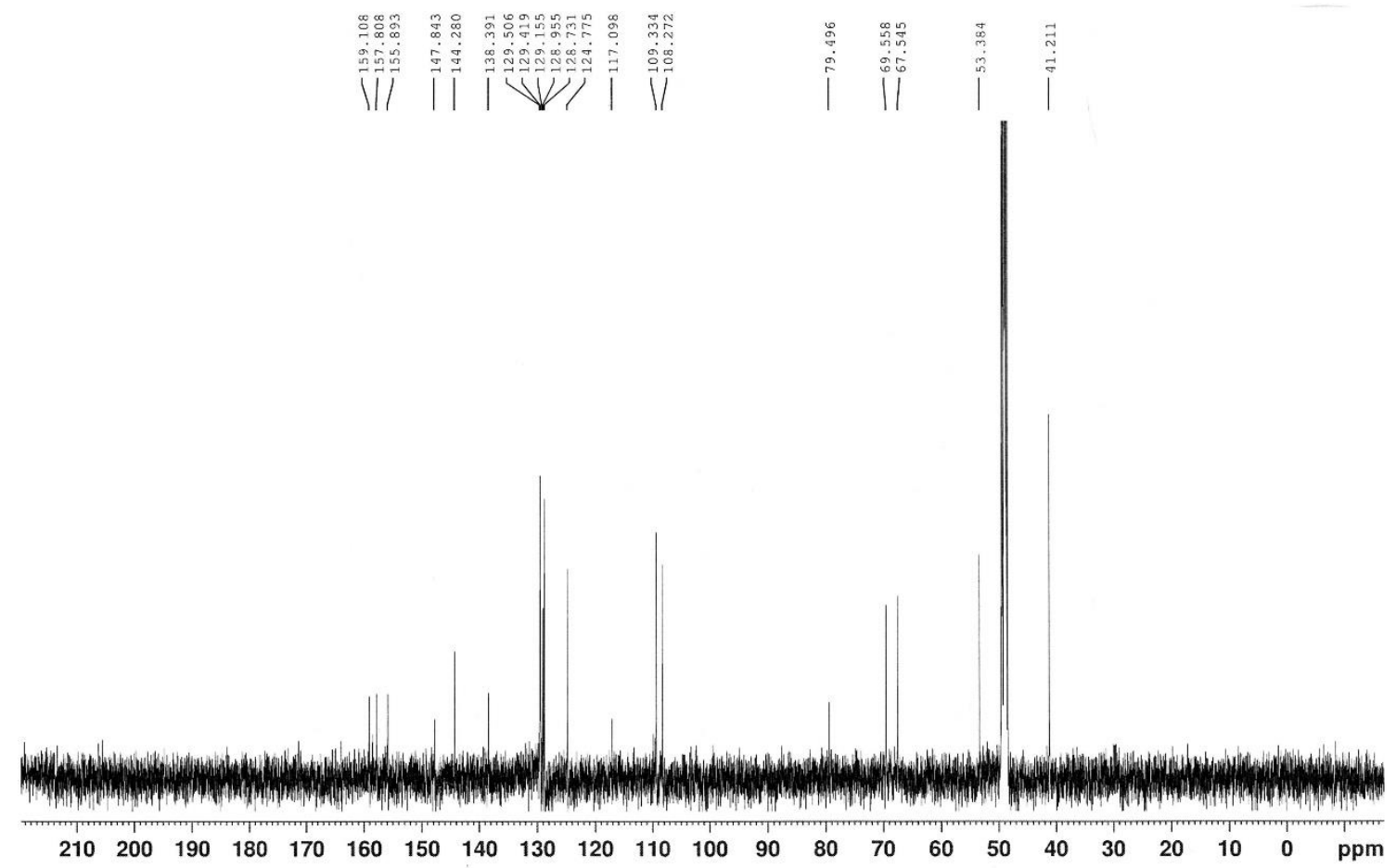


${ }^{1} \mathrm{H}-\mathrm{NMR}$ spectrum of $9\left(500 \mathrm{MHz}, \mathrm{CD}_{3} \mathrm{OD}\right)$

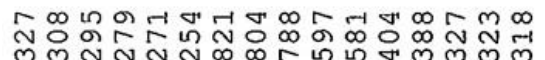

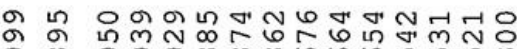

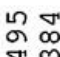

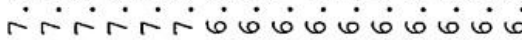

○

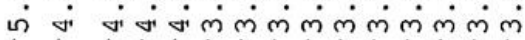

1
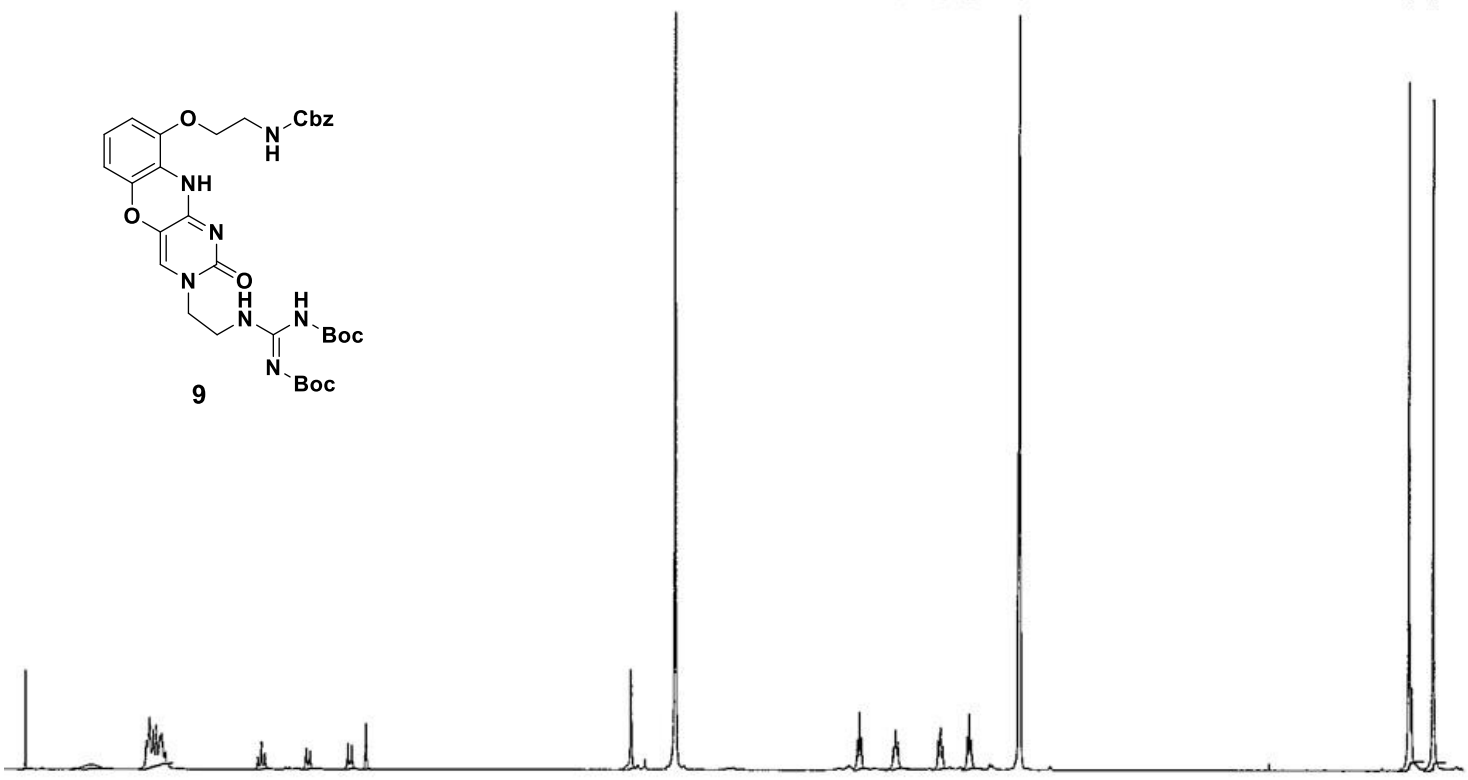

7.5
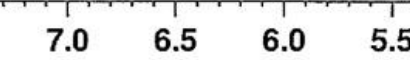

$5.0 \quad 4.5$

(ल) 3.0 (4)

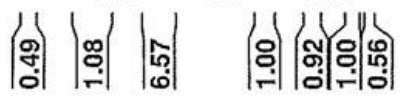

(ั)

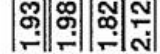

$\begin{array}{lll}2.5 & 2.0 & \text { ppm }\end{array}$

${ }^{13} \mathrm{C}-\mathrm{NMR}$ spectrum of 9 (125 MHz, CD $\left.3 \mathrm{OD}\right)$

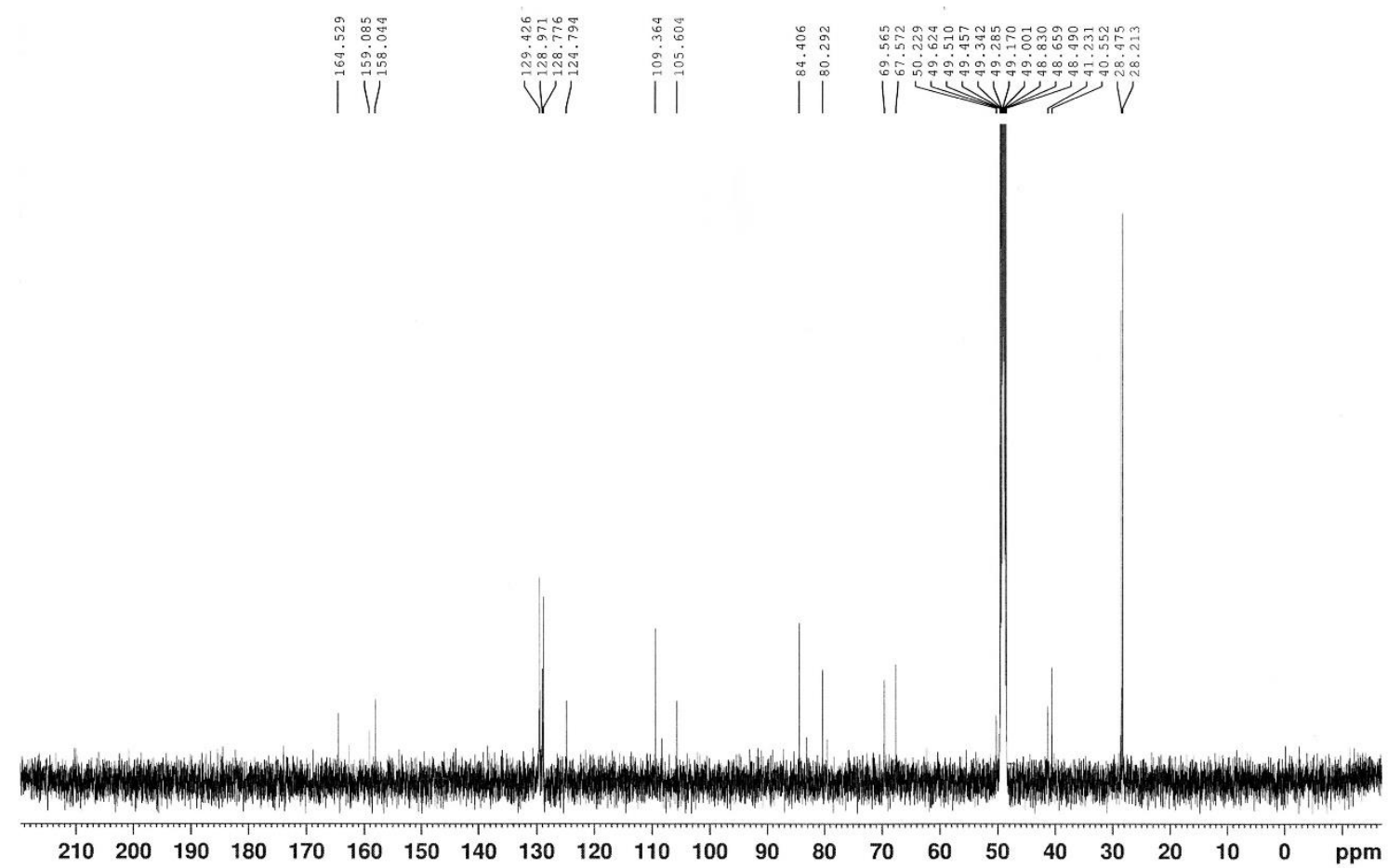

${ }^{1} \mathrm{H}-\mathrm{NMR}$ spectrum of $\mathbf{1 0}\left(500 \mathrm{MHz}, \mathrm{CD}_{3} \mathrm{OD}\right)$ 


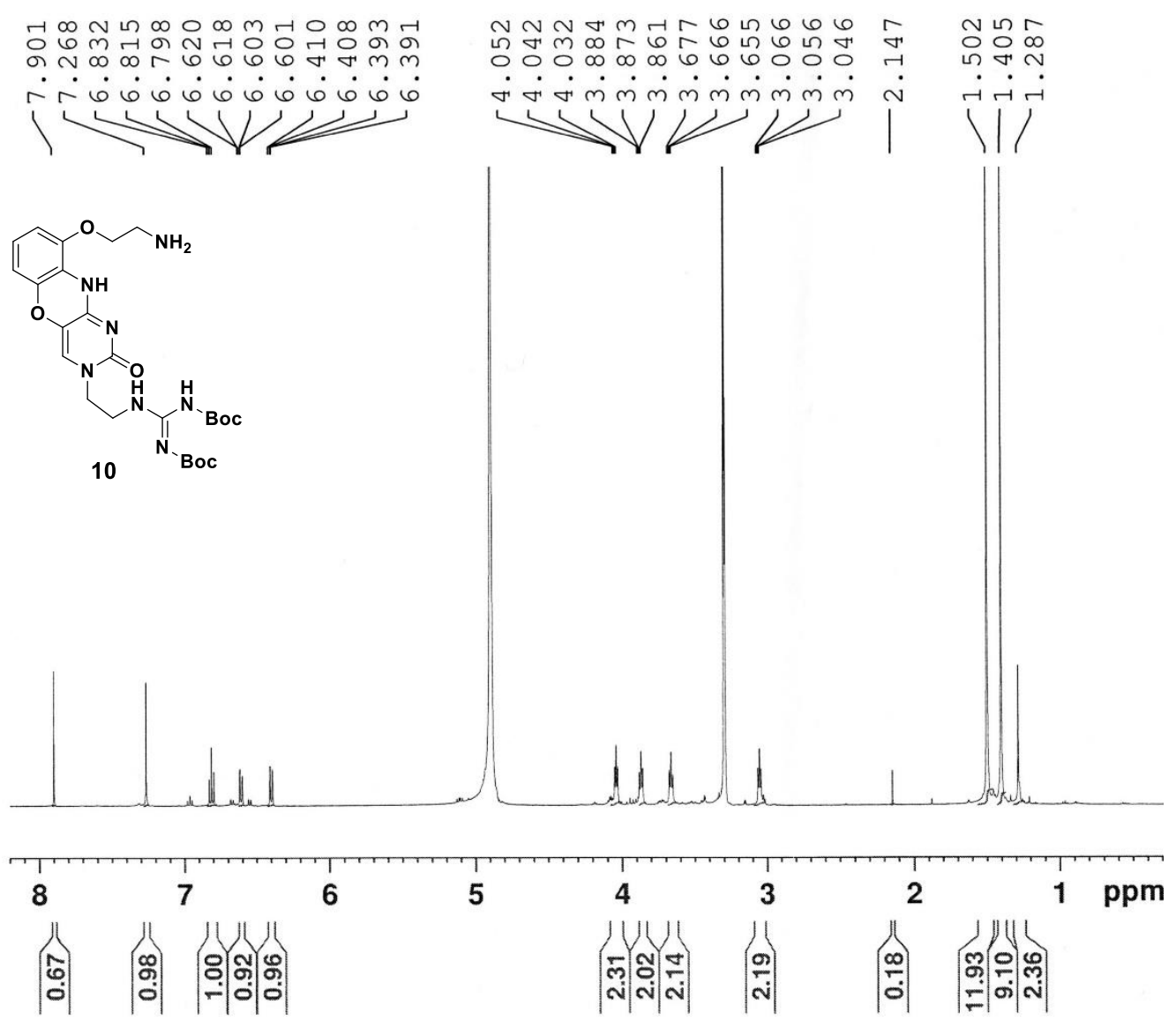

${ }^{13} \mathrm{C}-\mathrm{NMR}$ spectrum of $\mathbf{1 0}\left(125 \mathrm{MHz}, \mathrm{CD}_{3} \mathrm{OD}\right)$

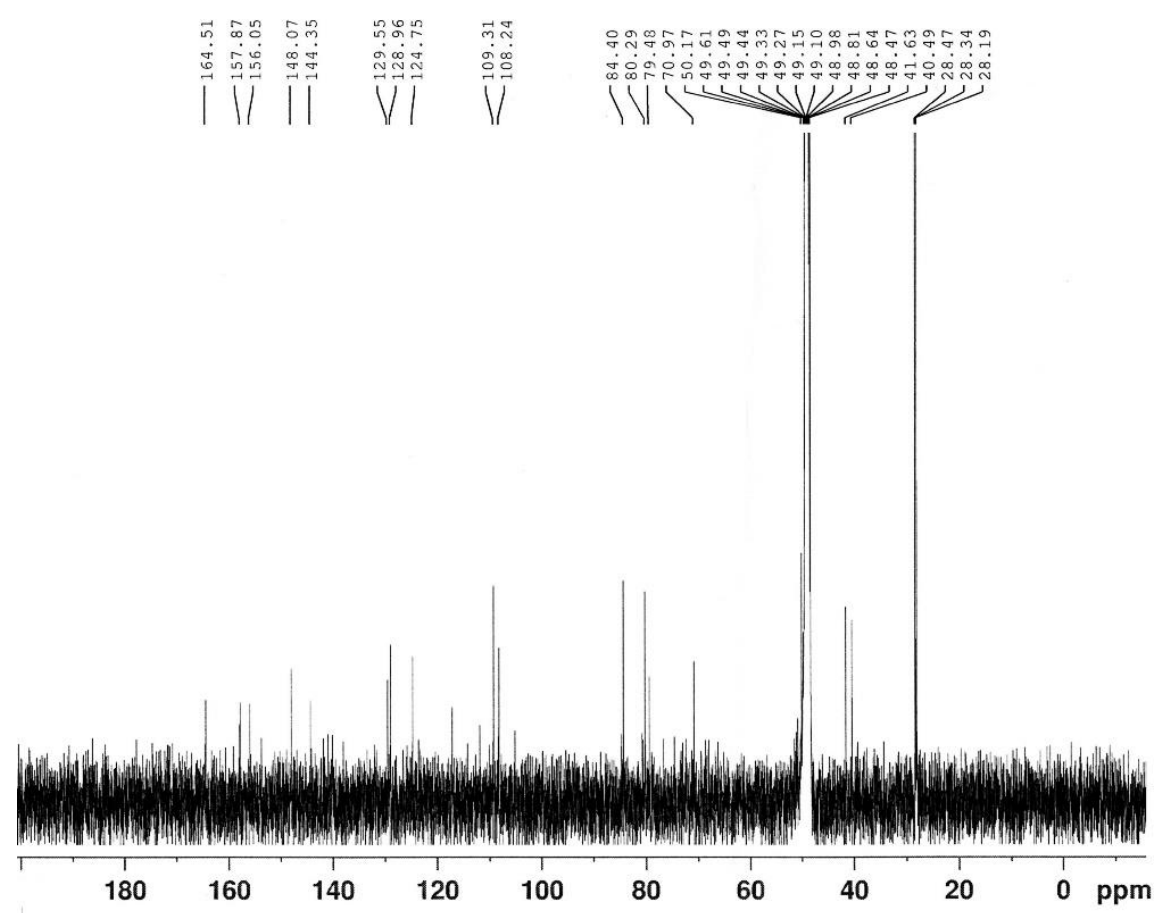


${ }^{1} \mathrm{H}-\mathrm{NMR}$ spectrum of $\mathbf{1 5 a}\left(500 \mathrm{MHz}, \mathrm{CD}_{3} \mathrm{OD}\right)$

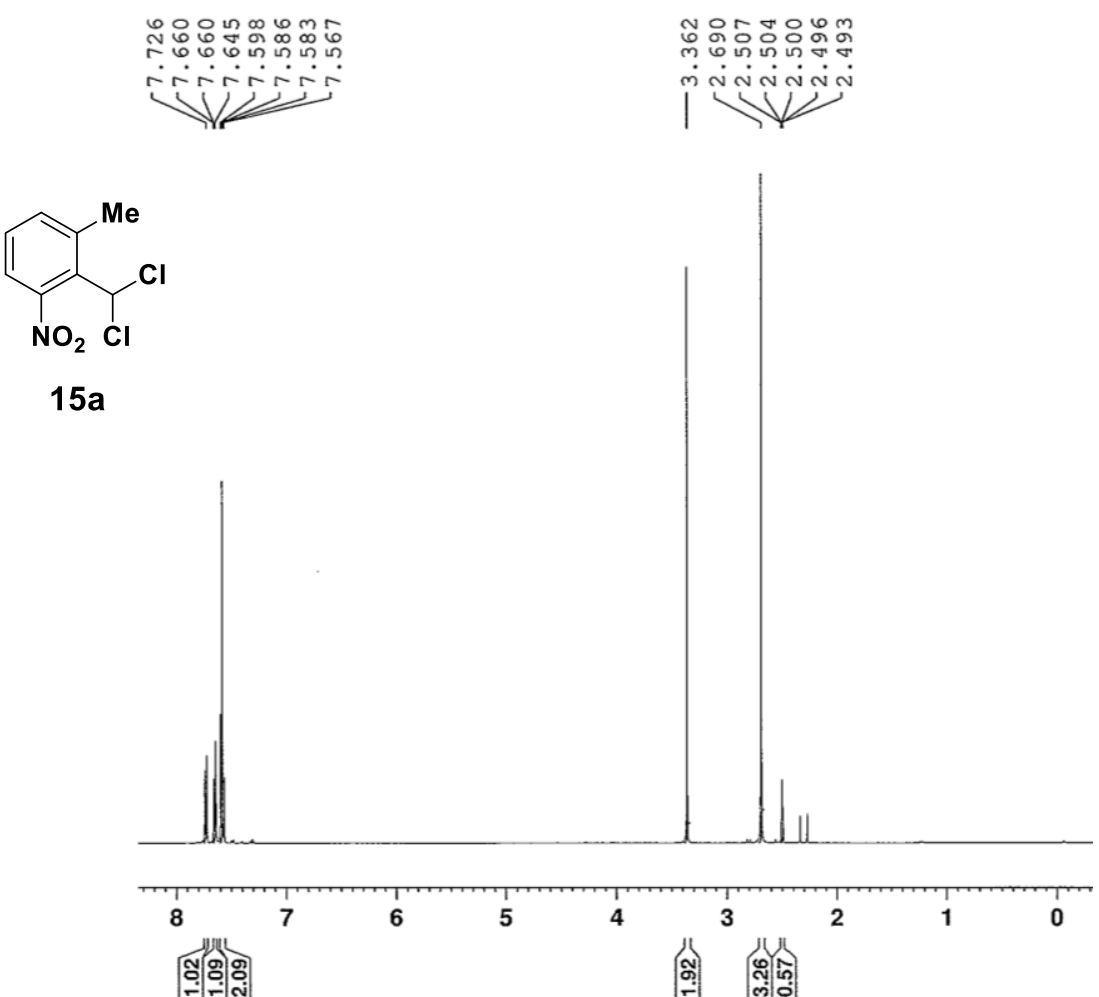

${ }^{13} \mathrm{C}-\mathrm{NMR}$ spectrum of $\mathbf{1 5 a}\left(125 \mathrm{MHz}, \mathrm{CD}_{3} \mathrm{OD}\right)$

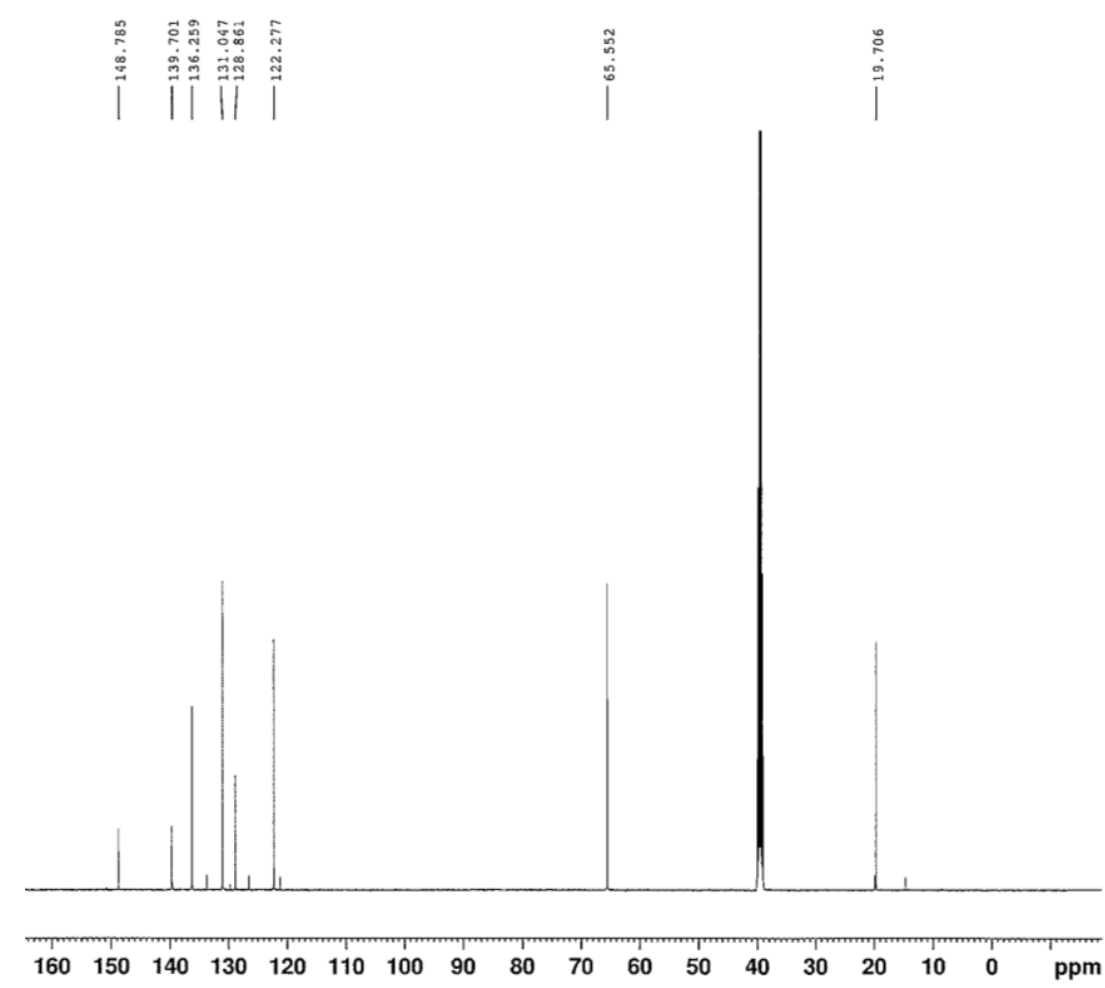

${ }^{1} \mathrm{H}-\mathrm{NMR}$ spectrum of $\mathbf{1 5 b}\left(500 \mathrm{MHz}, \mathrm{CD}_{3} \mathrm{OD}\right)$ 


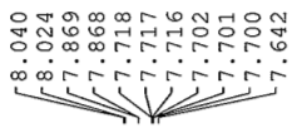

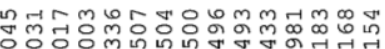

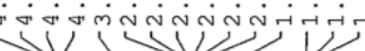

Me<smiles>Cc1ccc(C(Cl)Cl)c([N+](=O)[O-])c1</smiles>

$15 b$

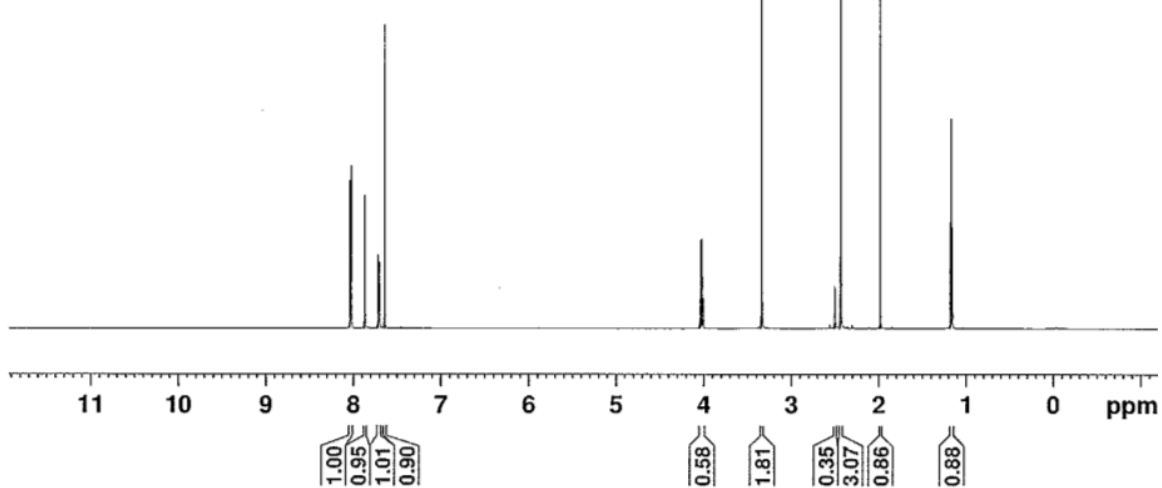

${ }^{13} \mathrm{C}-\mathrm{NMR}$ spectrum of $\mathbf{1 5 b}\left(125 \mathrm{MHz}, \mathrm{CD}_{3} \mathrm{OD}\right)$

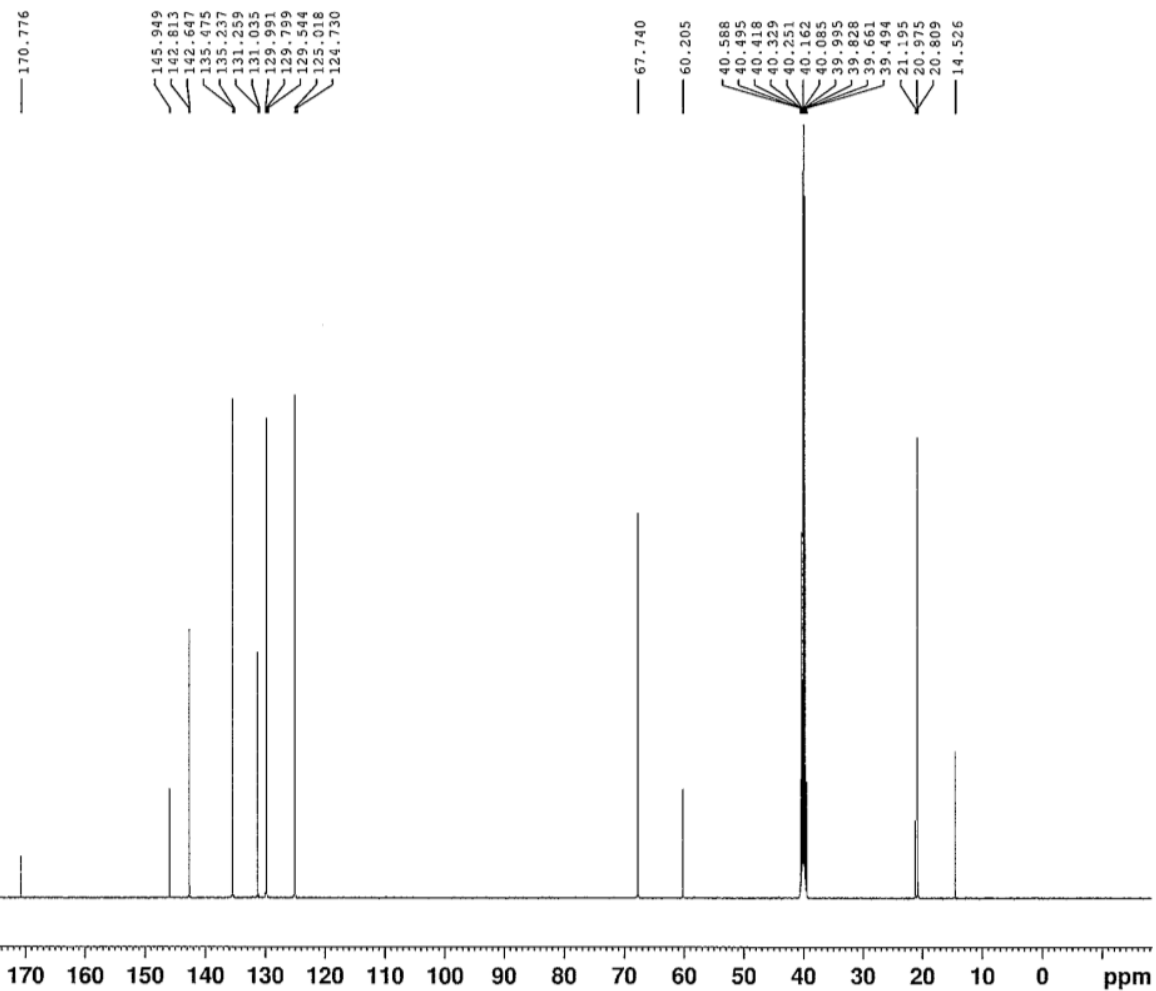

${ }^{1} \mathrm{H}-\mathrm{NMR}$ spectrum of $\mathbf{1 6 a}\left(500 \mathrm{MHz}, \mathrm{CD}_{3} \mathrm{OD}\right)$ 


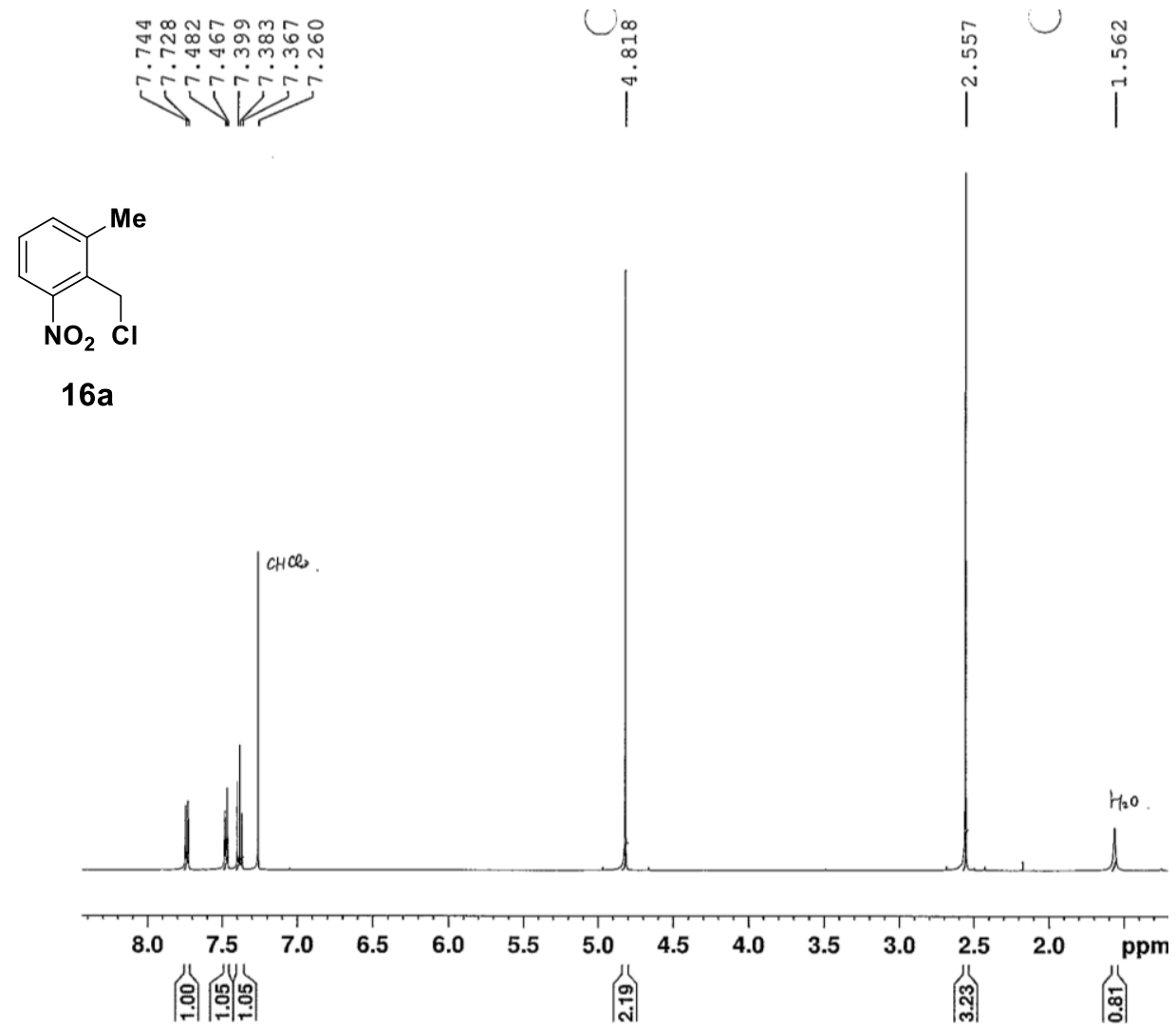

${ }^{13} \mathrm{C}-\mathrm{NMR}$ spectrum of $\mathbf{1 6 a}\left(125 \mathrm{MHz}, \mathrm{CD}_{3} \mathrm{OD}\right)$

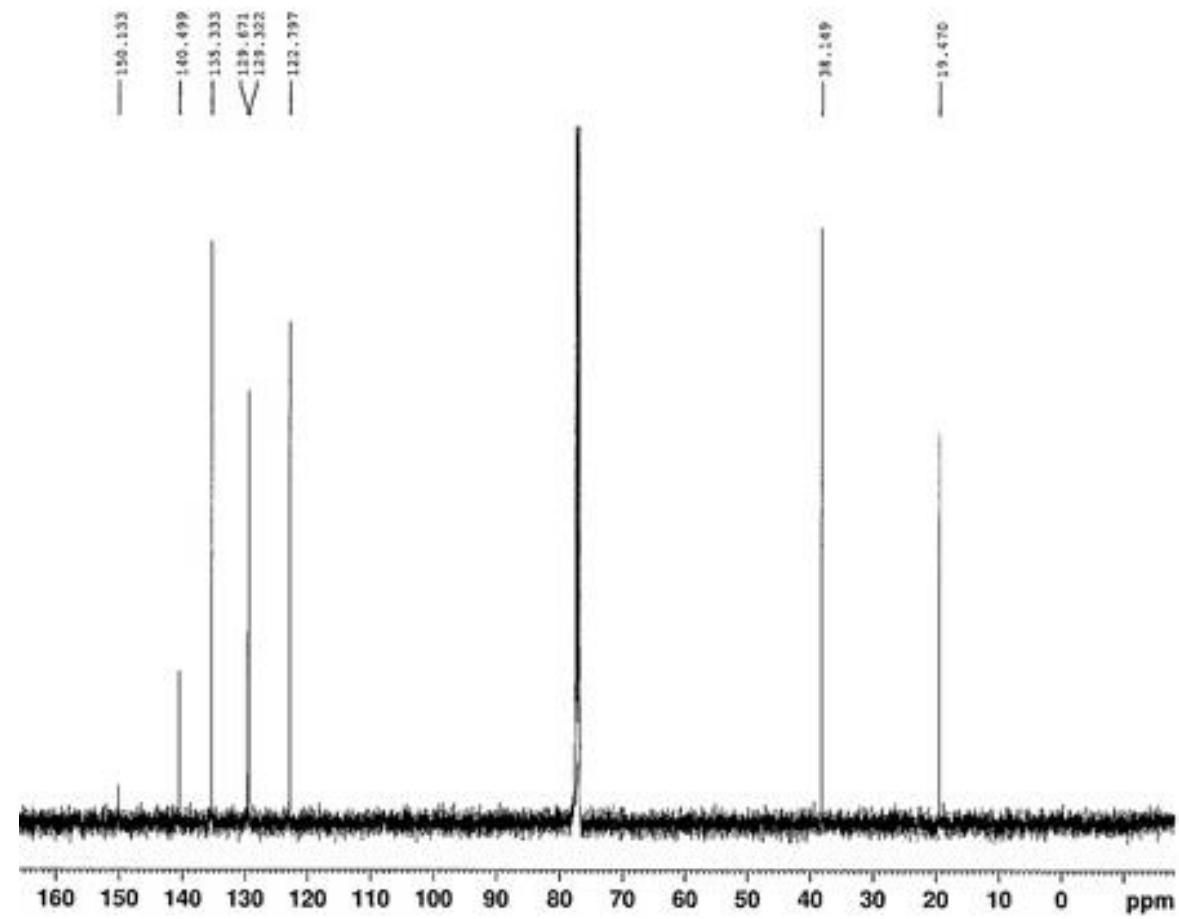

${ }^{1} \mathrm{H}-\mathrm{NMR}$ spectrum of $\mathbf{1 6} \mathbf{b}\left(500 \mathrm{MHz}, \mathrm{CD}_{3} \mathrm{OD}\right)$ 


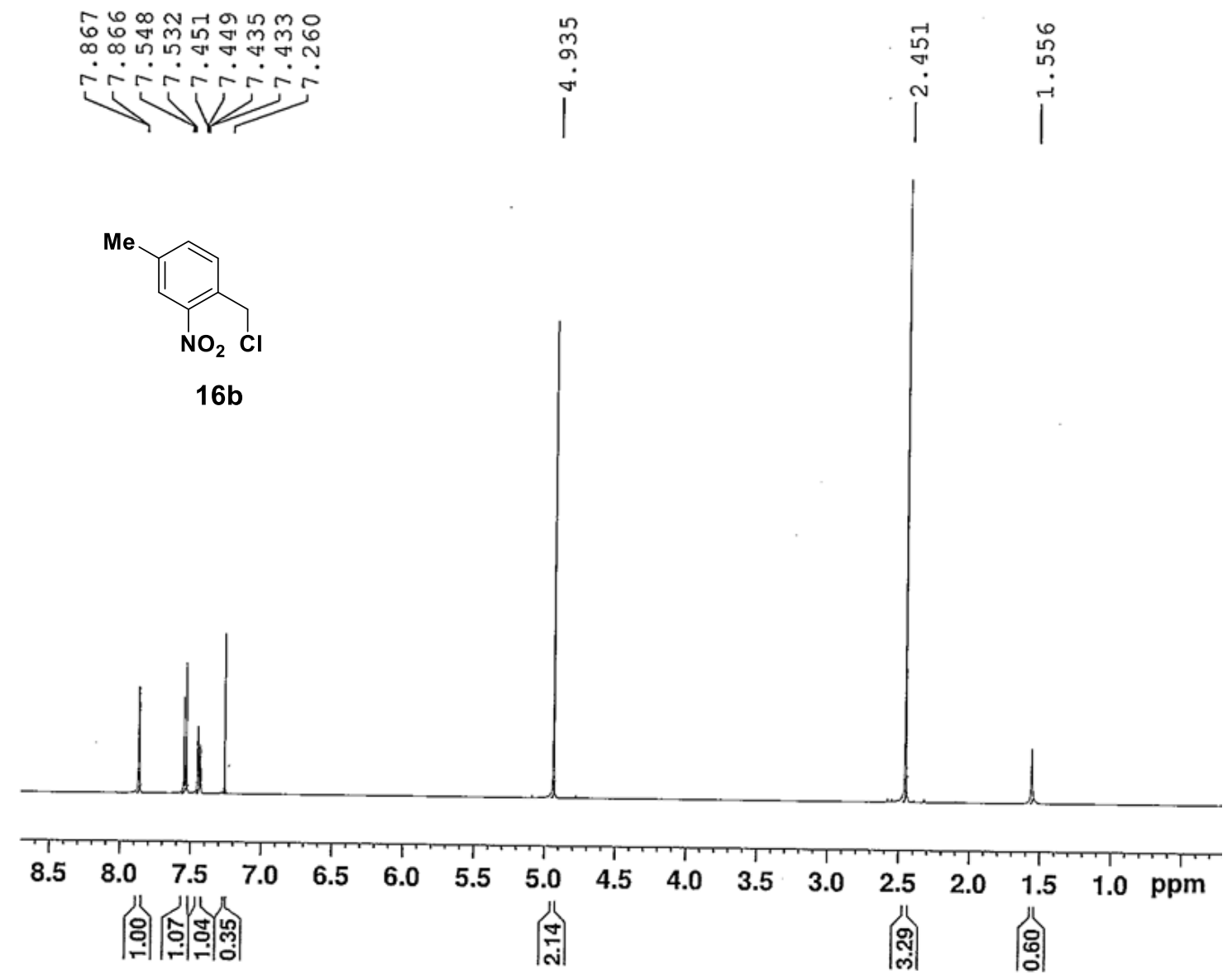

${ }^{13} \mathrm{C}$-NMR spectrum of $\mathbf{1 6 b}\left(125 \mathrm{MHz}, \mathrm{CD}_{3} \mathrm{OD}\right)$

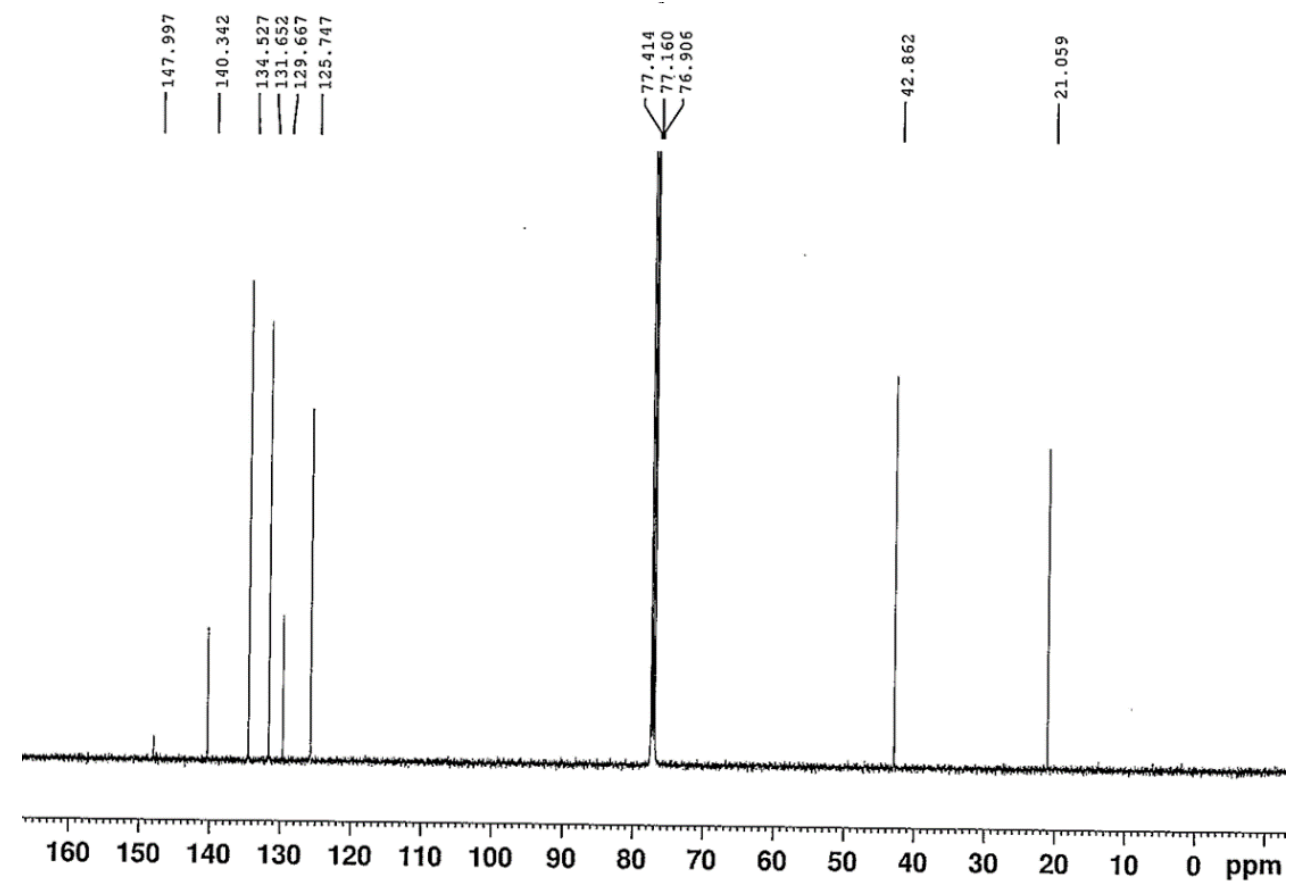


${ }^{1} \mathrm{H}-\mathrm{NMR}$ spectrum of $\mathbf{1 7 a}\left(500 \mathrm{MHz}, \mathrm{CD}_{3} \mathrm{OD}\right)$
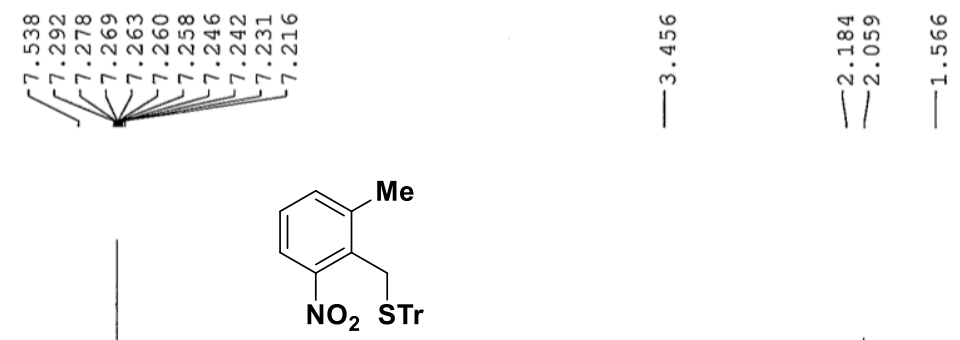

$17 a$
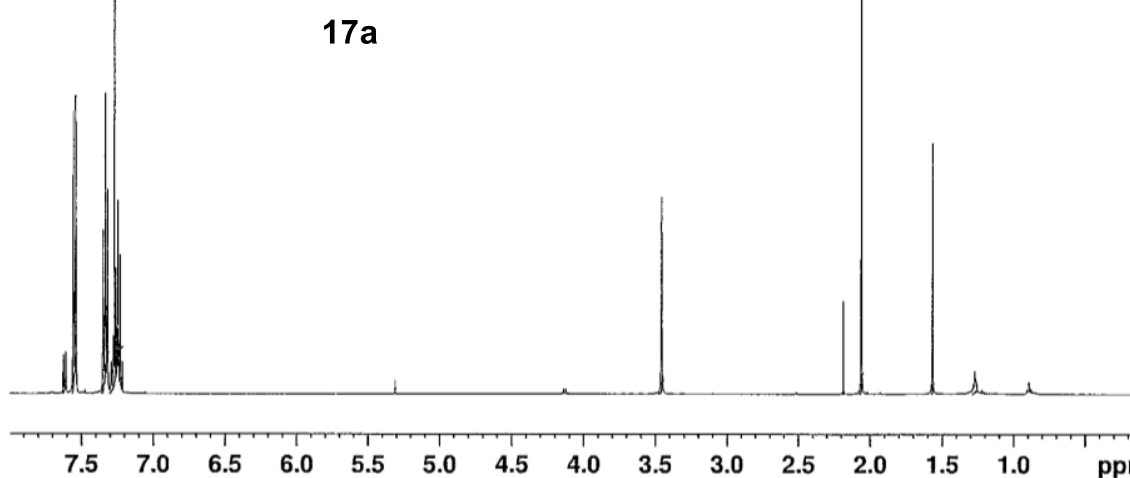
위엥

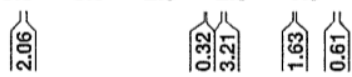

${ }^{13} \mathrm{C}-\mathrm{NMR}$ spectrum of $\mathbf{1 3 a}\left(125 \mathrm{MHz}, \mathrm{CD}_{3} \mathrm{OD}\right)$

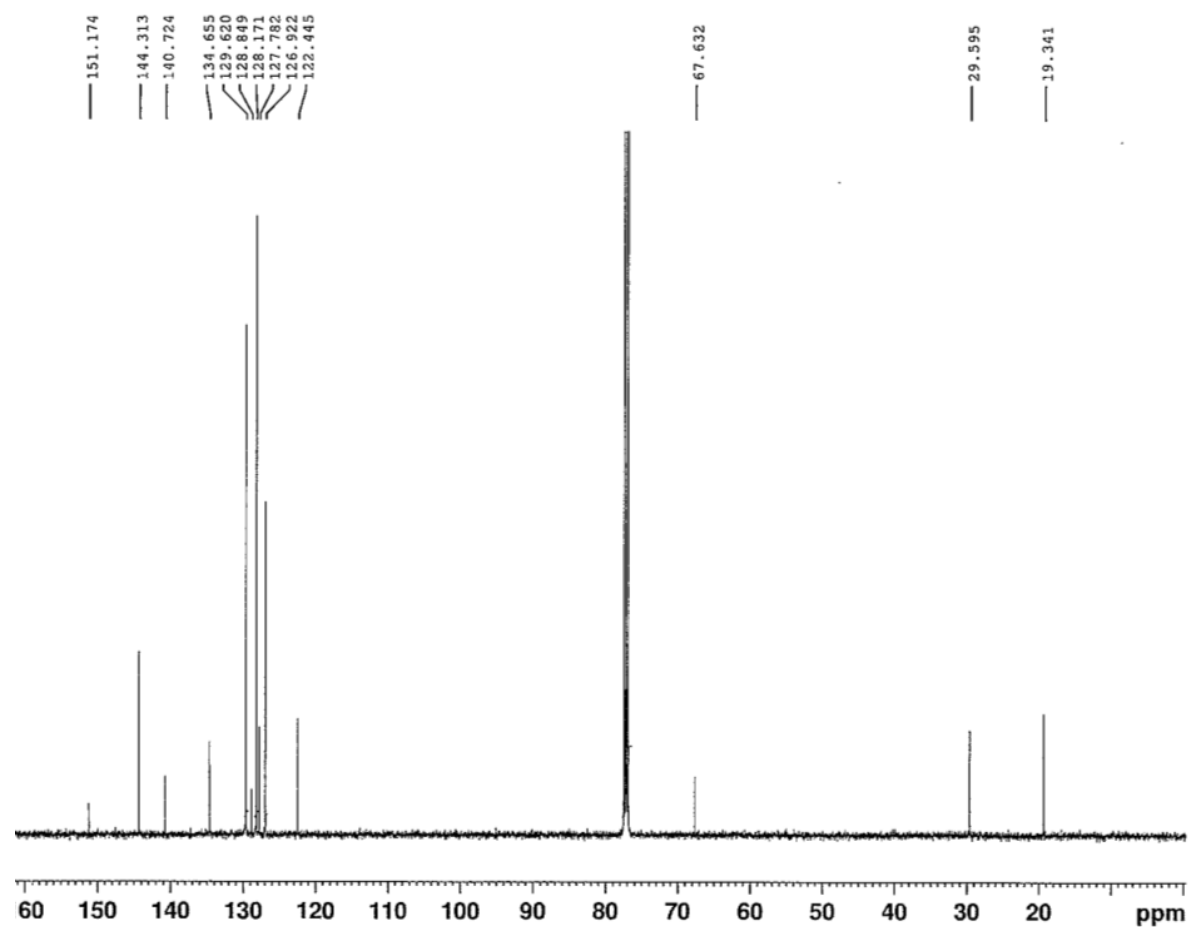


${ }^{1} \mathrm{H}-\mathrm{NMR}$ spectrum of $\mathbf{1 7 b}\left(500 \mathrm{MHz}, \mathrm{CD}_{3} \mathrm{OD}\right.$

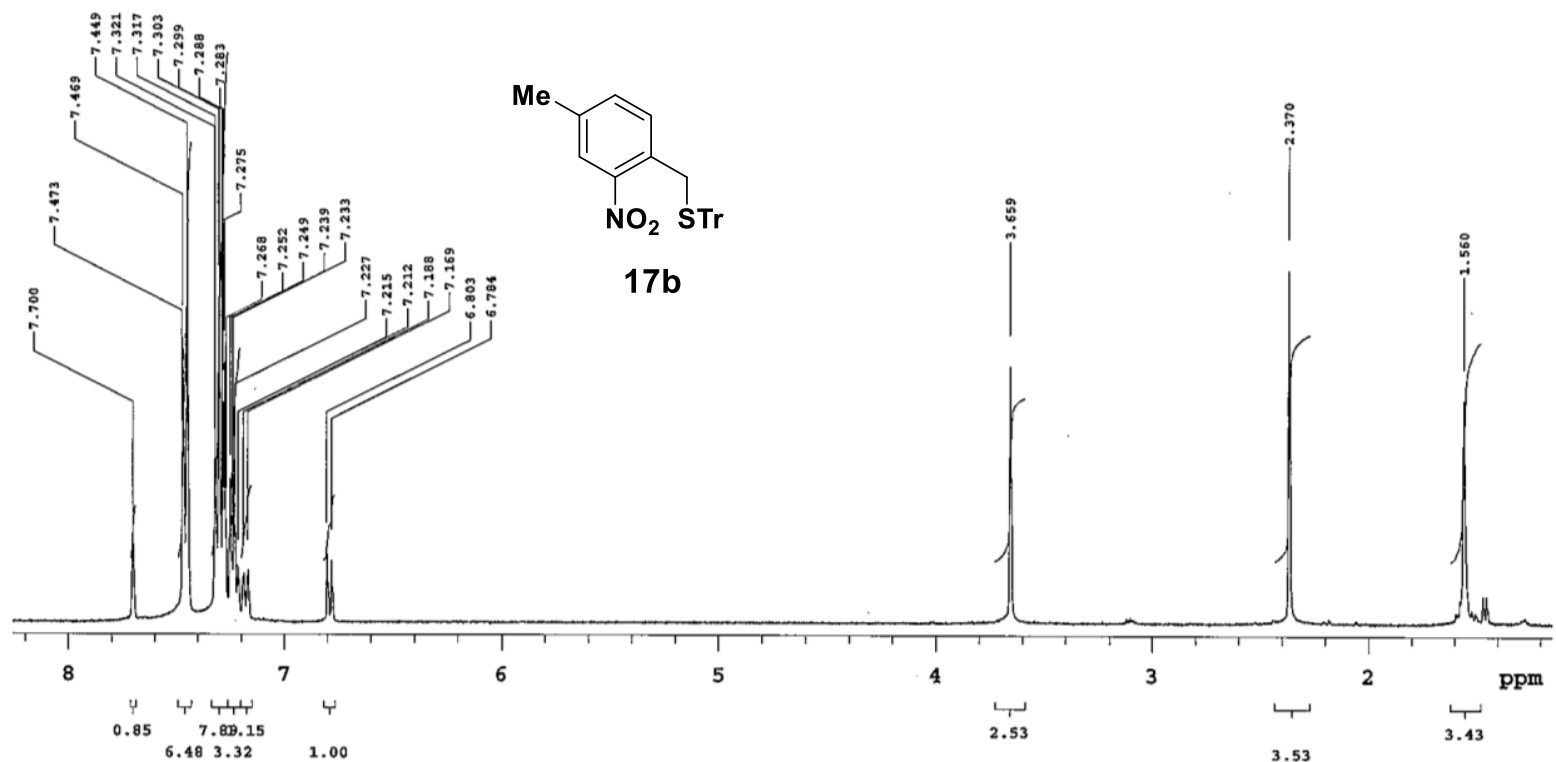

${ }^{13} \mathrm{C}-\mathrm{NMR}$ spectrum of $\mathbf{1 7 b}\left(125 \mathrm{MHz}, \mathrm{CD}_{3} \mathrm{OD}\right.$

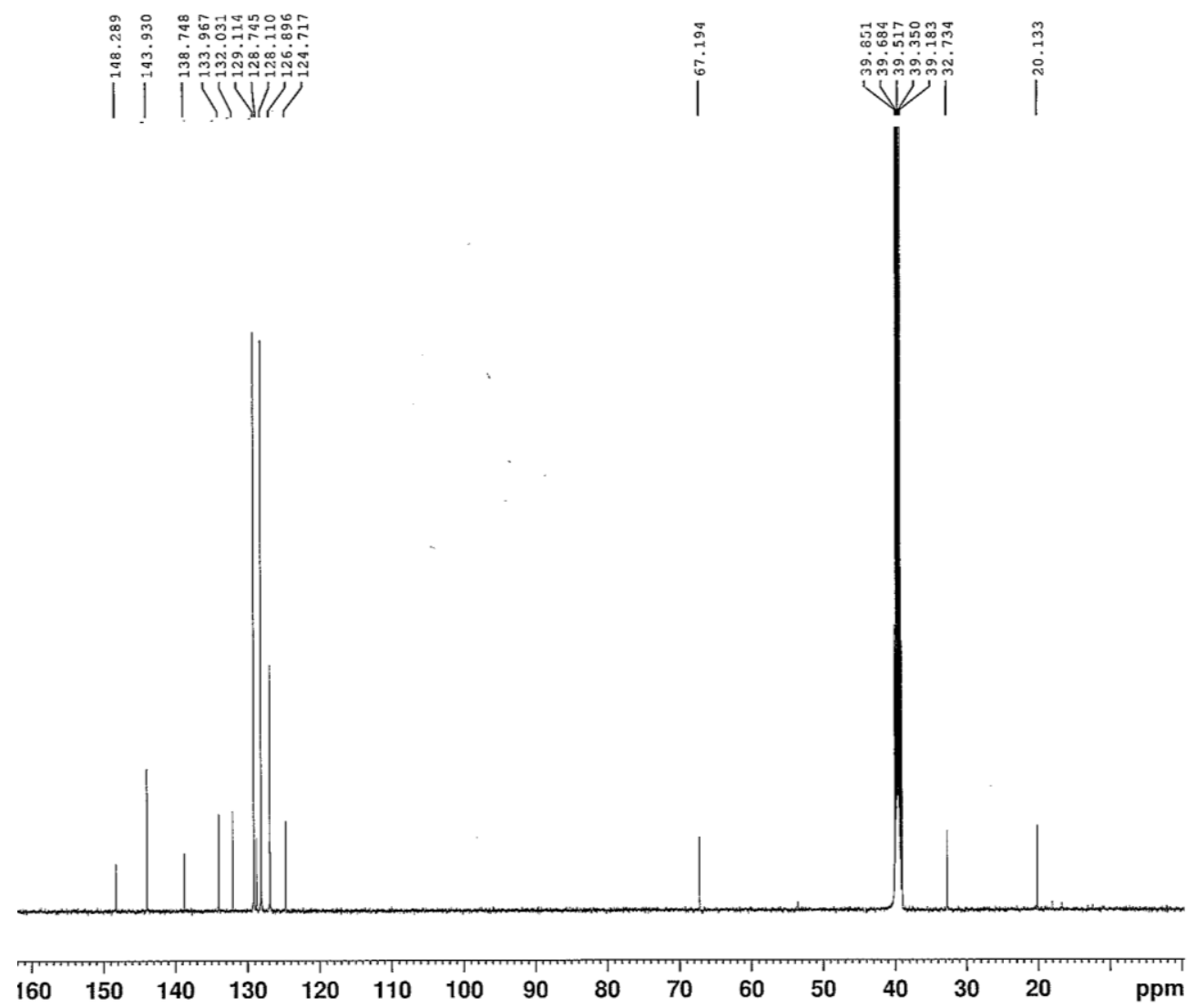


${ }^{1} \mathrm{H}-\mathrm{NMR}$ spectrum of $12\left(500 \mathrm{MHz}, \mathrm{CD}_{3} \mathrm{OD}\right)$

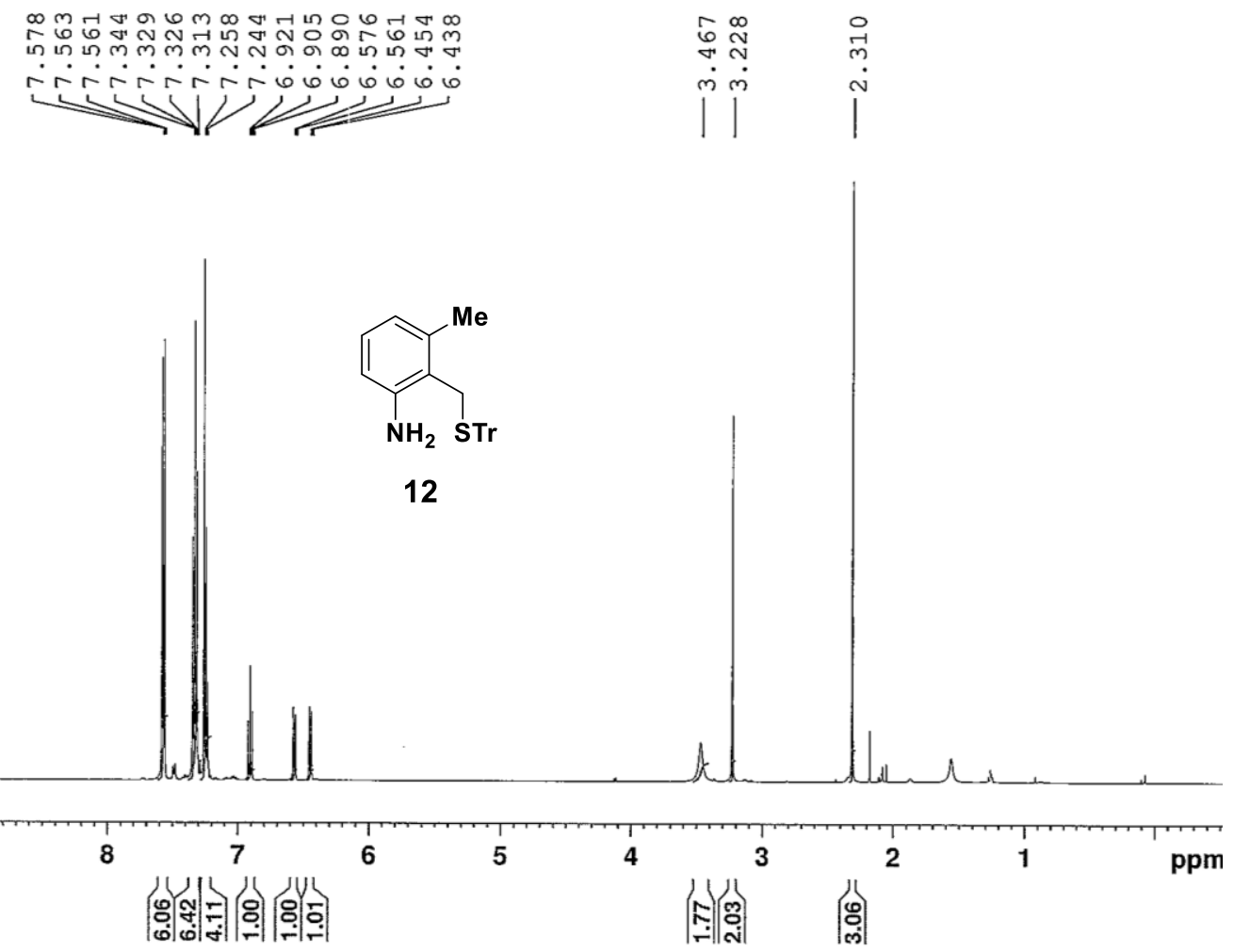

${ }^{13} \mathrm{C}-\mathrm{NMR}$ spectrum of 12 (125 MHz, $\left.\mathrm{CD}_{3} \mathrm{OD}\right)$

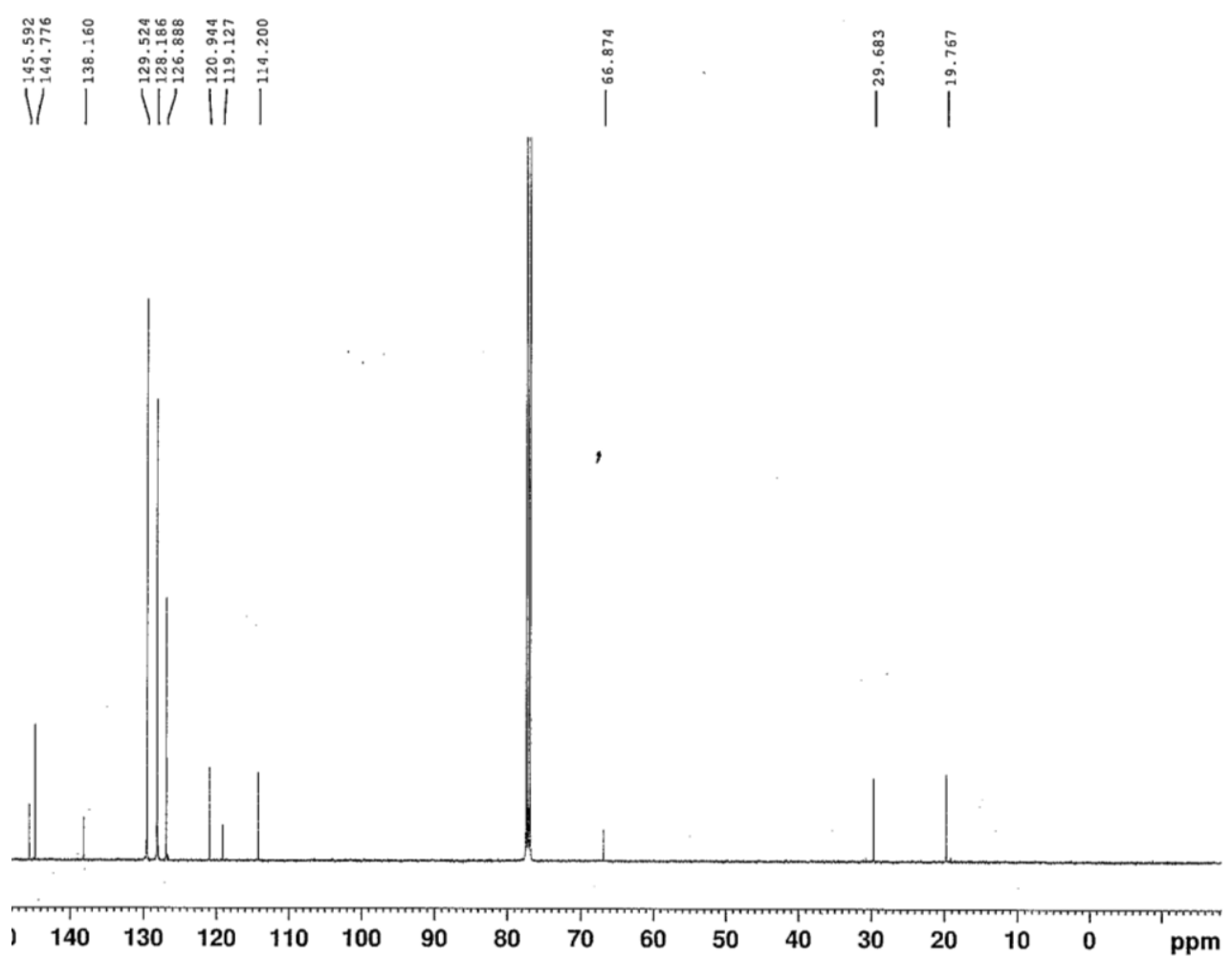


${ }^{1} \mathrm{H}-\mathrm{NMR}$ spectrum of $13\left(500 \mathrm{MHz}, \mathrm{CD}_{3} \mathrm{OD}\right)$
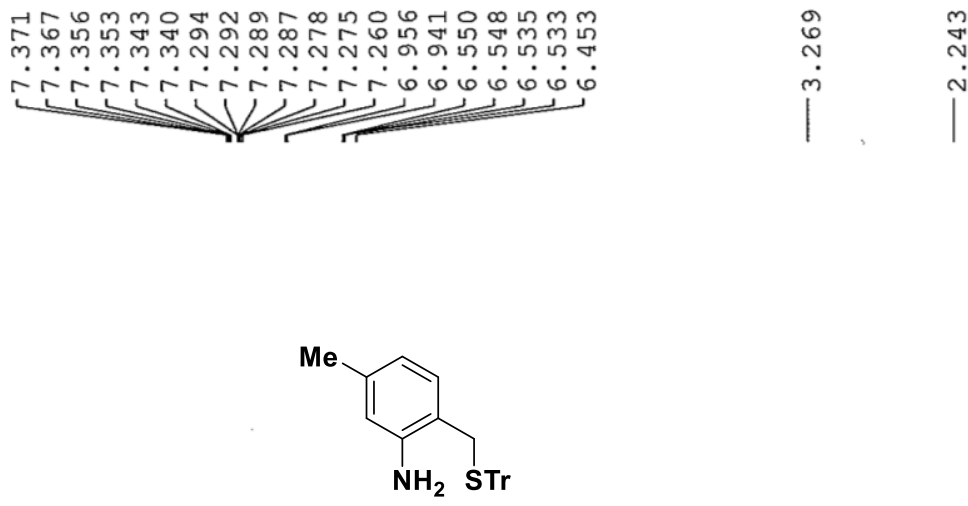

13
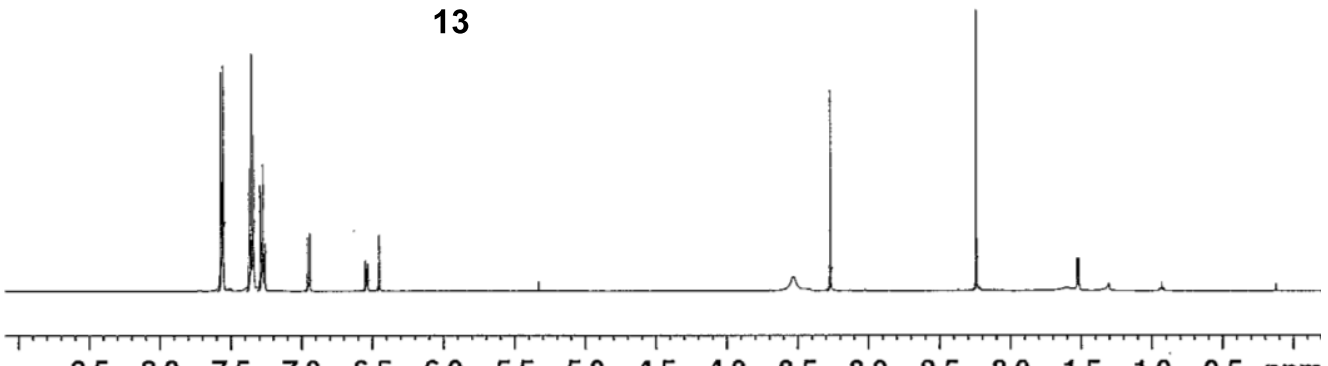

$\begin{array}{llllllllllllllllll}8.5 & 8.0 & 7.5 & 7.0 & 6.5 & 6.0 & 5.5 & 5.0 & 4.5 & 4.0 & 3.5 & 3.0 & 2.5 & 2.0 & 1.5 & 1.0 & 0.5 & \mathrm{ppm}\end{array}$

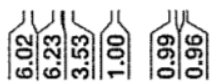

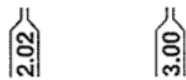

${ }^{13} \mathrm{C}-\mathrm{NMR}$ spectrum of $\mathbf{1 3}\left(125 \mathrm{MHz}, \mathrm{CD}_{3} \mathrm{OD}\right)$
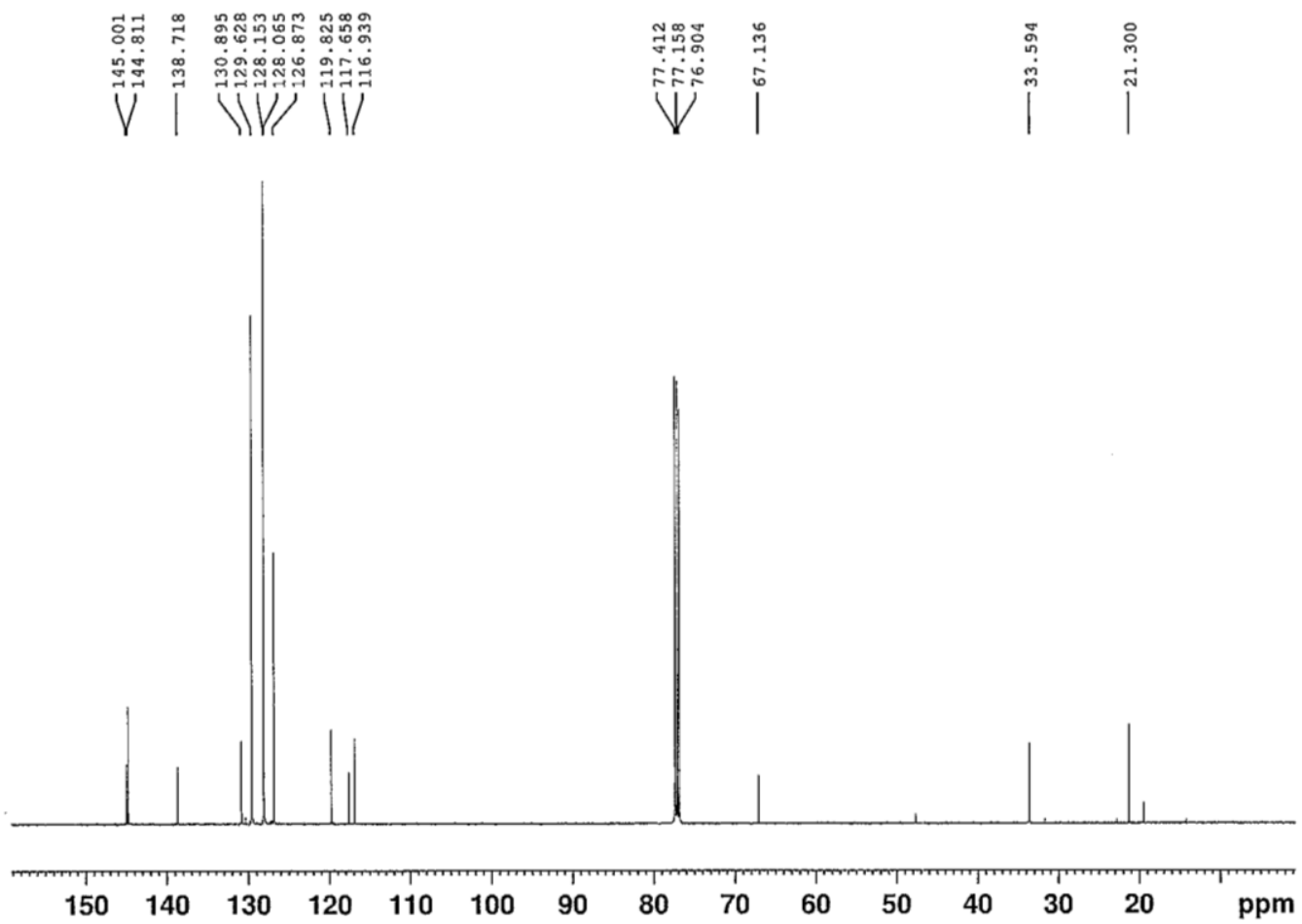
${ }^{1} \mathrm{H}-\mathrm{NMR}$ spectrum of the precursor of NGG-H (3')

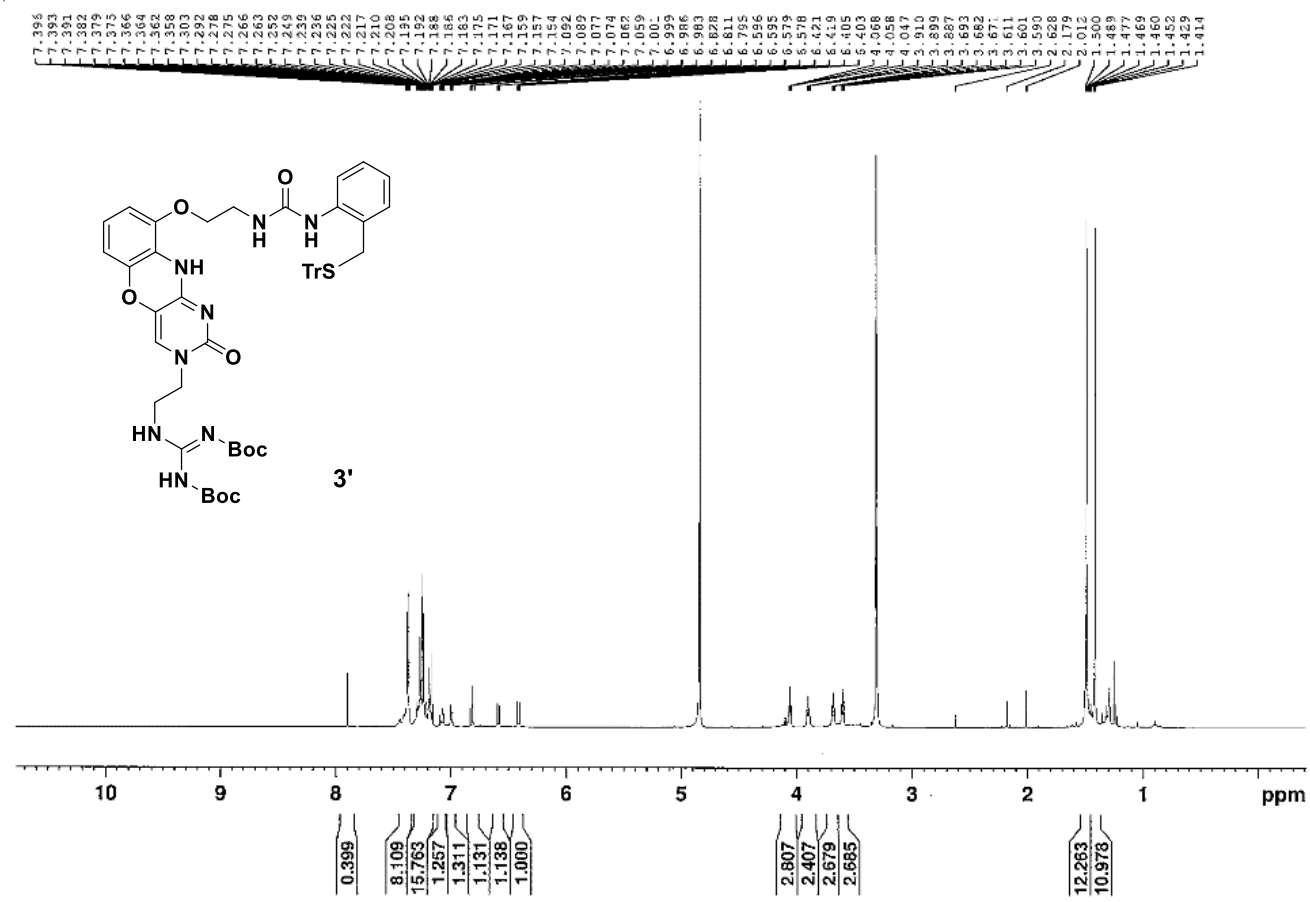

${ }^{13} \mathrm{C}-\mathrm{NMR}$ spectrum of the precursor of NGG-H (3') (125 MHz, CD $\left.{ }_{3} \mathrm{OD}\right)$

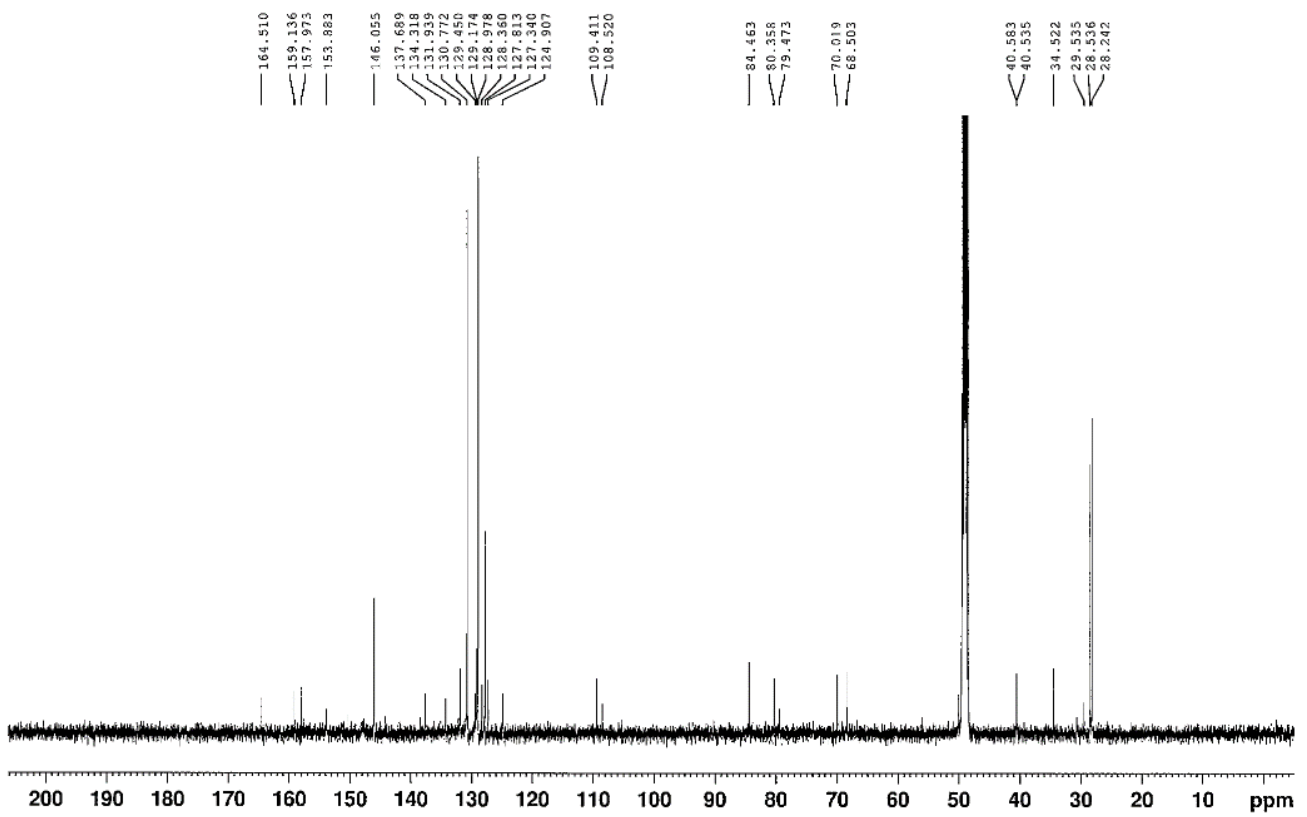


${ }^{1} \mathrm{H}-\mathrm{NMR}$ spectrum of NGG-H (3) $\left(500 \mathrm{MHz}, \mathrm{CD}_{3} \mathrm{OD}\right)$
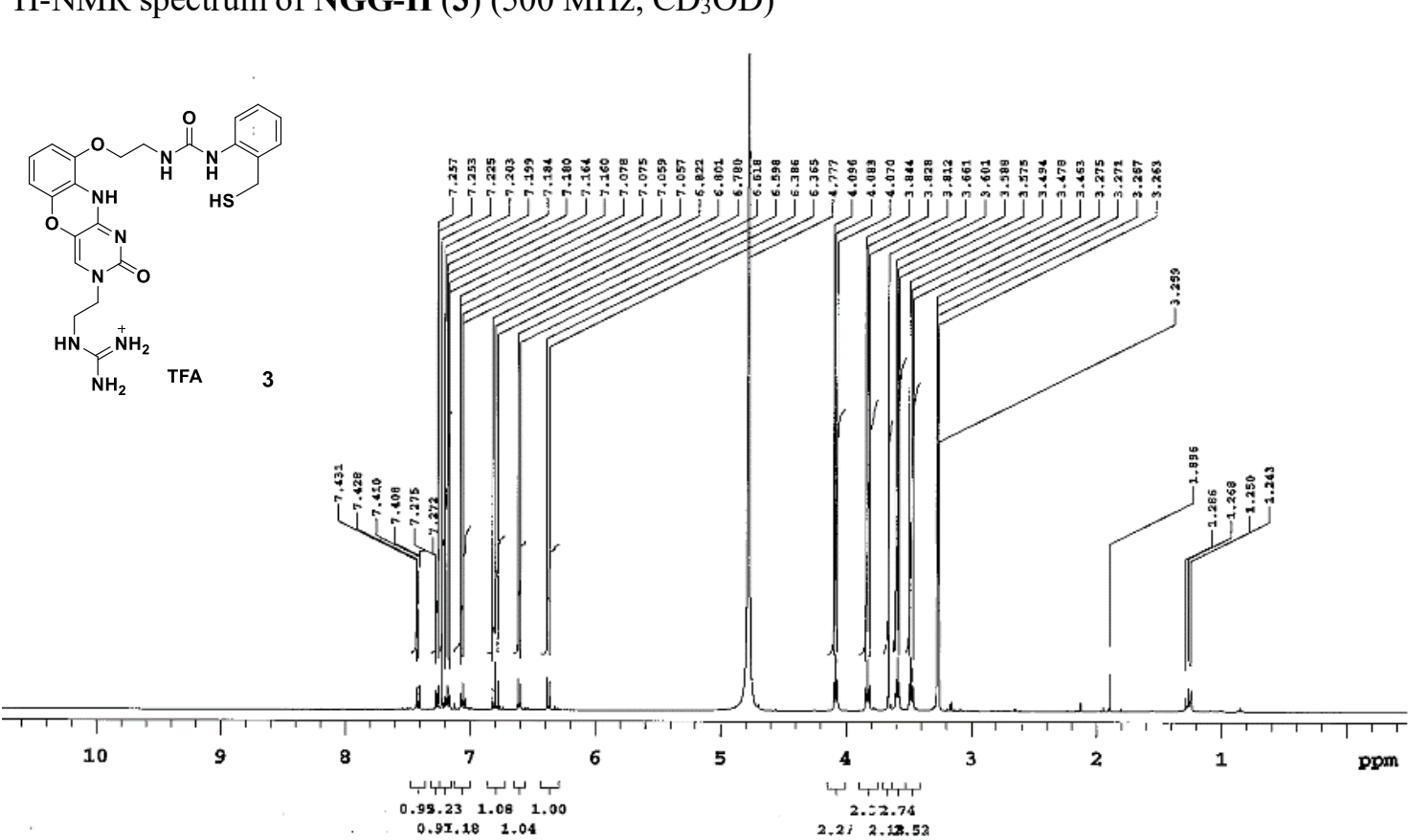

${ }^{13} \mathrm{C}$-NMR spectrum of NGG-H (3) $\left(125 \mathrm{MHz}, \mathrm{CD}_{3} \mathrm{OD}\right)$
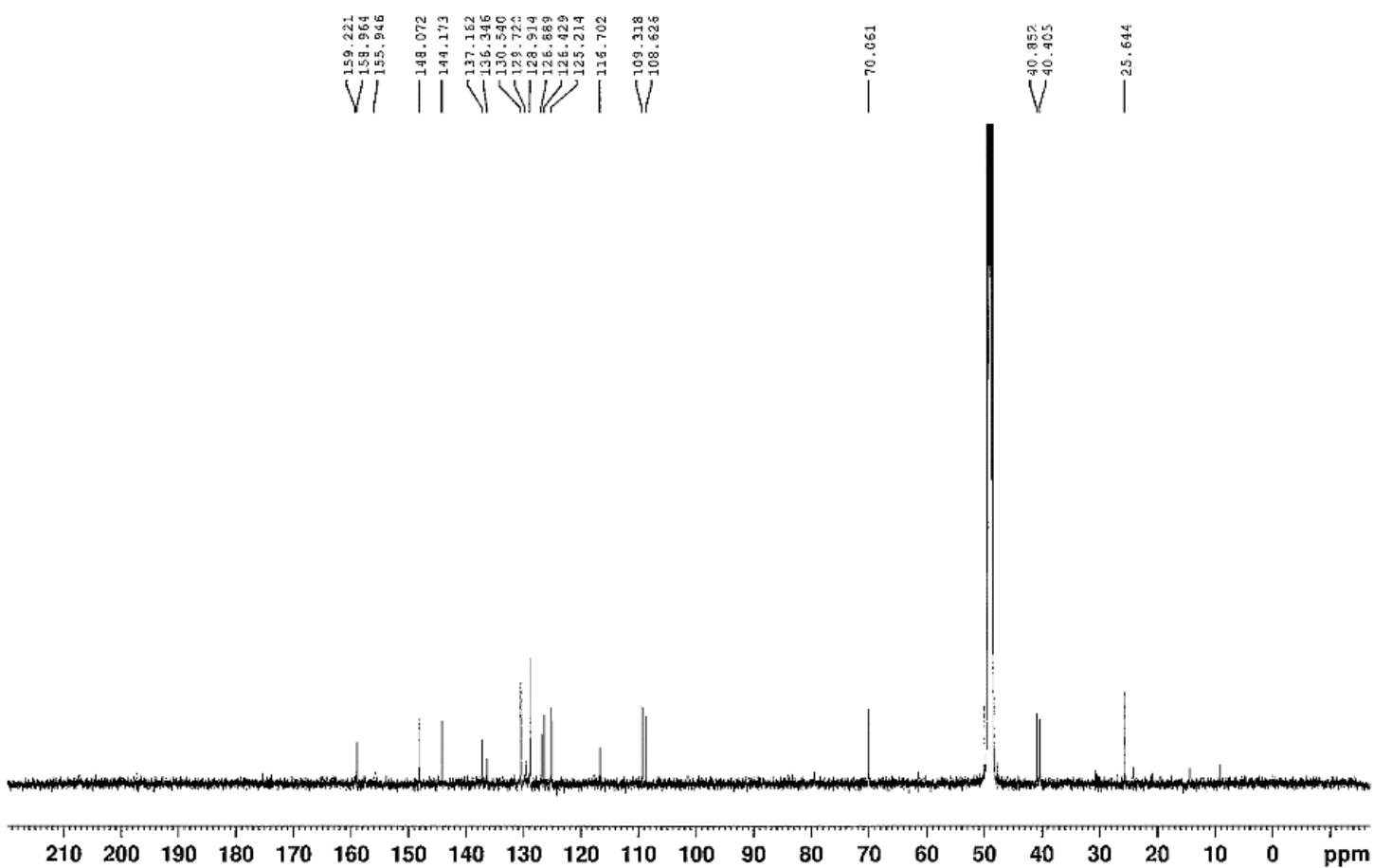
${ }^{1} \mathrm{H}-\mathrm{NMR}$ spectrum of the precursor of NGG-oMe (4') (500 MHz, $\left.\mathrm{CD}_{3} \mathrm{OD}\right)$

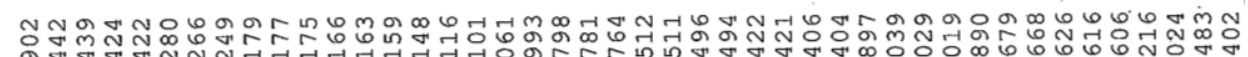

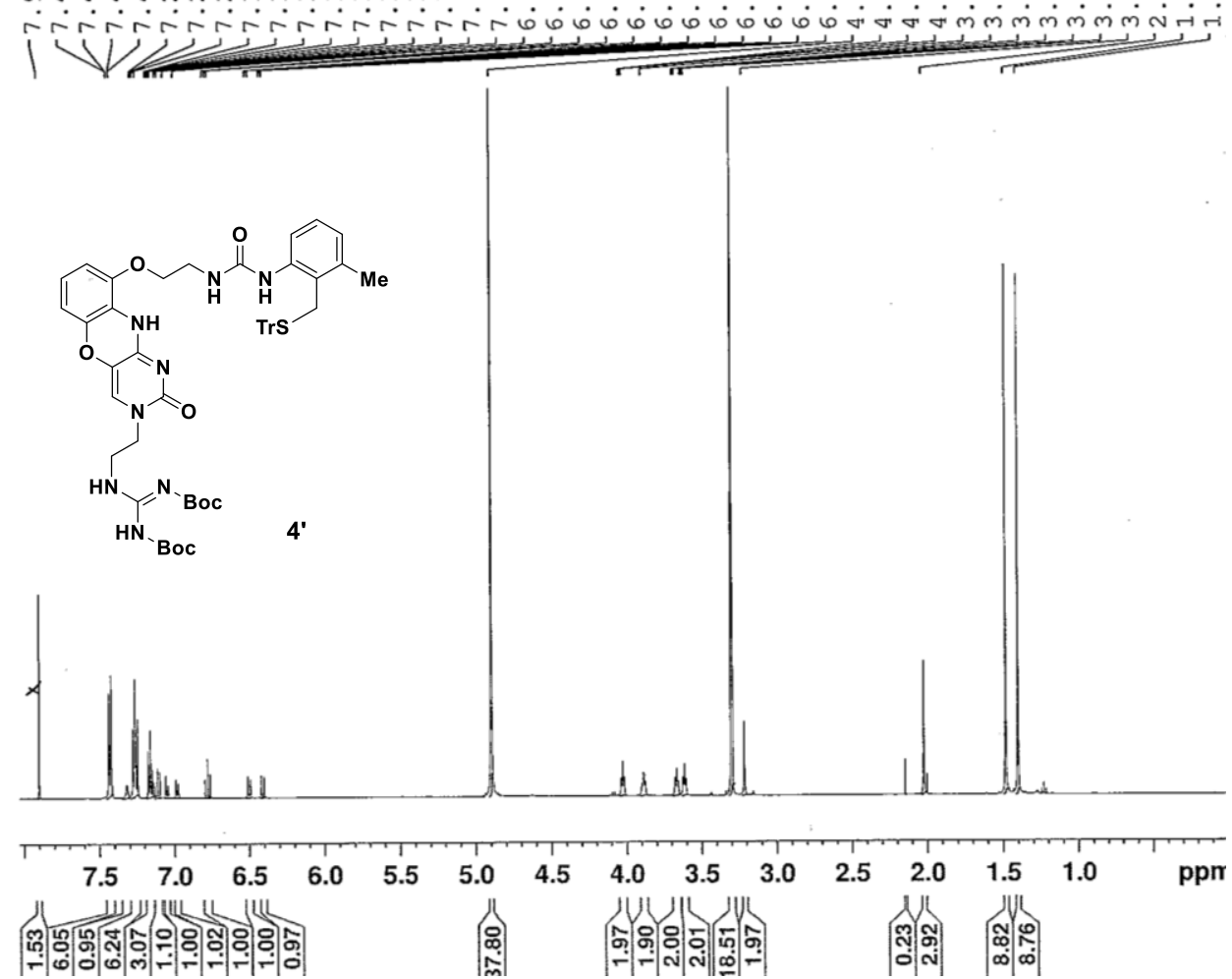

${ }^{13} \mathrm{C}-\mathrm{NMR}$ spectrum of the precursor of NGG-oMe (4') (125 MHz, $\left.\mathrm{CD}_{3} \mathrm{OD}\right)$

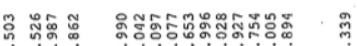

它

$\overrightarrow{\|} \vec{\imath}|N| \mathbb{H}$

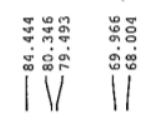

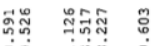

V๊ं

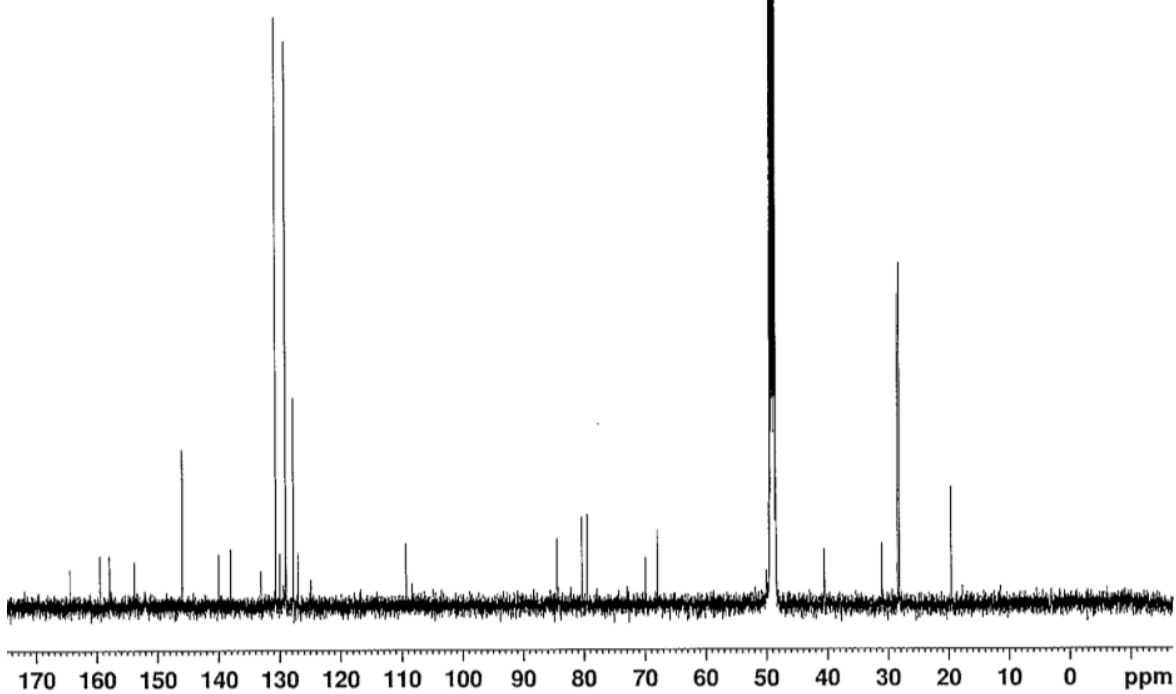


${ }^{1} \mathrm{H}-\mathrm{NMR}$ spectrum of NGG-oMe (4) (500 MHz, $\mathrm{CD}_{3} \mathrm{OD}$ )

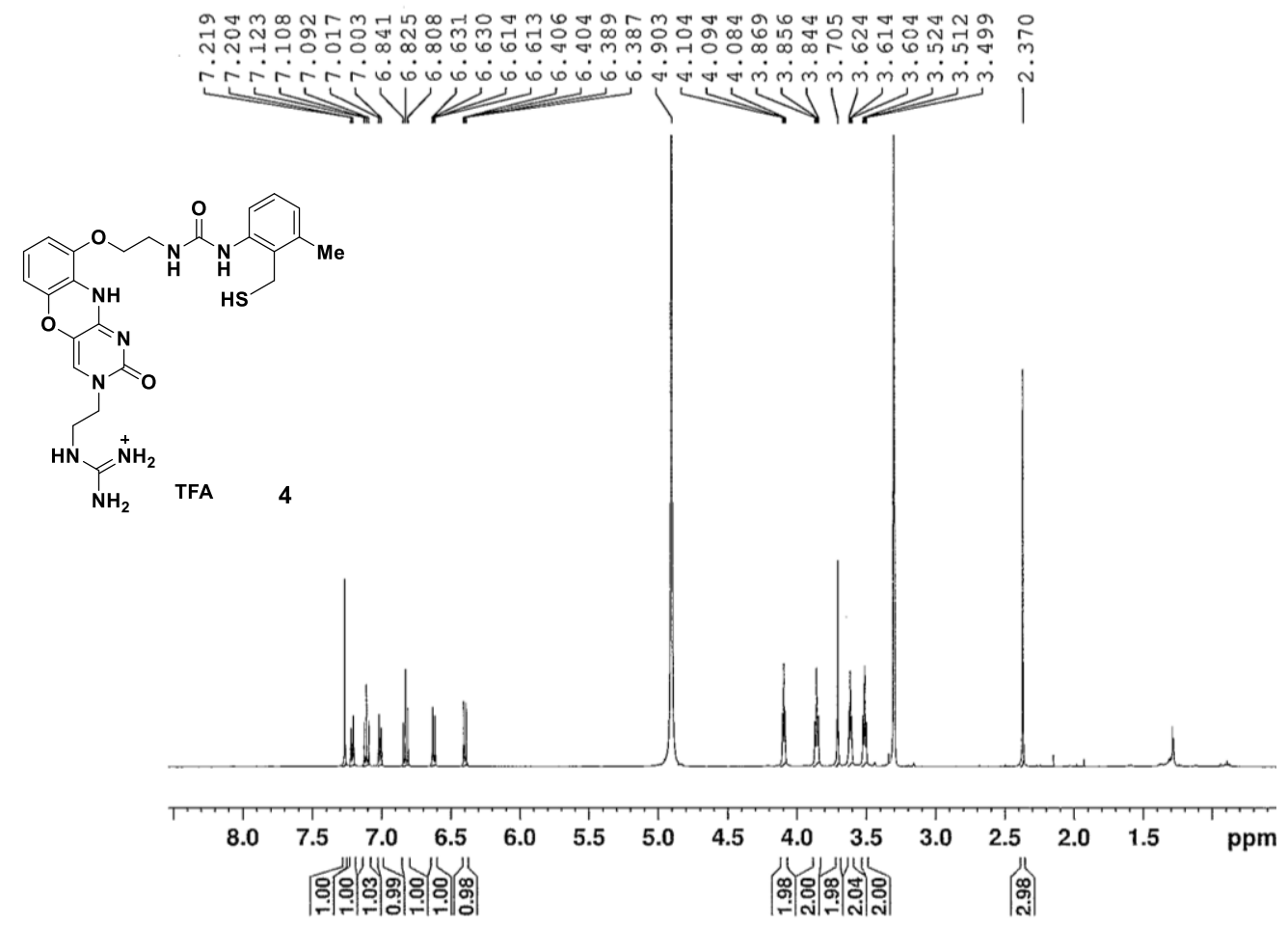

${ }^{13} \mathrm{C}-\mathrm{NMR}$ spectrum of NGG-oMe (4) (125 MHz, $\left.\mathrm{CD}_{3} \mathrm{OD}\right)$

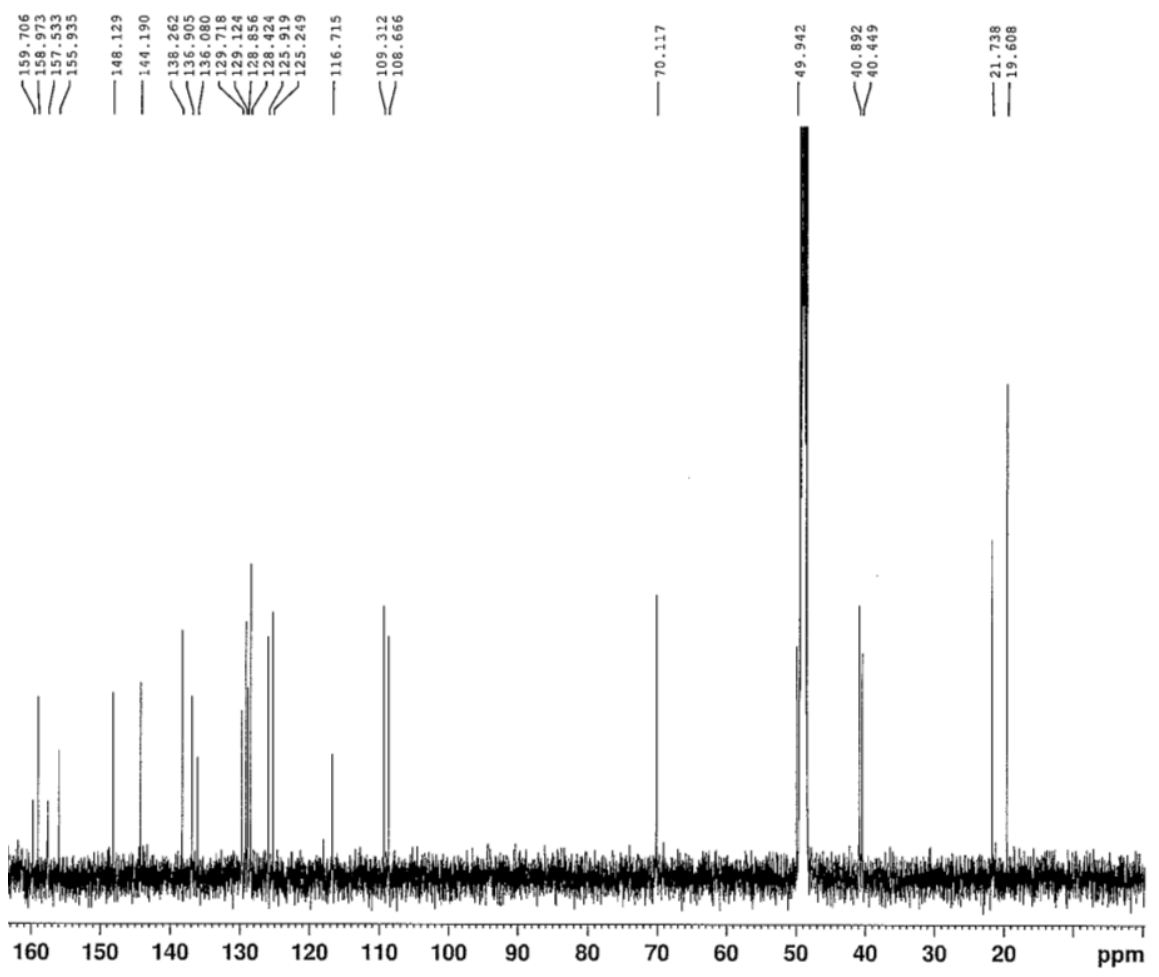


${ }^{1} \mathrm{H}-\mathrm{NMR}$ spectrum of the precursor of NGG-pMe (5') $\left(500 \mathrm{MHz}, \mathrm{CD}_{3} \mathrm{OD}\right)$

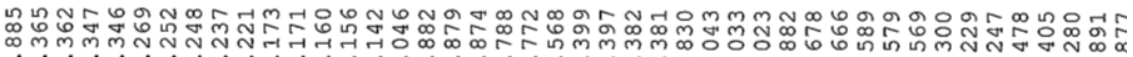

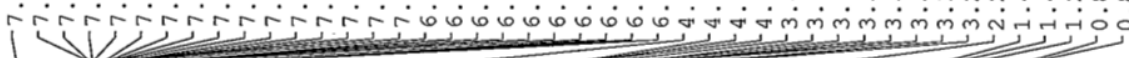
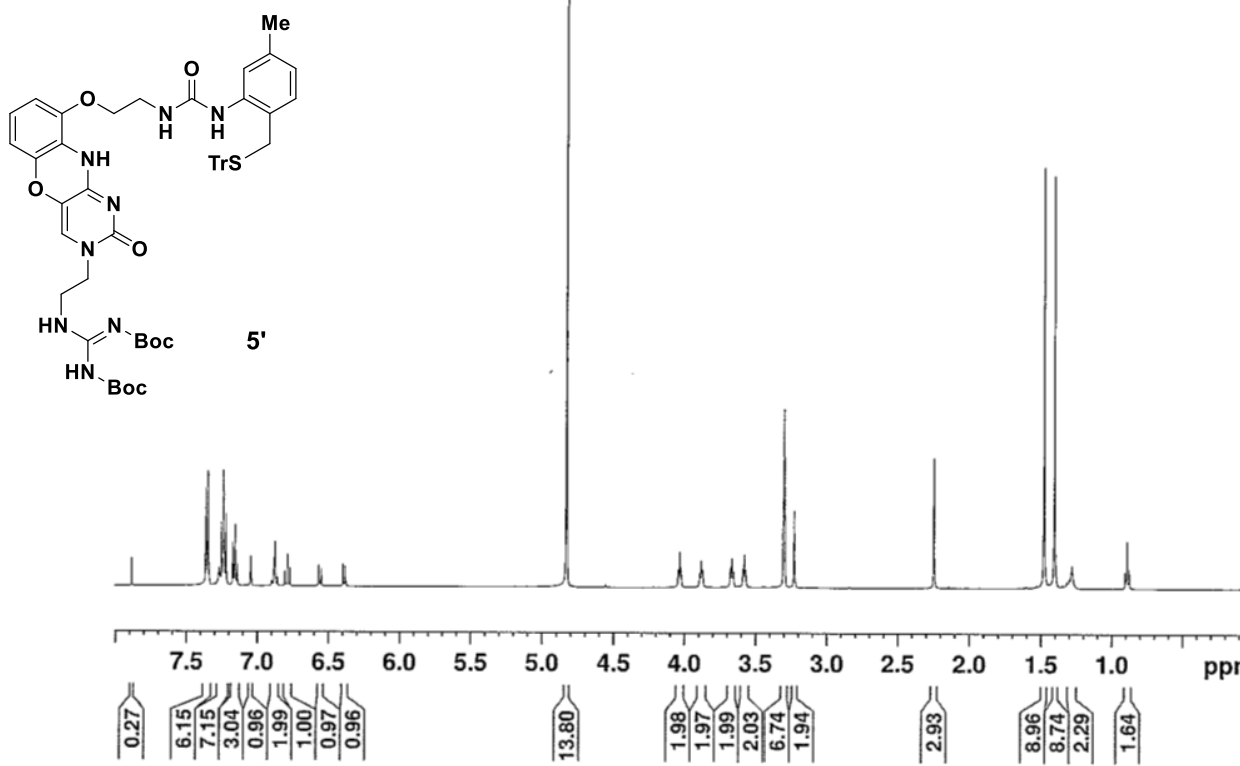

${ }^{13} \mathrm{C}-\mathrm{NMR}$ spectrum of the precursor of NGG-pMe (5') (125 MHz, $\left.\mathrm{CD}_{3} \mathrm{OD}\right)$

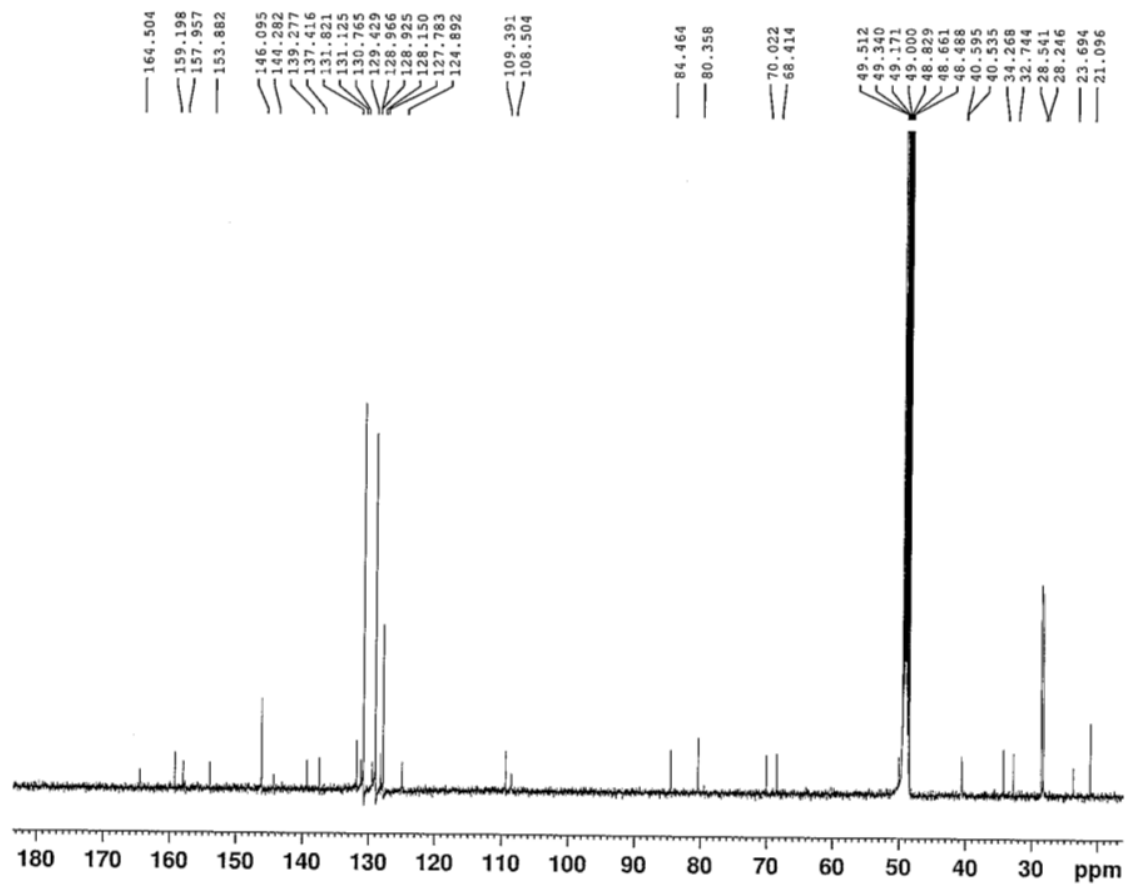


${ }^{1} \mathrm{H}-\mathrm{NMR}$ spectrum of NGG-pMe (5) (500 MHz, $\left.\mathrm{CD}_{3} \mathrm{OD}\right)$

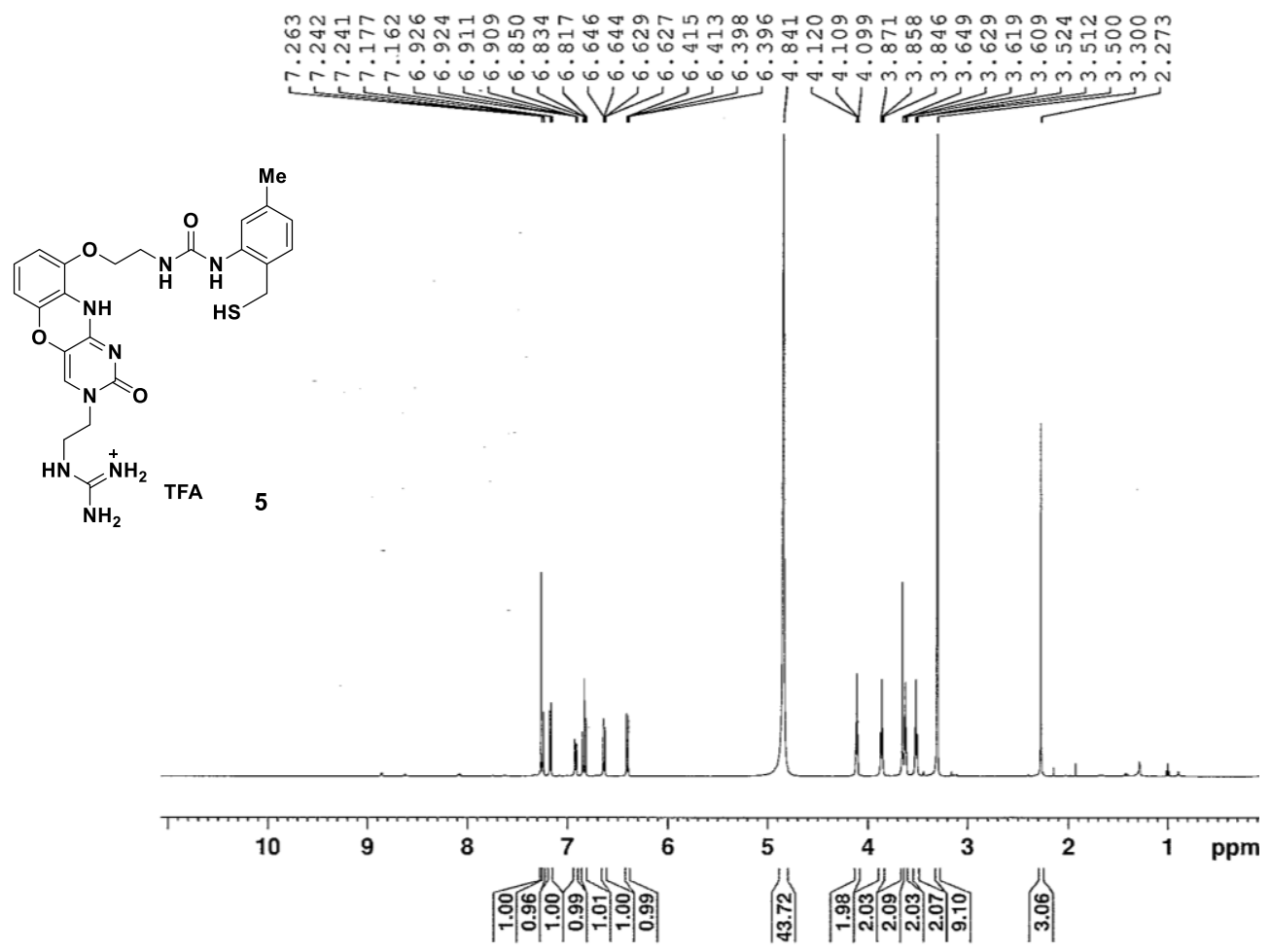

${ }^{13} \mathrm{C}-\mathrm{NMR}$ spectrum of NGG-pMe (5) (125 MHz, $\left.\mathrm{CD}_{3} \mathrm{OD}\right)$

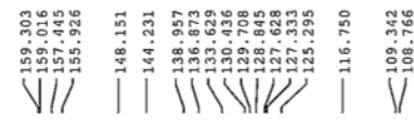

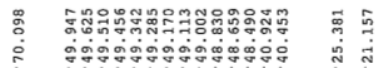

VII || $|1| V|V| \mid$

i

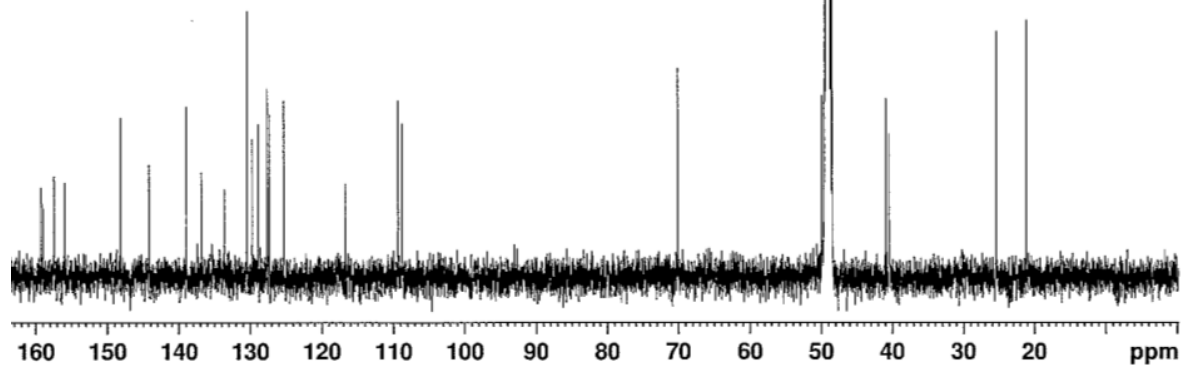


${ }^{1} \mathrm{H}-\mathrm{NMR}$ spectrum of $18\left(500 \mathrm{MHz}, \mathrm{CD}_{3} \mathrm{OD}\right)$

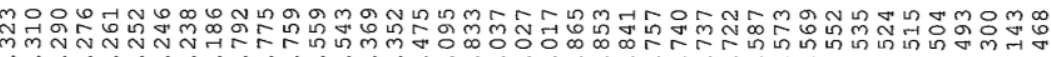

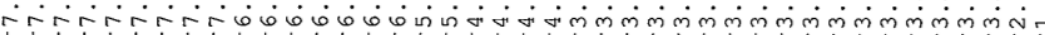

$\mathrm{NVF}$
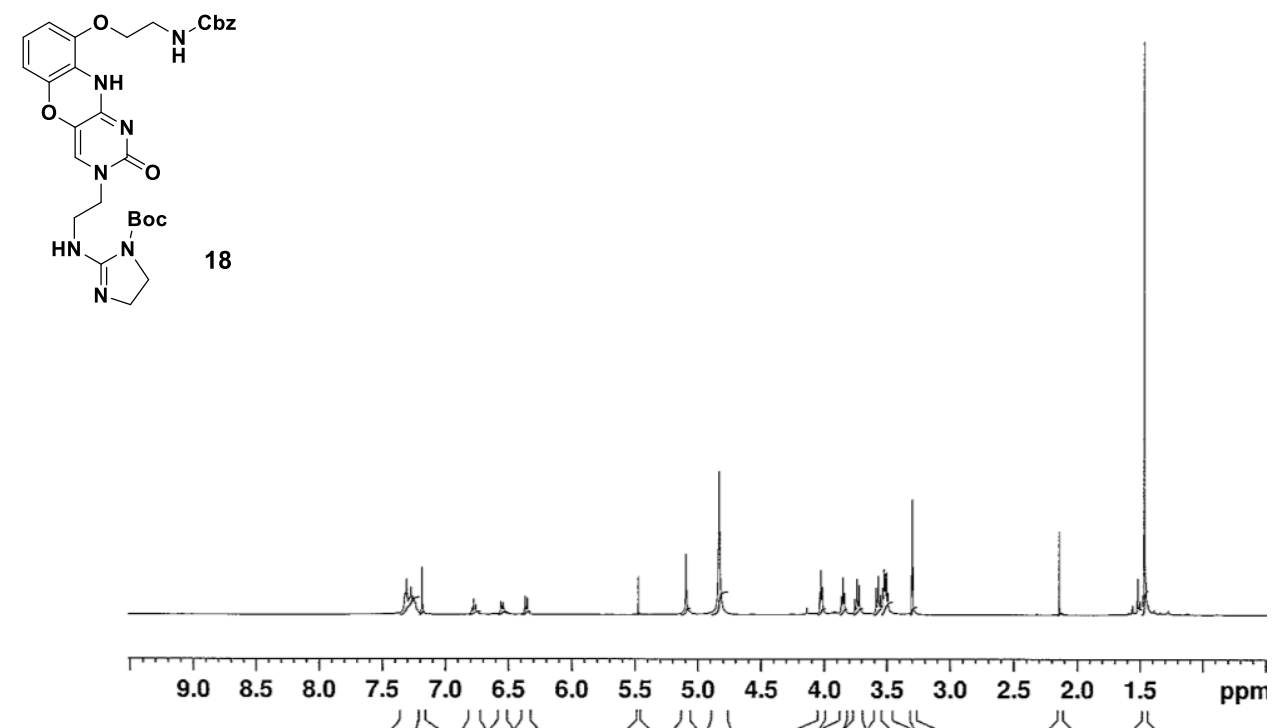

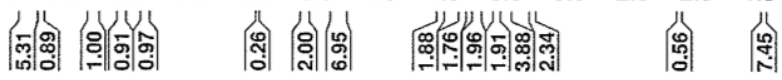

${ }^{13} \mathrm{C}-\mathrm{NMR}$ spectrum of $18\left(125 \mathrm{MHz}, \mathrm{CD}_{3} \mathrm{OD}\right)$

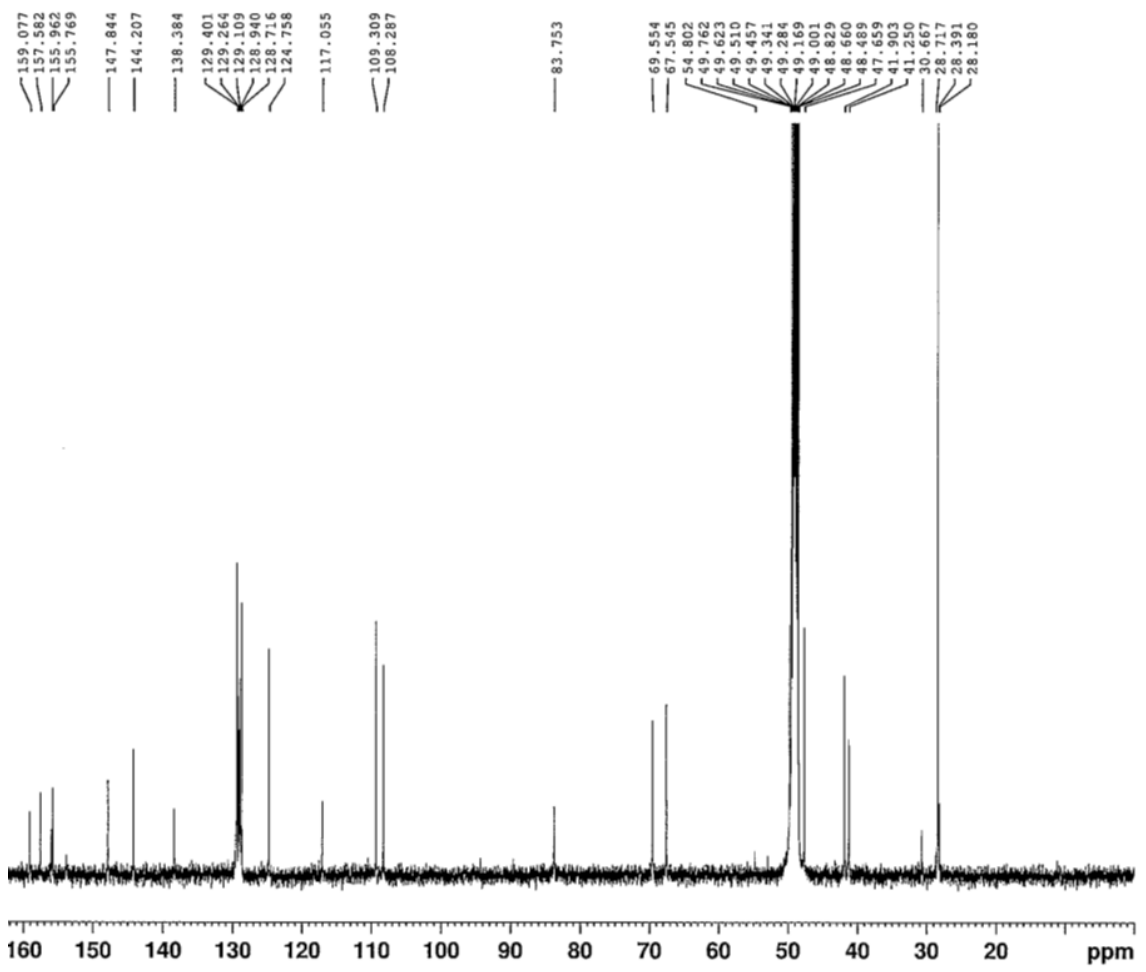


${ }^{1} \mathrm{H}-\mathrm{NMR}$ spectrum of $19\left(500 \mathrm{MHz}, \mathrm{CD}_{3} \mathrm{OD}\right)$

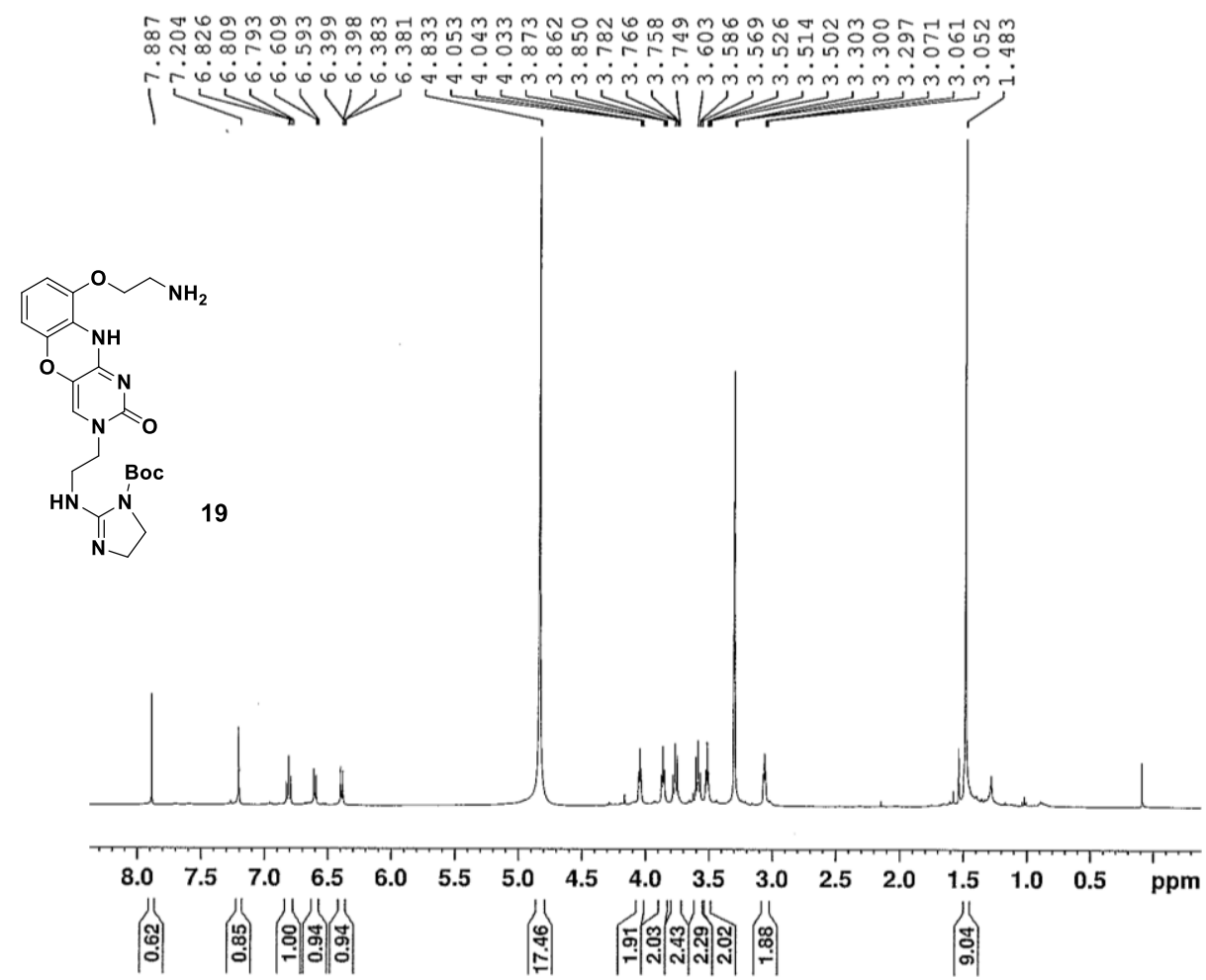

${ }^{13} \mathrm{C}-\mathrm{NMR}$ spectrum of $\mathbf{1 9}\left(125 \mathrm{MHz}, \mathrm{CD}_{3} \mathrm{OD}\right)$

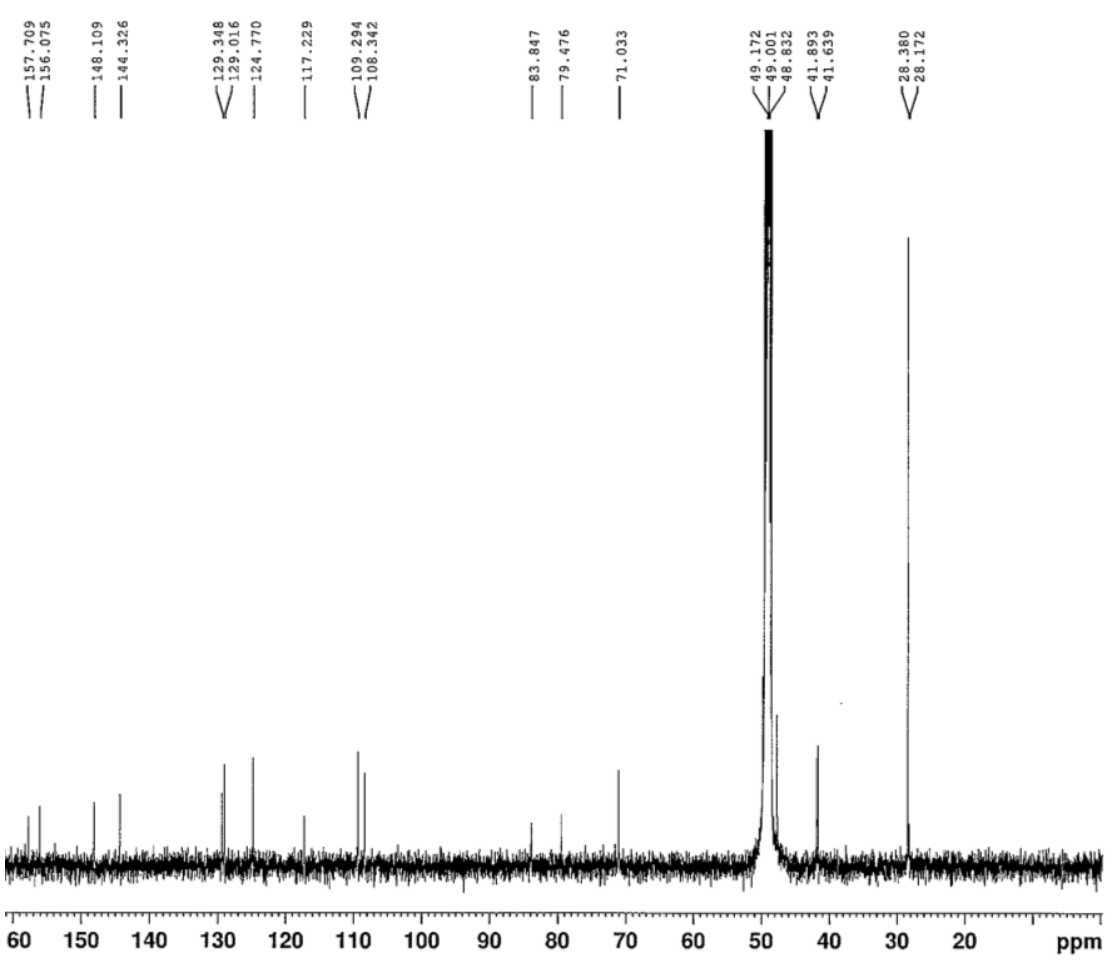


${ }^{1} \mathrm{H}-\mathrm{NMR}$ spectrum of NG-cG (14) $\left(500 \mathrm{MHz}, \mathrm{CD}_{3} \mathrm{OD}\right)$

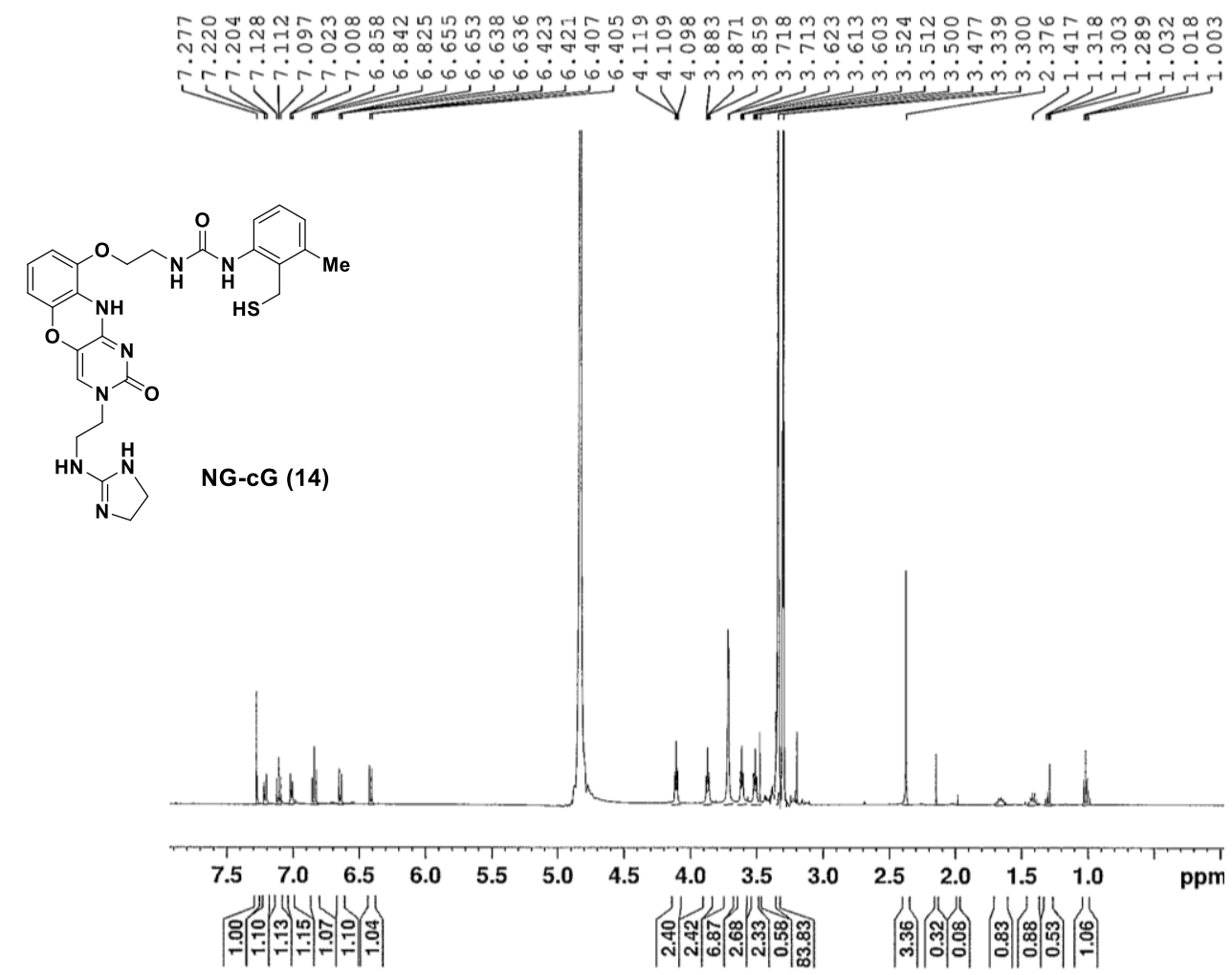

${ }^{13} \mathrm{C}-\mathrm{NMR}$ spectrum of NG-cG (14) (125 MHz, $\left.\mathrm{CD}_{3} \mathrm{OD}\right)$

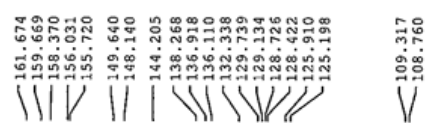

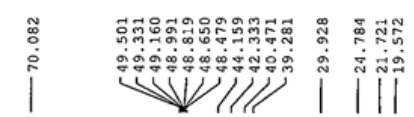

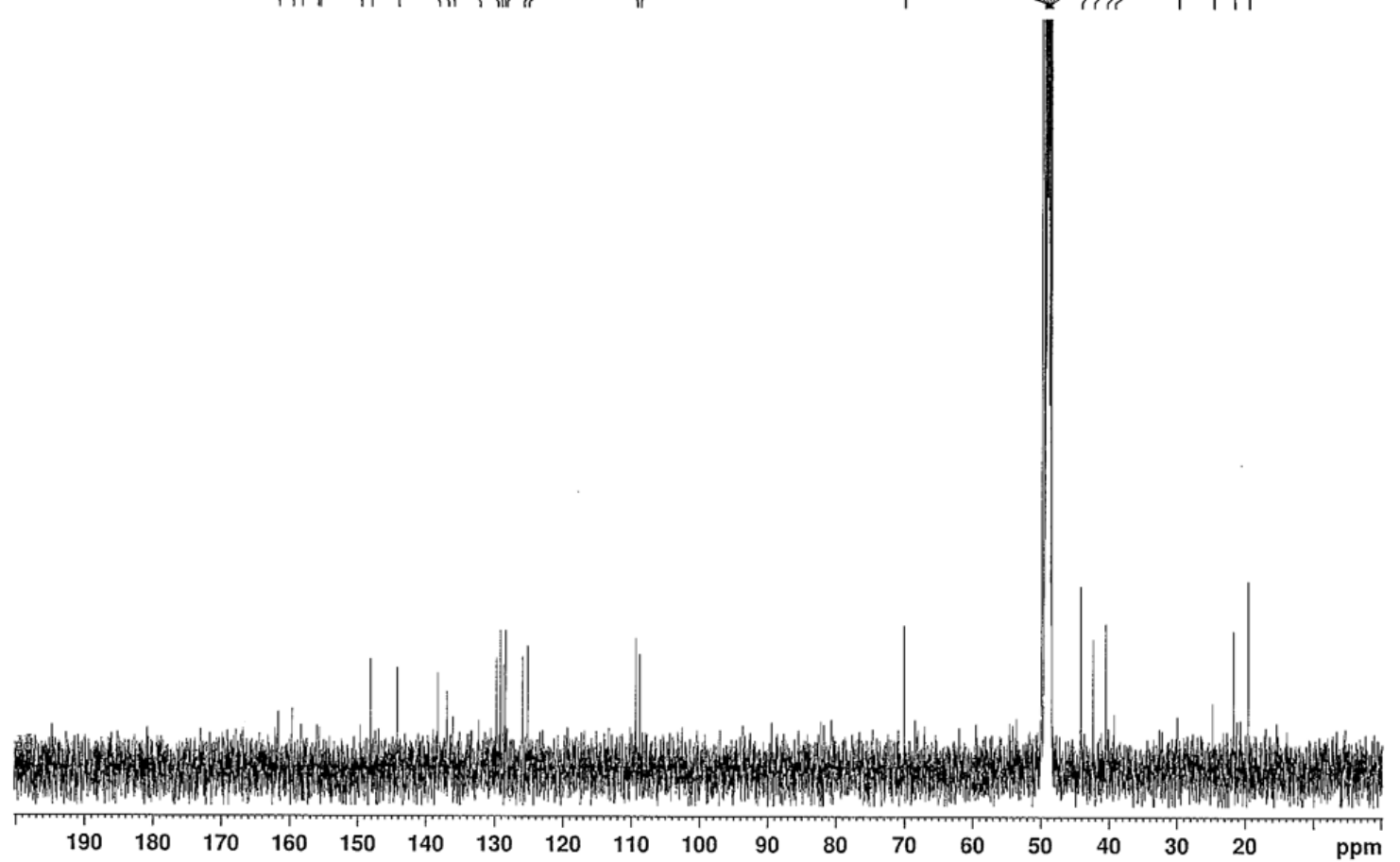

p. 36 
${ }^{1} \mathrm{H}-\mathrm{NMR}$ spectrum of NGG-H-cGMP adduct (whole spectrum)

NGG-H-cGMP adduct in $\mathrm{D}_{6}$-DMSO and $\mathrm{CD}_{3} \mathrm{COOD}$ at $50.0^{\circ} \mathrm{C}$

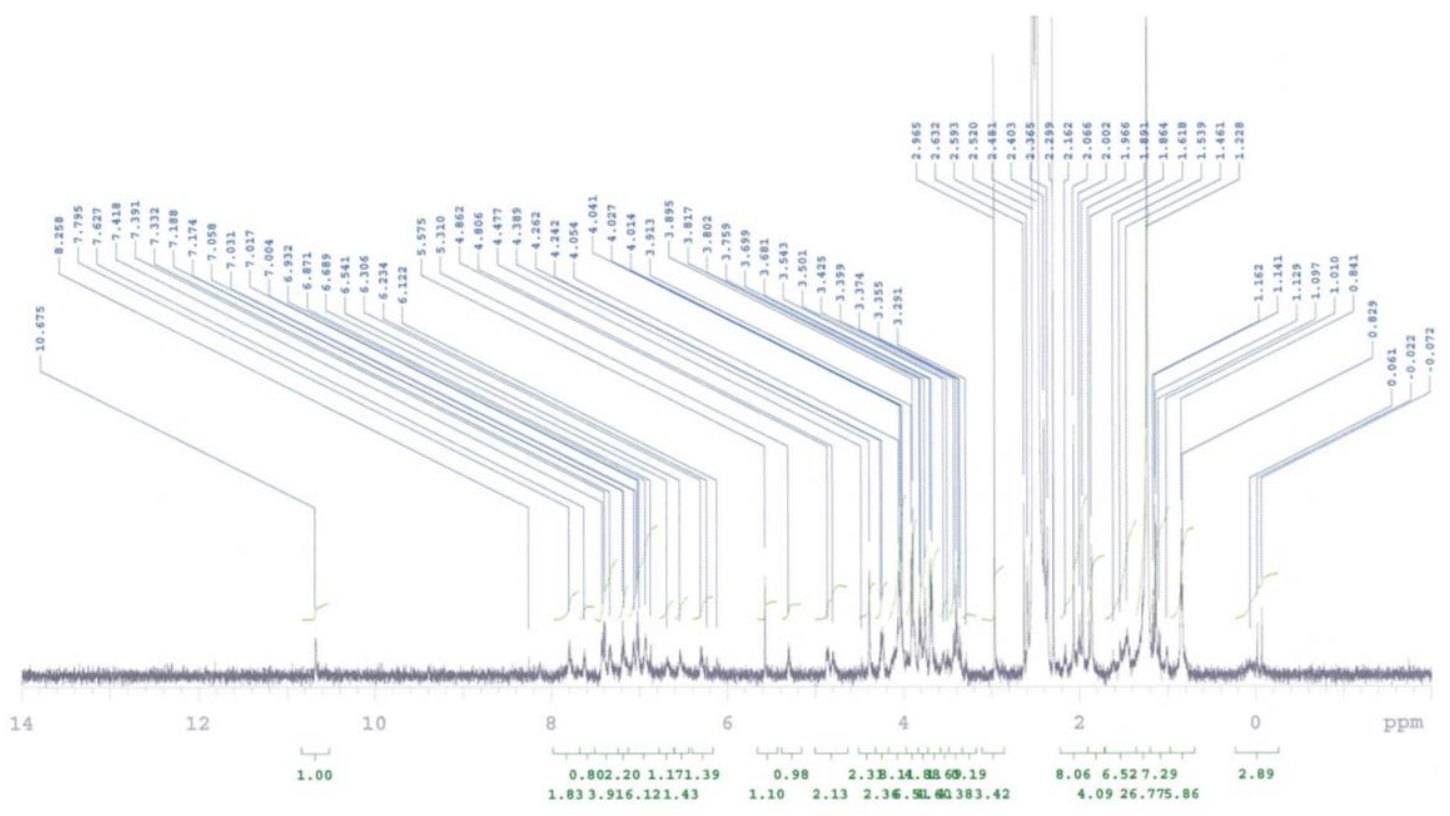

Expanded spectrum from 8.4 to $3.2 \mathrm{ppm}$
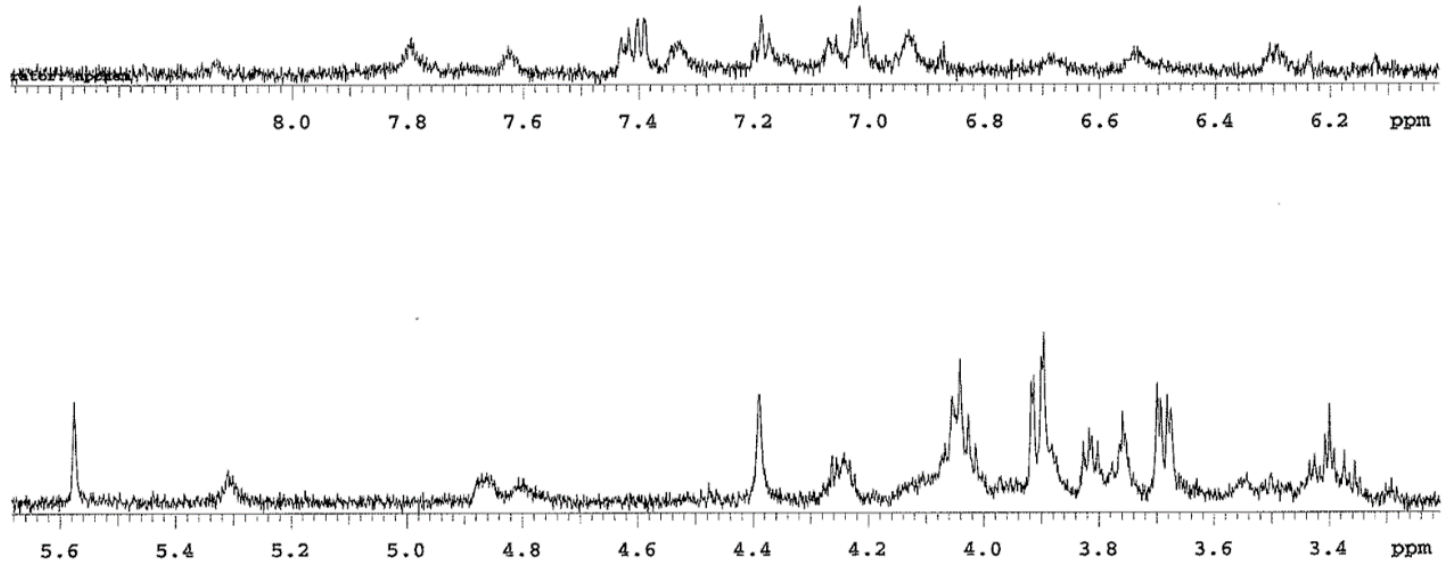
ROESY spectrum of NGG-H-cGMP adduct (whole spectrum)

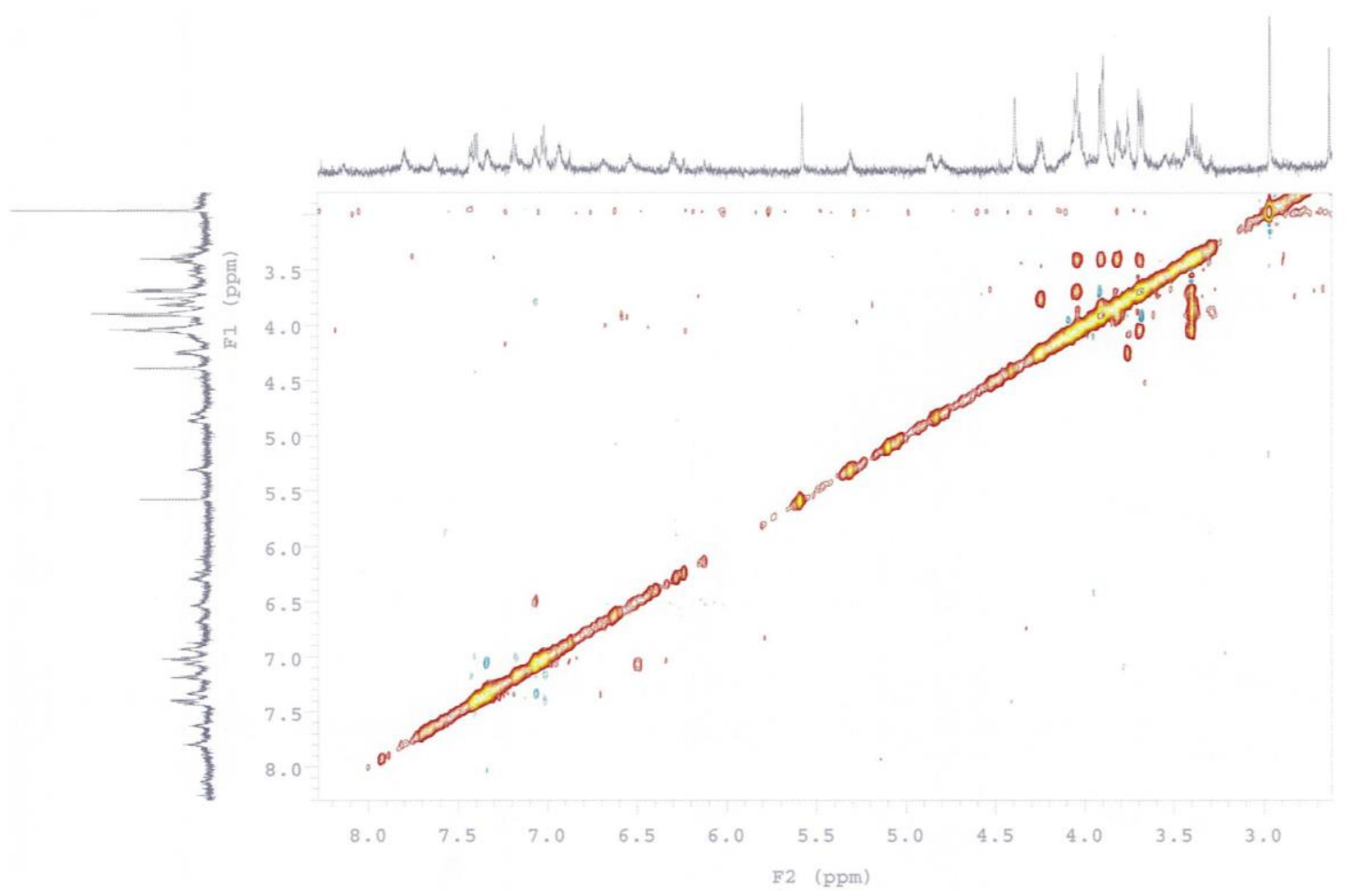

Expanded spectrum from 4.4 to $3.2 \mathrm{ppm}$ 